Chapter 27.

\title{
Cucurbit Production in Florida
}

\author{
BOTANY \\ Family - Cucurbitaceae \\ Nomenclature \\ Cucumber - Cucumis sativus \\ Cantaloupe- Cucumis melo \\ Summer squash - Cucurbita pepo \\ Pumpkin (jack-o-lantern is C. pepo; some processing \\ pumpkins are C. maxima and C. moschata) \\ Butternut squash - Cucurbita moschata \\ Tropical pumpkin (Calabaza) - Cucurbita moschata \\ Winter squash - Cucurbita maxima e.g. hubbard, \\ buttercup, and Turk's Turban \\ Watermelon - Citrullus lanatus
}

\section{Origin}

Cucurbits originated in several different locations: cucumber (India); cantaloupe (Africa); summer squash (Mexico, Central America); butternut squash (Mexico, Central America); winter squash (South America); and watermelon (Central Africa).

\section{Related Species}

Several Oriental and specialty vegetables, including Chinese winter melon, calabash gourd, luffa gourd, bitter melon, and chayote are also included in the Cucurbitaceae family.

\section{VARIETIES}

Variety selection, often made several months before planting, is one of the most important management decisions made by the grower. Failure to select the most suitable variety or varieties may lead to loss of yield or market acceptability.

The following characteristics should be considered in selection of vine crop varieties for use in Florida:

Yield: The variety selected should produce crops equivalent to the best varieties available. In recent years, the average harvested yields per acre of vine crops in Florida have been: fresh market cucumber - $525 \mathrm{bu}$, processing cucumbers - 10 tons, cantaloupe $-200 \mathrm{cwt}$, pumpkins experimental yields average about $200 \mathrm{cwt}$, summer squash - $300 \mathrm{bu}$, Tropical pumpkin (calabaza) $500 \mathrm{cwt}$, and water- melon - 250 cwt. In most instances, however, harvested yield is usually much less than potential yield because of market constraints.

Disease Resistance: Varieties that combine disease resistance with other desirable horticultural characteristics should be selected when possible. Most modern cucumber varieties are resistant or tolerant to angular leaf spot, anthracnose, downy mildew, powdery mildew, cucumber mosaic virus, and scab. Some cantaloupe varieties have tolerance to downy and powdery mildew, and fruit should be resistant to fruit rots. Unfortunately, disease tolerance is limited in squash and pumpkin varieties at the present time. However, summer squash varieties resistant to a number of diseases, including viruses, are available to growers in limited numbers. Watermelon varieties selected for use in Florida should have resistance to anthracnose-race 1 and fusarium wilt. There is considerable variation among varieties in the degree of fusarium resistance; select varieties with high wilt resistance that have qualities compatible with other requirements.

Horticultural Quality: Slicing cucumber fruit should be smooth and uniformly dark green, have an appropriate length:diameter ratio, have small seeds that are slow to develop, and have a desirable flavor. Pickling cucumber fruit should be firm, medium to dark green in color, have a small seed cavity, an L/D ratio of about 3 at $1^{1 / 4} \mathrm{in}$. diameter, and good brining qualities if it is to be brined. Gynoecious plants are preferred. Western-type cantaloupes should be sutureless (smooth) or nearly so, round to slightly oval, fully netted, and about $3 \mathrm{lb}$ average weight with a thick deep-salmon interior, and should have a small tight seed cavity, high soluble solids ( $11 \%$ is required for the U.S. Fancy grade), and a pleasant aroma and taste. Easterntype cantaloupes are sutured and have soft flesh. Desirable traits in pumpkin varieties include a deep orange rind that colors early, smooth fruit, a stem that is proportional to the fruit size and adheres tightly to the fruit, and freedom from fruit rots. Summer squash fruit should have color appropriate to the market requirements, retain their gloss as they mature, and be slow to develop seed. Winter squash fruit should be attractively colored; have a smooth, hard rind; deep orange flesh; be resistant to storage rot; and have an appropriate storage life. Watermelon fruit size and shape; rind color, thickness, and toughness; seed size, number, and color; and flesh color, texture, and soluble solids (10\% 
is required for designation as very good internal quality) are all important characteristics to be considered in selection of watermelon varieties. Ability to germinate in cold soils and general plant vigor may be important in certain situations.

Adaptability: Vine crops are well adapted to production in Florida for spring, early summer, and fall markets and to the winter market in the very warmest growing areas. Successful varieties must perform well under the range of environmental conditions encountered in these seasons and in various locations in Florida.

Market Acceptability: For all vine crops, growers must be aware of the needs of the particular market they intend to supply, and grow varieties that produce crops that satisfy that market.

\section{VINE CROP VARIETIES FOR FLORIDA}

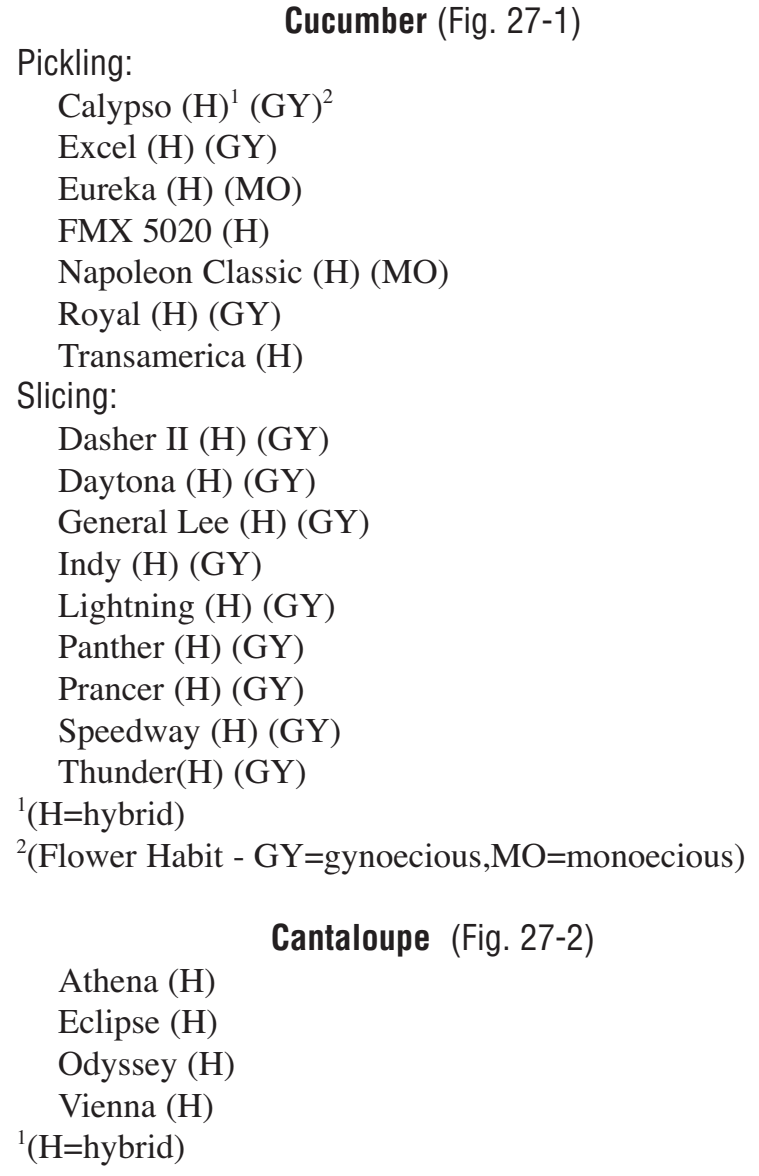

Miniature: $<1 \mathrm{lb}$

Halloween Pumpkin

Jack-Be-Little

Jack-Be-Quick

Munchkin

Wee-Be-Little (PVP) ${ }^{1}$

\section{Halloween Pumpkin (continued)}

Small: $1-5 \mathrm{lb}$

Baby Pam

Little Lantern

Trickster $(\mathrm{H})^{2}$

Medium: 5-10 lb

Autumn Gold $(\mathrm{H})$

Jack of All Trades (H)

Magician (H)

Magic Lantern (H)

Merlin (H)

October $(\mathrm{H})$

Wizard $(\mathrm{H})$

Large: $10-20 \mathrm{lb}$

Big Autumn (H)

Connecticut Field

Gold Medal $(\mathrm{H})$

ProGold $510(\mathrm{H})$

Giant: 25-80 lb

Prizewinner $(\mathrm{H})$

${ }^{1}(\mathrm{PVP}=$ Plant Variety Protection)

${ }^{2}(\mathrm{H}=$ hybrid $)$

Summer (yellow):

Dixie $(\mathrm{H})^{1}(\mathrm{CN})^{2}$

Enterprise $(\mathrm{H})(\mathrm{SN})^{2}$

Gentry $(\mathrm{H})(\mathrm{CN})$

Goldbar (H) (SN)

Lemondrop L (H) (SN)

Medalion $(\mathrm{H})(\mathrm{CN})$

Prelude $(\mathrm{H})(\mathrm{CN})$

Prelude II $(\mathrm{H})(\mathrm{CN})$

Sunbrite $(\mathrm{H})(\mathrm{CN})$

Sunglo $(\mathrm{H})(\mathrm{CN})$

Suwannee $(\mathrm{H})(\mathrm{CN})$

Summer (zucchini):

Cash Flow $(\mathrm{H})$

Dividend $(\mathrm{H})$

Green Eclipse (H)

Senator $(\mathrm{H})$

Seneca Zucchini $(\mathrm{H})$

Spineless Beauty (H)

Acorn (Fig. 27-3):

Mesa Queen (H)

Table Ace $(\mathrm{H})$

TayBelle PM (H)

Butternut (Fig. 27-4):

Ultra $(\mathrm{H})$

Waltham

Zenith $(\mathrm{H})$

${ }^{1}$ (H=hybrid)

${ }^{2}$ (Type $-\mathrm{CN}=$ crookneck, $\mathrm{SN}=$ straightneck)

Tropical Pumpkin (Calabaza)

Agriset 9001 - vining type

El Dorado $(\mathrm{H})$ - compact plant

La Estrella $(\mathrm{H})$ - compact plant 


\section{Watermelon}

Diploid:

Celebration $(\mathrm{H})^{1}$

Gold Strike (H) (orange flesh)

Jamboree $(\mathrm{H})$

Mardi Gras (H)

Regency (H)

Royal Star $(\mathrm{H})$

Royal Sweet $(\mathrm{H})$

Sangria $(\mathrm{H})$

Sentinel $(\mathrm{H})$

Summer Flavor $790(\mathrm{H})$

Summer Flavor $800(\mathrm{H})$

Summer Flavor $900(\mathrm{H})$

Triploid (Seedless, Large):

Dillion $(\mathrm{H})$ for trial

Freedom $(\mathrm{H})$

Genesis $(\mathrm{H})$

Gypsy (H)

Millionaire (H)

Olympia (H)

Revolution $(\mathrm{H})$

Ruby Premium $(\mathrm{H})$ for trial

SugarHeart $(\mathrm{H})$

Sugar Shack $(\mathrm{H})$ for trial

Sugar Time $(\mathrm{H})$ for trial

Super Crisp (H)

SummerSweet $5244(\mathrm{H})$

SummerSweet $5544(\mathrm{H})$

Super Seedless $7177(\mathrm{H})$

Sweet Delight $(\mathrm{H})$ for trial

Tri-X-212 (H) for trial

Tri-X-313 (H)

\section{Watermelon continued}

Triploid (Seedless, Large) continued:

Tri-X-Carousel $(\mathrm{H})$

Tri-X-Palomar $(\mathrm{H})$

Triton $(\mathrm{H})$ (yellow flesh)

Triploid (Seedless, Mini):

Extazy $(\mathrm{H})$

Mohican $(\mathrm{H})$

Petite Treat (H)

Solitare (H)

Valdoria $(\mathrm{H})$

Vanessa $(\mathrm{H})$

Wonder $(\mathrm{H})$

${ }^{1}(\mathrm{H}=$ hybrid $)$

\section{SEEDING AND PLANTING}

Planting dates and seeding information for cucurbits are given in Table 1.

\section{TRIPLOID WATERMELON PRODUCTION}

Fruit of diploid watermelon varieties may contain as many as 1,000 seeds in each fruit. The presence of seeds throughout the flesh makes the removal of seeds while eating difficult. The seeds in slices or chunks of watermelon sold in retail stores or salad bars are a nuisance. One reason that seedless grapes are more popular with consumers than seeded varieties is that the consumer does not have to be concerned with and inconvenienced by the seeds while the fruit is being eaten. With proper care, seedless water-

Table 1. Seeding and planting information for cucurbits.

\begin{tabular}{|c|c|c|c|c|c|c|}
\hline Planting dates & Cucumber & Cantaloupe & Pumpkin $^{1}$ & \multicolumn{2}{|c|}{ Squash } & Watermelon \\
\hline North Florida & $\begin{array}{l}\text { Feb - Apr; } \\
\text { Aug - Sept }\end{array}$ & $\begin{array}{l}\text { Feb } 15- \\
\text { Apr } 15\end{array}$ & Early July & \multicolumn{2}{|c|}{$\begin{array}{l}\text { Feb - Apr; } \\
\text { Aug - Sept }\end{array}$} & $\begin{array}{l}\text { Feb } 15- \\
\text { Apr } 15\end{array}$ \\
\hline Central Florida & $\begin{array}{l}\text { Jan - Mar; } \\
\text { Sept }\end{array}$ & $\begin{array}{l}\text { Jan } 15- \\
\text { Mar } 15\end{array}$ & Mid July & \multicolumn{2}{|c|}{$\begin{array}{l}\text { Jan - Apr; } \\
\text { Aug - Sept }\end{array}$} & $\begin{array}{l}\text { Jan } 15- \\
\text { Mar } 15\end{array}$ \\
\hline South Florida & Sept - Feb & $\begin{array}{l}\text { Dec } 15- \\
\text { Mar } 1\end{array}$ & Early August & \multicolumn{2}{|c|}{ Aug - Mar } & $\begin{array}{l}\text { Dec } 15- \\
\text { Mar } 1\end{array}$ \\
\hline \multicolumn{4}{|l|}{ Seeding information } & Bush & Vining & \\
\hline Distance between rows ${ }^{2}$ (in) & $48-60$ & $60-72$ & $60-108$ & $36-48$ & $60-108$ & $60-108$ \\
\hline Distance between plants (in) & $6-12$ & $24-36$ & $36-60$ & $12-24$ & $36-60$ & $24-72$ \\
\hline Seeding depth (in) & $0.5-0.75$ & $0.5-1.0$ & $1.5-2.0$ & $1.0-1.5$ & $1.5-2.0$ & $1.5-2.0$ \\
\hline Seed per acre (lb) & $2-4$ & $1-2$ & $4-5$ & $2-3$ & $1-1.5$ & $1-3$ \\
\hline Days to maturity from seed & $40-65$ & $85-110$ & $80-100$ & $40-50$ & $85-120$ & $80-100$ \\
\hline $\begin{array}{l}\text { Days to maturity from } \\
\text { transplant }\end{array}$ & $\begin{array}{c}\text { Not } \\
\text { recommended }\end{array}$ & $70-90$ & $70-90$ & $\begin{array}{c}\text { Not } \\
\text { recommended }\end{array}$ & $\begin{array}{c}\text { Not } \\
\text { recommended }\end{array}$ & $60-90$ \\
\hline Plant populations ${ }^{3}$ (acre) & 21,780 & 4,356 & 2,904 & 14,520 & 2,904 & 4,356 \\
\hline \multicolumn{7}{|c|}{$\begin{array}{l}{ }^{1} \text { For Halloween market, for tropical pumpkin follow planting dates for squash. } \\
{ }^{2} \text { Cucumber and squash can be grown in two rows per bed (especially mulch culture) with } 12 \text { to } 18 \text { inches between rows on the bed } \\
\text { (Fig. 27-5). } \\
{ }^{3} \text { Populations based on closest between and within row spacing. }\end{array}$} \\
\hline
\end{tabular}


melons have a longer shelf life than seeded melons. This may be due to the fact that flesh break down occurs in the vicinity of seeds, which are absent, in seedless melons.

Hybrid triploid (seedless) watermelons have been grown for over 40 years in the United States. However, it was not until recently that improved varieties, aggressive marketing, and increased consumer demand created a rapidly expanding market for triploid watermelons. The seedless condition is actually sterility resulting from a cross between two plants of incompatible chromosome complements. The normal chromosome number in most living organisms is referred to as $2 \mathrm{~N}$. Triploid watermelons are produced on highly sterile triploid $(3 \mathrm{~N})$ plants which result from crossing a normal diploid $(2 \mathrm{~N})$ plant with a tetraploid (4N). The tetraploid is used as the female or seed parent and the diploid is the male or pollen parent (Diagram 1). Since the tetraploid seed parent produces only 5 to $10 \%$ as many seeds as a normal diploid plant, seed cost is considerably more than that of diploid, open-pollinated varieties and higher than diploid watermelon varieties. Tetraploid lines are usually developed by treating diploid plants with a chemical called colchicine.

Tetraploid parental lines normally have a light, medium, or dark green rind without stripes. By contrast, the diploid pollen parent almost always has a fruit with a striped rind. The resulting hybrid triploid melon will inherit a striped pattern. Growers may occasionally find a non-striped fruit in fields of striped triploid watermelons. These are the result of accidental self pollinations of the tetraploid seed parent during triploid seed production. Tetraploid fruit are of high quality but will have seeds and must not be sold as seedless. The amount of tetraploid contamination is dependent upon methods and care employed in triploid seed production.

Sterile triploid plants normally do not produce viable seed. However, small, white rudimentary seeds or seedcoats, which are eaten along with the fruit as in cucumber, develop within the fruit. The number and size of these rudimentary seeds vary with variety. An occasional dark, hard, viable seed is found in triploid melons.

Triploid watermelons can be grown successfully in areas where conventional seeded varieties are produced. However, they require some very unique cultural practices for successful production.

\section{Stand Establishment}

Containerized production of triploid watermelon transplants is essential because of the special conditions required for seed germination, emergence, and early plant development not found in open-field situations. Furthermore, the extra cost of seedling production is justified because triploid watermelon seeds costs are about six times greater than those of diploid hybrid seeds and
60 times greater than open-pollinated diploid watermelon seeds. One seed per cell should be planted 1 inch deep with the radicle (pointed end) up to reduce seedcoat adherence to the cotyledons. Transplants have been successfully produced with peat pellets or in trays containing sterile media with 1 to 2 inch cell size. The tray is watered lightly to bring the seed and mix in contact. Stacked trays are placed in a germination chamber $85-90^{\circ} \mathrm{F}$ for two days or until radicles are visible in the cell drainage holes. The trays are then arranged in a greenhouse with day temperature $70-80^{\circ} \mathrm{F}$ and night temperature $65-70^{\circ} \mathrm{F}$ where temperature control can be achieved. Plants are fertilized every three days with a solution containing $50 \mathrm{ppm} \mathrm{N}$ from $\mathrm{Ca}\left(\mathrm{NO}_{3}\right)_{2}$ and $\mathrm{KNO}_{3}$ from cotyledon expansion until the first true leaf is fully expanded, then with a $200 \mathrm{ppm} \mathrm{N}$ solution applied every other day until the second true leaf is fully expanded, finally the fertilizer is reduced for several days before transplanting to the field. Plants are ready for transplanting when the roots are sufficiently developed to permit removal from the cell with the entire growing mix volume intact. This will require three to five weeks depending on cell size and growing conditions.

\section{Field Arrangement}

Watermelon fruit set and enlargement is dependent upon growth regulators from the pollen grains and from embryos in developing seeds within the fruit. Inadequate pollination results in triploid watermelon fruit that are triangular in shape and of poor quality. Inadequate pollination may increase the incidence of hollowheart. Triploid watermelon flowers do not produce sufficient viable pollen to induce fruit set and development. Therefore, pollen from a normal or a special diploid pollenizer watermelon variety must be provided. Fields should be interplanted with pollenizer, diploid watermelon plants to provide additional pollen. Planting the pollenizer variety in the outside row and then every third row is one recommendation. As an alternative, the pollenizer variety may be planted every third plant in a row but this may make harvesting difficult. When special pollenizers such as Companion or SP-1 are used they are interplanted so the field can be $100 \%$ seedless. Follow suppliers instructions. Under no circumstances should the pollenizer variety and the seedless variety be planted in separate but adjacent blocks!

It is important to use a pollenizer variety that is marketable because up to one-third of all melons produced in the field will be of this variety. The rind pattern and/or shape of the seeded pollenizer fruit should be easily distinguished from that of the triploid fruit to reduce confusion at harvest. Selection of a pollenizer variety should also take into account market demand, plant vigor, pollen production, disease resistance, and environmental conditions.

It is important that pollen from the diploid pollenizer variety is available when female blossoms on the triploid plants are open and ready for pollination. As a general 


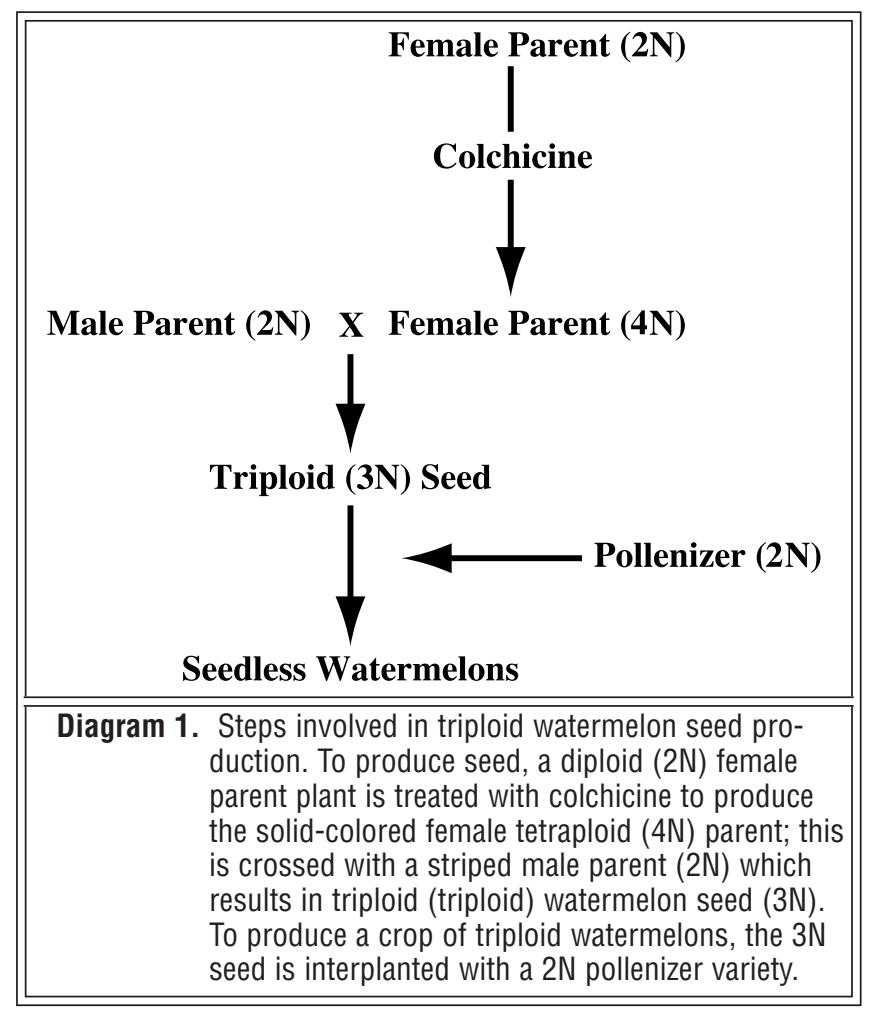

rule, direct field seeding of the pollenizer variety should be done on the same day the triploid seed is planted in the greenhouse. If transplants are used for pollenizers, they can be seeded a few days before triploid transplants are scheduled to be seeded. Small fruited, icebox varieties usually flower earlier than standard watermelon varieties. If icebox varieties are to be used as the pollenizer, then direct seeding should be delayed a week to ten days. The diploid pollenizer variety will frequently set fruit and stop producing male blossoms while the triploid variety is still producing many female blossoms. Growers may make a second planting of a pollenizer two to three weeks after the initial planting to provide pollen for the late-developing female blossoms. We have found no consistent differences among any standard and icebox types in effectiveness of pollination. Icebox varieties used as pollenizers result in high early yields; standard varieties used as pollenizers result in high total yields.

Occasionally, as many as 20 or more hard seeds are found in triploid fruit. These fruit with hard seeds are frequently from the first and second harvests. High numbers of hard seeds in early fruit may be the result of stress conditions such as drought, flood, fertilizer imbalance, or extremes in temperature.

\section{Cultural Practices}

Plant spacing requirements vary depending on variety selection, growing area, time of planting, and soil type. In general, early growth of triploid plants is slower than that of diploid plants. However, triploid plant size eventually exceeds that of diploid plants. Seed development in fruit of diploid varieties inhibits further flowering and fruit set. This inhibition does not exist in triploids; therefore, plants continue to produce fruit as long as viral infection does not occur, insects and foliar diseases are controlled and environmental conditions are favorable. Triploid plant population density may be 10 to $20 \%$ less than that recommended for production of diploid watermelon varieties. Triploid watermelon production has been successful with 25-30 sq. ft. per plant.

All methods of irrigation including overhead, drip, seepage, and furrow are used successfully in producing triploid watermelons. Maintaining soil moisture at optimum levels is critical for triploid watermelon production. Water stress (drought) can increase the incidence of blossom-end rot and result in poorly shaped, bottle-neck fruit. Excessive field moisture has been associated with hollowheart, a disorder which seems to be more severe in some varieties of triploid melons than in diploid varieties.

\section{FERTILIZER AND LIME}

For unmulched crops, incorporate all $\mathrm{P}_{2} \mathrm{O}_{5}$, micronutrients, and 25 to $50 \%$ of $\mathrm{N}$ and $\mathrm{K}_{2} \mathrm{O}$ in the bed area. Apply no more than $25 \% \mathrm{~N}$ and $\mathrm{K}_{2} \mathrm{O}$ broadcast for subsurface irrigated crops. This "modified broadcast" method improves fertilizer efficiency. Apply remaining $\mathrm{N}$ and $\mathrm{K}_{2} \mathrm{O}$ as a sidedressing when squash has four to six true leaves or when vines begin to run.

For mulched crops under subsurface irrigation, broadcast all $\mathrm{P}_{2} \mathrm{O}_{5}$, micronutrients, and 20 to $25 \%$ of $\mathrm{N}$ and $\mathrm{K}_{2} \mathrm{O}$ in the bed area. Apply remaining $\mathrm{N}$ and $\mathrm{K}_{2} \mathrm{O}$ in bands in grooves (2 to 3 inches deep) and 8 to 10 inches from row. Use a single band in bed center for twin-row crops and two shoulder bands for single-row crops.

For mulched crops with sprinkler irrigation, incorporate all fertilizer in bed before mulching. Cover with unfertilized soil so fertilized soil is likely to remain moist. Plastic mulch might need to be perforated to provide irrigation infiltration on deep, droughty sands. Supplemental $\mathrm{N}$ and $\mathrm{K}_{2} \mathrm{O}$ can be applied by liquid fertilizer injection wheel.

For drip irrigated crops, broadcast all $\mathrm{P}_{2} \mathrm{O}_{5}$, micronutrients, and up to 20 to $25 \%$ of $\mathrm{N}$ and $\mathrm{K}_{2} \mathrm{O}$ in the bed. Apply remaining $\mathrm{N}$ and $\mathrm{K}_{2} \mathrm{O}$ through the irrigation tube.

Soil test and fertilizer recommendations for cucurbits on mineral soils are given in Table 2. An injection schedule for $\mathrm{N}$ and $\mathrm{K}$ for cucurbits grown on soils testing very low in $\mathrm{K}$ is given in Table $3 \mathrm{a}$ and $3 \mathrm{~b}$. 


\section{PLANT TISSUE ANALYSIS}

Plant tissue analysis information for cucurbits is given in Table 4. The analysis was done at the early bloom stage, using the most recently matured leaf.

\section{PETIOLE SAP TESTING}

Fresh sap can be pressed from leaf petioles and analyzed for nitrogen and potassium concentrations. Results can be used to make adjustments in the fertilization program. Sufficiency ranges for sap testing for cucurbit crops are presented in Table 5.

\section{IRRIGATION}

Cucurbit water requirements are slightly lower than those of other vegetable crops. Peak water requirements during rapid growth and development may average $90 \%$ of reference evapotranspiration levels (ETo), decreasing to $70 \%$ of ETo during the final growth period (Tables 3 to 6, Chapter 8, Principles and Practices of Irrigation Management for Vegetables). Many of these crops have extensive root systems and can obtain available ground moisture, thus reducing irrigation requirements. It is important to note that excessive irrigation can reduce crop yields by leaching crop nutrients or promoting disease. However, plant stress from limited water availability will also reduce fruit size and quality.

\section{POLLINATION OF CUCURBITS}

Cucurbit plants have separate male (staminate) and female (pistillate) flowers (Fig. 27-6). Male flowers generally appear on the plants several days before female flowers. The female flower is easily recognized by the presence of a miniature fruit below the flower petals. Pollen from the male flower must be transferred to the female flower for pollination and subsequent fruit development to occur.

Therefore, it appears that a sufficiently high honeybee population is necessary to insure that each flower is visited at least eight times. How does this translate into hives per acre? Recommendations from various sources range from two hives per acre to one hive per 5 acres (Fig. 27-7). Under most conditions, however, one strong hive per 2 acres should result in sufficient bee activity to effect needed pollination.

Cucurbit flowers open shortly after sunrise and remain open until late afternoon or early evening. Accordingly, each flower is open for only a few hours. The period of maximum honeybee - the most common and effective pollinator of cucurbits - activity closely coincides with the period when the flower is open. Honeybee visitation begins an hour or two after sunrise and continues until mid-afternoon. If temperatures are very warm, bee activity may decline about noon. Research on cantaloupe pollination conducted in California showed that bee visitations increased until 10 a.m. and then declined until 3 p.m. when activity almost ceased.

Research on watermelon at the Central Florida Research and Education Center-Leesburg showed that the number of bee visitations was more important than the length of time that each bee stayed on the flower. Well-shaped, fully expanded fruit occurred following eight bee visitations to a female flower (Fig. 27-8). Fruit set was significantly reduced when only four or two bee visitations were made. Hives should be spaced around the perimeter of large fields to provide distribution of bees over the entire field. To maintain the health and activity of the bee colonies, pesticide applications to the crop should be made when bees are not present in the field, usually at dusk or after dark.

\section{WEED MANAGEMENT}

Herbicides labeled for weed control in cucurbit crops are listed in Table 6.

\section{DISEASE MANAGEMENT}

Chemicals approved for disease management in cucurbits are listed in the following tables:

Table 7 - Cucumber

Table 8 - Cantaloupe

Table 9 - Pumpkin

Table 10 - Squash

Table 11 - Watermelon

\section{INSECT MANAGEMENT}

Insecticides approved for use on cucurbit crops are outlined in the following tables:

Table 12 - Cucumber

Table 13 - Squash

Table 14 - Cantaloupe

Table 15 - Watermelon 


\section{PRODUCTION COSTS}

Example breakeven production costs for cucurbits grown

in Florida are given in the following tables:

Table 16 - Cucumber

Table 17 - Summer squash

Table 18 - Watermelon (Manatee/Hillsborough area)

Table 19 - Watermelon (Southwest Florida)

Table 2. Soil test and fertilizer recommendations for cucurbits on mineral soils. ${ }^{1}$

\begin{tabular}{|c|c|c|c|c|c|c|c|c|c|c|c|c|}
\hline Target pH & $\begin{array}{l}\text { Bed } \\
\text { spacing (ft) }\end{array}$ & $\mathrm{N} \mathrm{lb} / \mathrm{A}^{3}$ & \multicolumn{7}{|c|}{ (Ib/A/crop season) } & \multicolumn{3}{|c|}{$\mathrm{K}_{2} \mathrm{O}^{3}$} \\
\hline Cucumber & & & & & & & & & & & & \\
\hline 6.5 & 6 & 150 & 120 & 100 & 80 & 0 & 0 & 120 & 100 & 80 & 0 & 0 \\
\hline $\begin{array}{l}\text { Muskmelon } \\
6.5\end{array}$ & 5 & 150 & 150 & 120 & 100 & 0 & 0 & 150 & 120 & 100 & 0 & 0 \\
\hline $\begin{array}{l}\text { Pumpkin } \\
6.5\end{array}$ & 8 & 150 & 120 & 100 & 80 & 0 & 0 & 120 & 100 & 80 & 0 & 0 \\
\hline $\begin{array}{l}\text { Squash }{ }^{2} \\
6.5\end{array}$ & 6 & 150 & 120 & 100 & 80 & 0 & 0 & 120 & 100 & 80 & 0 & 0 \\
\hline $\begin{array}{l}\text { Watermelon } \\
6.0\end{array}$ & 8 & 150 & 150 & 120 & 100 & 0 & 0 & 150 & 120 & 100 & 0 & 0 \\
\hline $\begin{array}{l}{ }^{1} \text { See Chapter } \\
{ }^{2} \text { Summer an } \\
{ }^{3} \text { Seeds and t } \\
\text { applied thro }\end{array}$ & $\begin{array}{l}\text { ction on supple } \\
\text { ter } \\
\text { lants may ben } \\
\text { he plant hole } 0\end{array}$ & $\begin{array}{l}\text { mental fer } \\
\text { fit from ap } \\
\text { r near the }\end{array}$ & ation & in an & oluti & & 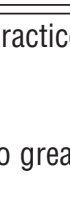 & 1. & the & & & , and \\
\hline
\end{tabular}

Table 3a . Injection schedule for $\mathrm{N}$ and $\mathrm{K}$ for cucurbit crops grown on soils testing very low in $\mathrm{K}$.

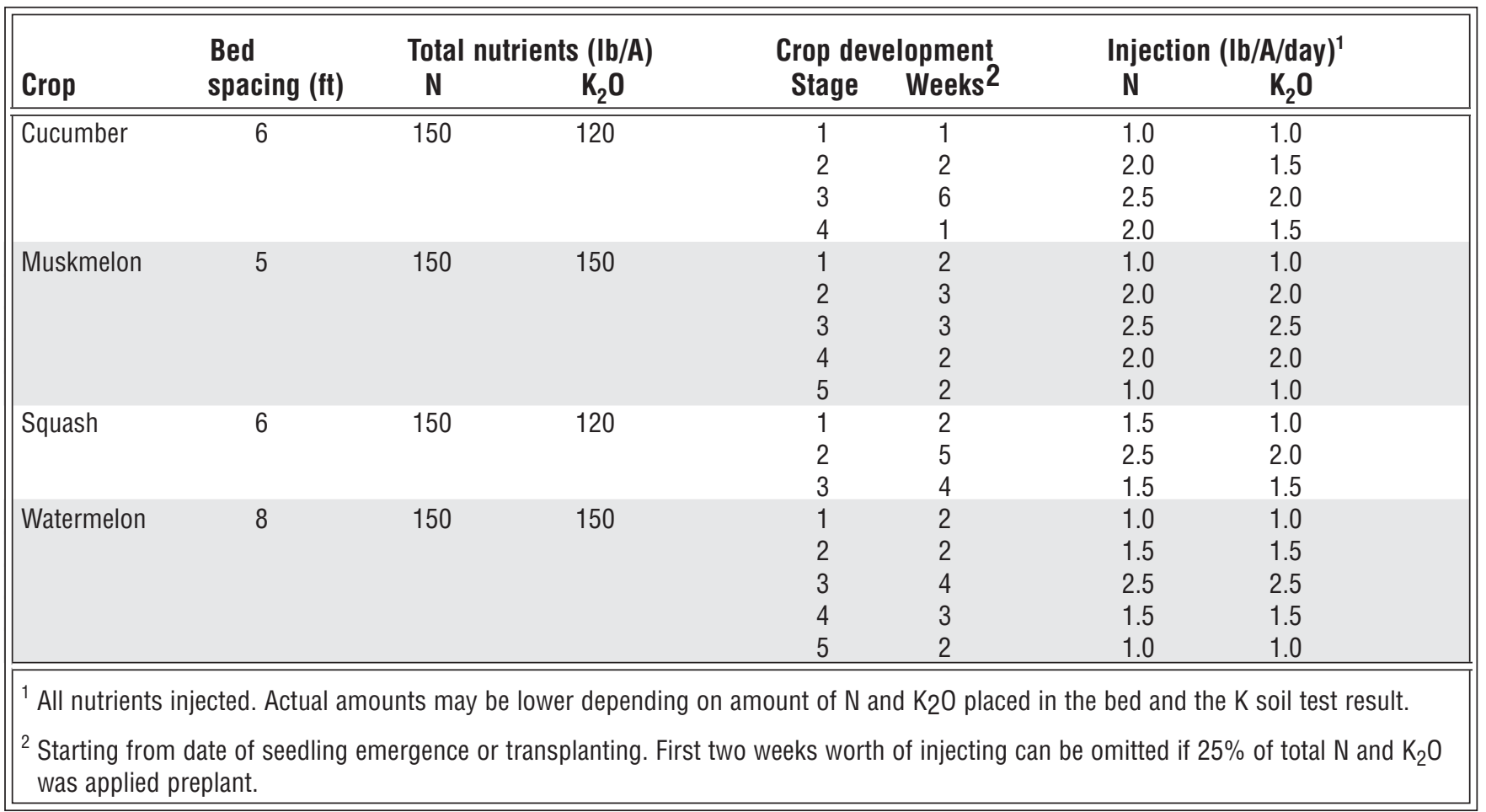


Table 3b. Supplemental fertilization recommendations for cucurbit crops grown in Florida on sandy soils testing very low in Mehlich-1 potassium $\left(\mathrm{K}_{2} \mathrm{O}\right)$.

\begin{tabular}{|c|c|c|c|c|}
\hline \multirow[b]{2}{*}{$\begin{array}{l}\text { Production } \\
\text { System }\end{array}$} & \multirow[b]{2}{*}{ Nutrient } & \multicolumn{3}{|c|}{ Recommended-Supplemental fertilization ${ }^{2}$} \\
\hline & & Leaching rain ${ }^{\mathrm{t}, \mathrm{u}}$ & $\begin{array}{l}\text { Measured "low" plant } \\
\text { nutrient content x.w.u }\end{array}$ & Extended harvest season ${ }^{x . u}$ \\
\hline Plasticulture & $\begin{array}{l}\mathrm{N} \\
\mathrm{K}_{2} \mathrm{O}\end{array}$ & $\mathrm{n} / \mathrm{a}$ & $\begin{array}{l}1.5 \text { to } 2 \mathrm{lbs} / \mathrm{A} / \text { day for } 7 \text { days } \mathrm{s}^{\mathrm{y}} \\
1.5 \text { to } 2 \mathrm{lbs} / \mathrm{A} / \text { day for } 7 \text { days }\end{array}$ & $\begin{array}{l}1.5 \text { to } 2 \mathrm{lbs} / \mathrm{A} / \text { day }^{\mathrm{y}, \mathrm{v}} \\
1.5 \text { to } 2 \mathrm{lbs} / \mathrm{A} / \text { day }^{\mathrm{y}, \mathrm{v}}\end{array}$ \\
\hline Bare ground & $\begin{array}{l}\mathrm{N} \\
\mathrm{K}_{2} \mathrm{O}\end{array}$ & $\begin{array}{l}30 \mathrm{lbs} / \mathrm{A}^{\mathrm{s}} \\
20 \mathrm{lbs} / \mathrm{A}^{\mathrm{s}}\end{array}$ & $\begin{array}{l}30 \mathrm{lbs} / \mathrm{A}^{\mathrm{s}} \\
20 \mathrm{lbs} / \mathrm{A}^{\mathrm{s}}\end{array}$ & $\begin{array}{l}30 \mathrm{lbs} / \mathrm{A}^{\mathrm{v}} \\
20 \mathrm{lbs} / \mathrm{A}^{\mathrm{v}}\end{array}$ \\
\hline \multicolumn{5}{|c|}{$\begin{array}{l}\text { y Fertilizer injections may be done daily or weekly. Inject fertilizer at the end of the irrigation event and allow enough time for proper } \\
\text { flushing afterwards. }\end{array}$} \\
\hline \multicolumn{5}{|c|}{$\begin{array}{l}\text { × Plant nutritional status may be determined with tissue analysis or fresh petiole-sap testing, or any other calibrated method. The "low" } \\
\text { diagnosis needs to be based on UF/IFAS interpretative thresholds. }\end{array}$} \\
\hline \multicolumn{5}{|c|}{ w Plant nutritional status must be diagnosed every week to repeat supplemental application. } \\
\hline \multicolumn{5}{|c|}{${ }^{v}$ Plant nutritional status must be diagnosed after each harvest before repeating supplemental fertilizer application. } \\
\hline \multicolumn{5}{|c|}{$\begin{array}{l}\text { "Supplemental fertilizer applications are allowed when irrigation is scheduled following a recommended method (see chapter } 8 \text { on } \\
\text { irrigation scheduling in Florida). Supplemental fertilization is to be applied in addition to base fertilization when appropriate. } \\
\text { Supplemental fertilization is not to be applied "in advance' with the preplant fertilizer. }\end{array}$} \\
\hline \multicolumn{5}{|c|}{${ }^{\mathrm{t}} \mathrm{A}$ leaching rain is defined as a rainfall amount of 3 inches in 3 days or 4 inches in 7 days. } \\
\hline \multicolumn{5}{|c|}{${ }^{\mathrm{s}}$ Supplemental amount for each leaching rain. } \\
\hline
\end{tabular}

Table 4. Plant tissue analysis at early bloom stage for cucurbits. Dry weight basis.

\begin{tabular}{|c|c|c|c|c|c|c|c|c|c|c|c|c|}
\hline \multirow[b]{2}{*}{ Status } & $\mathbf{N}$ & $\mathbf{P}$ & $K$ & $\mathrm{Ca}$ & $\mathrm{Mg}$ & $S$ & $\mathrm{Fe}$ & Mn & $\mathrm{Zn}$ & B & $\mathrm{Cu}$ & Mo \\
\hline & \multicolumn{6}{|c|}{ Percent } & \multicolumn{6}{|c|}{ Parts per million } \\
\hline \multicolumn{13}{|l|}{ Cucumber } \\
\hline Deficient & $<2.5$ & 0.25 & 1.6 & 1.0 & 0.3 & 0.3 & 40 & 30 & 20 & 20 & 5 & 0.2 \\
\hline Adequate range & $2.5-5.0$ & $0.25-0.6$ & $1.6-3.0$ & $1.0-3.5$ & $0.3-0.6$ & $0.3-0.8$ & $40-100$ & $30-100$ & $20-50$ & $20-60$ & $5-10$ & $0.3-1.0$ \\
\hline High & $>5.0$ & 0.6 & 3.0 & 3.5 & 0.6 & 0.8 & 100 & 100 & 50 & 60 & 20 & 2.0 \\
\hline Toxic $(>)$ & & & & & & & & 900 & 950 & 150 & & \\
\hline \multicolumn{13}{|l|}{ Cantaloupe } \\
\hline Deficient & $<4.0$ & 0.4 & 5.0 & 1.0 & 0.35 & 0.2 & 40 & 20 & 20 & 20 & 5 & 0.6 \\
\hline Adequate range & $4.0-5.0$ & $0.4-0.7$ & $5.0-7.0$ & $1.0-2.0$ & $0.35-0.45$ & $0.2-0.8$ & $40-100$ & $20-100$ & $20-60$ & $20-80$ & $5-10$ & $0.6-1.0$ \\
\hline High & $>5.0$ & 0.7 & 7.0 & 2.0 & 0.45 & 0.8 & 100 & 100 & 60 & 80 & 10 & 1.0 \\
\hline Toxic $(>)$ & & & & & & & & 900 & & 150 & & \\
\hline \multicolumn{13}{|l|}{ Pumpkin } \\
\hline Deficient & $<3.0$ & 0.3 & 2.3 & 0.9 & 0.35 & 0.2 & 40 & 40 & 20 & 25 & 5 & 0.3 \\
\hline Adequate range & $3.0-6.0$ & $0.3-0.5$ & $2.3-4.0$ & $0.9-1.5$ & $0.35-0.60$ & $0.2-0.4$ & $40-100$ & $40-100$ & $20-50$ & $25-40$ & $5-10$ & $0.3-0.5$ \\
\hline High & $>6.0$ & 0.5 & 4.0 & 1.5 & 0.6 & 0.4 & 100 & 100 & 50 & 40 & 10 & 0.5 \\
\hline \multicolumn{13}{|l|}{ Summer Squash } \\
\hline Deficient & $<3.0$ & 0.25 & 2.0 & 1.0 & 0.3 & 0.2 & 40 & 40 & 20 & 25 & 5 & 0.3 \\
\hline Adequate range & $3.0-5.0$ & $0.25-0.5$ & $2.0-3.0$ & $1.0-2.0$ & $0.3-0.5$ & $0.2-0.5$ & $40-100$ & $40-100$ & $20-50$ & $25-40$ & $5-20$ & $0.3-0.5$ \\
\hline High & $>5.0$ & 0.5 & 3.0 & 2.0 & 0.5 & 0.5 & 100 & 100 & 50 & 40 & 20 & 0.5 \\
\hline \multicolumn{13}{|l|}{ Watermelon } \\
\hline Deficient & $<2.5$ & 0.25 & 2.7 & 1.0 & 0.25 & 0.2 & 30 & 20 & 20 & 20 & 5 & 0.3 \\
\hline Adequate range & $2.5-3.5$ & $0.25-0.50$ & $2.7-3.5$ & $1.0-2.0$ & $0.25-0.50$ & $0.2-0.4$ & $30-100$ & $20-100$ & $20-40$ & $20-40$ & $5-10$ & $0.3-0.5$ \\
\hline High & $>3.5$ & 0.5 & 3.5 & 2.0 & 0.5 & 0.4 & 100 & 100 & 40 & 40 & 10 & 0.5 \\
\hline
\end{tabular}


Table 5. Sufficiency ranges for petiole sap testing for cucurbits.

\begin{tabular}{|c|c|c|}
\hline \multirow[t]{2}{*}{ Crop development stage } & \multicolumn{2}{|c|}{ Fresh petiole sap concentration (ppm) } \\
\hline & $\mathrm{NO}_{3}-\mathrm{N}$ & K \\
\hline \multicolumn{3}{|l|}{ Cucumber } \\
\hline First blossom & $800-1000$ & $\mathrm{NR}^{1}$ \\
\hline Fruit three-inches long & $600-800$ & \\
\hline First harvest & $400-600$ & \\
\hline \multicolumn{3}{|l|}{ Cantaloupe } \\
\hline First blossom & $1000-1200$ & $3000-3200^{1}$ \\
\hline Fruits two-inches long & $800-1000$ & - \\
\hline First harvest & $700-800$ & - \\
\hline \multicolumn{3}{|l|}{ Squash } \\
\hline First blossom & $900-1000$ & $\mathrm{NR}^{1}$ \\
\hline First harvest & $800-900$ & \\
\hline \multicolumn{3}{|l|}{ Watermelon } \\
\hline Vines 6" in length & $1200-1500$ & $4000-5000$ \\
\hline Fruits 2" in length & $1000-1200$ & $4000-5000$ \\
\hline Fruits one-half mature & $800-1000$ & $3500-4000$ \\
\hline At first harvest & $600-800$ & $3000-3500$ \\
\hline
\end{tabular}


Table 6. Chemical weed controls: cucurbit crops (muskmelons, cucumbers, squash, watermelon)

\begin{tabular}{|c|c|c|c|c|}
\hline \multirow[b]{2}{*}{ Herbicide } & \multirow[b]{2}{*}{ Labeled crops } & \multirow{2}{*}{$\begin{array}{l}\text { Time of } \\
\text { application to crop }\end{array}$} & \multicolumn{2}{|c|}{ Rate (Ibs. Al./Acre) } \\
\hline & & & Mineral & Muck \\
\hline $\begin{array}{l}\text { Bensulide } \\
\text { (Prefar 4E) }\end{array}$ & $\begin{array}{l}\text { Cucurbit Vegetable group: } \\
\text { Cucumbers, Melons, Squash } \\
\text { (summer and winter), Pumpkins, } \\
\text { edible gourds, bitter melon }\end{array}$ & $\begin{array}{l}\text { Preplant incorporated, } \\
\text { Preemergence }\end{array}$ & $5.0-6.0$ & -- \\
\hline \multicolumn{5}{|c|}{$\begin{array}{l}\text { Remarks: Controls germinating grasses. Incorporate } 1 \text { to } 2 \text { inches. Note precautions of reapplying within } 12 \text { months and planting non- } \\
\text { registered crops within } 18 \text { months. Label states control of crabgrass, foxtail, goosegrass, fall panicum and sprangletop. }\end{array}$} \\
\hline $\begin{array}{l}\text { Bensulide }+ \\
\text { Naptalam } \\
\text { (Prefar 4E + Alanap) }\end{array}$ & $\begin{array}{l}\text { Cantaloupes, Muskmelons, } \\
\text { Cucumbers, Watermelons }\end{array}$ & $\begin{array}{l}\text { Preplant or } \\
\text { Preemergence }\end{array}$ & $\begin{array}{l}5.0 \\
\text { (Bensulide) } \\
+3.0-4.0 \\
\text { (Naptalam) }\end{array}$ & --- \\
\hline \multicolumn{5}{|c|}{$\begin{array}{l}\text { Remarks: Combination (tank mix) will provide wider range of weed control than either material alone. Incorporate into the soil lightly }(0 . \\
\text { to } 1.0 \text { inch) with suitable equipment prior to planting or incorporate preemergent treatments with overhead irrigation. Follow all precau- } \\
\text { tions on both labels. }\end{array}$} \\
\hline $\begin{array}{l}\text { Carfentrazone } \\
\text { (Aim) }\end{array}$ & $\begin{array}{l}\text { Cucurbit Crop Group } \\
\text { (All) }\end{array}$ & $\begin{array}{l}\text { Preplant } \\
\text { Directed-hooded } \\
\text { Row-middles }\end{array}$ & 0.031 & 0.031 \\
\hline
\end{tabular}

Remarks: Aim may be applied as a preplant burndown treatment and/or as a post-directed hooded application to row middles for the burndown of emerged broadleaf weeds. May be tank mixed with other registered herbicides. may be applied at up to $2 \mathrm{oz}(0.031 \mathrm{lb}$ ai). use a quality spary adjuvant such as crop oil concentrate (coc) or non-ionic surfactant at recommended rates.

\begin{tabular}{|c|c|c|c|}
\hline Clethodim (Select) & $\begin{array}{l}\text { Cucurbits (cucumber, squash, } \\
\text { melons and all commodities in } \\
\text { crop group) }\end{array}$ & Postemergence & $0.1-0.125$ \\
\hline
\end{tabular}

Remarks: Use Select for the control of annual and perennial grasses. Use a crop-oil concentrate at $1 \% \mathrm{v} / \mathrm{v}$ in the finished spray volume. Do not apply more than $8 \mathrm{fl}$. oz. product/A per application. Do not apply within 14 days of harvest.

\begin{tabular}{|c|c|c|c|c|}
\hline $\begin{array}{l}\text { Clomozone } \\
\text { (Command } 3 \mathrm{ME} \text { ) }\end{array}$ & $\begin{array}{l}\text { Summer squash } \\
\text { Winter squash }\end{array}$ & $\begin{array}{l}\text { Preemergence } \\
\text { Preemergence } \\
\text { Row Middles }\end{array}$ & $\begin{array}{l}0.15 \\
0.25-0.75 \\
0.75\end{array}$ & --- \\
\hline
\end{tabular}

Remarks: Labeled rate for summer squash if $0.25 \mathrm{lb}$ a.i. Bleaching has been seen under adverse conditions at this rate. Suggest use as tank mix to increase efficacy. May be applied to winter squash and processing pumpkins. See label for varieties and cultivars where application is prohibited. Do not use on Jack-0-Lantern type pumpkins. May be used on processing type varieties. Read disclaimer on the label before use.

\begin{tabular}{|c|c|c|c|c|}
\hline $\begin{array}{l}\text { DCPA } \\
\text { (Dacthal W-75) }\end{array}$ & $\begin{array}{l}\text { Seeded Melons: Cantaloupe, } \\
\text { Honeydew, Watermelon; } \\
\text { Cucumber, Squash: Summer, Winter }\end{array}$ & Early postemergence & $6-8$ & $\begin{array}{ll}-- \\
---\end{array}$ \\
\hline
\end{tabular}

Remarks: Apply only when plants have 4 to 5 true leaves, well established and growing conditions are favorable for good plant growth. Does not control emerged weeds. If weeds have emerged, cultivate prior to application. Do not incorporate.

\begin{tabular}{|llll}
\hline \hline Ethalfluralin + Clomozone & Cucumber, Melons, Watermelons, & Preemergence and Post-directed & $2-3$ pts \\
(Strategy) & Squash, Pumpkins & & ---
\end{tabular}

Remarks: Strategy is a premix of ethalfluralin and clomozone at $1.5+0.5 \mathrm{lbs} /$ gal. Apply 3 pts. product post-seeding to surface prior to weed and crop emergence. Must be applied no later than 2 days after seeding. Soil incorporate with overhead irrigation at $1 / 2$ inch, or with a rain(s) at no less that $1 \frac{1}{2}$ inch within 5 days. Excessive rains or irrigations may cause injury. For furrow irrigation where no rainfall is received, a shallow cultivation may be used to activate the herbicides. Do not apply before transplanting. Do not apply under row covers, hot caps or polyethylene mulches. May be applied as a post-directed spray to row middles after crop emergence or transplanting. Do not apply over plants. The premix controls a large number of grasses and broadleaf weeds.

\begin{tabular}{|c|c|c|c|}
\hline $\begin{array}{ll}\text { Glyphosate } & \text { Cucurbits } \\
\text { (Roundup, Durango) } & \\
\text { Touchdown, Glyphomax) } & \end{array}$ & $\begin{array}{l}\text { Chemical fallow } \\
\text { Preplant, pre mergence, } \\
\text { Pre transplant }\end{array}$ & $0.3-1.0$ & --- \\
\hline
\end{tabular}


Table 6. Continued.

\begin{tabular}{|c|c|c|c|c|}
\hline \multirow[b]{2}{*}{ Herbicide } & \multirow[b]{2}{*}{ Labeled crops } & \multirow{2}{*}{$\begin{array}{l}\text { Time of } \\
\text { application to crop }\end{array}$} & \multicolumn{2}{|c|}{ Rate (Ibs. Al./Acre) } \\
\hline & & & Mineral & Muck \\
\hline $\begin{array}{l}\text { Halosulfuron } \\
\text { (Sandea) }\end{array}$ & $\begin{array}{l}\text { Cucumber, Cantaloupe, Honeydew } \\
\text { and Crenshaw melons. }\end{array}$ & $\begin{array}{l}\text { Preemergence } \\
\text { Postemergence }\end{array}$ & 0.024 & --- \\
\hline
\end{tabular}

Remarks: Apply uniformly at $1 / 2$ oz. product with ground equipment in a minimum of 15 gallons of water per acre. For postemergence applications, apply after the crop has reached the 2 true leaf stage, but before flowering. Use a non ionic surfactant for postemergence applications. May be used for row middle treatments at up to $1 \mathrm{oz}$. product. Controls actively growing nutsedge species best POST. Do not apply within 30 days of harvest for cucumber and 57 days for the melon subgroup.

\begin{tabular}{|c|c|c|c|}
\hline $\begin{array}{l}\text { Halsulfuron } \\
\text { (Sandea) }\end{array}$ & $\begin{array}{l}\text { Cucurbit vegetables including } \\
\text { watermelon, squash, pumpkins } \\
\text { Cucumbers, and melons }\end{array}$ & $\begin{array}{l}\text { Preplant } \\
\text { Pretransplant } \\
\text { Row middles }\end{array}$ & $0.024-0.048$ \\
\hline
\end{tabular}

Remarks: May be applied between rows of direct seeded or transplanted crop for the control of nutsedges and listed broadleaf weeds. Apply at 0.5 to $1 \mathrm{oz}$. product per acre treated. Add a non-ionic surfactant.

\begin{tabular}{|c|c|c|}
\hline $\begin{array}{l}\text { Naptalam } \\
\text { (Alanap-L) }\end{array}$ & $\begin{array}{l}\text { Cantaloupes, Muskmelons, } \\
\text { Cucumbers, Watermelons }\end{array}$ & $\begin{array}{l}\text { Preemergence Preplant } \\
\text { (Irrigated Melons) }\end{array}$ \\
\hline
\end{tabular}

Remarks: Apply within 48 hours of seeding. Apply preemergence to weeds and incorporate with overhead irrigation. Label states control of germinating annuals such as lambsquarter, ragweed, purslane, cocklebur, white mustard, shepherdspurse, redroot pigweed, hairy galingosa and carpetweed.

\begin{tabular}{llll}
\hline $\begin{array}{l}\text { Naptalam } \\
\text { (Alanap-L) }\end{array}$ & Cantaloupes, Cucumbers, & Postemergence Posttransplant & $3.0-4.0$
\end{tabular}

Remarks: Apply 1 month after planting when vines are starting to run but before weeds have emerged or immediately after transplanting. Do not use when plants are under stress due to weather conditions. Do not tank mix with crop oil or adjuvants. Phytotoxicity may occur.

\begin{tabular}{||llll}
\hline \hline Paraquat & Watermelon, Squash, Pumpkin, & Preplant or Preemergence & $0.63-0.94$ \\
(Gramoxone Intron) & Cantaloupe, Muskmelon, Cucumber & & --- \\
(Firestorm) & & &
\end{tabular}

Remarks: Controls emerged weeds only. Apply prior, during or after planting, but before crop emerges. Use a non-ionic spreader.

\begin{tabular}{||lccc}
\hline \hline $\begin{array}{l}\text { Paraquat } \\
\text { (Gramoxone Intron) }\end{array}$ & Pelons & Postemergence directed spray & $0.47-0.93$
\end{tabular}

Remarks: Controls emerged weeds only. Apply 1.5 to 3.0 pts. per sprayed acre with ground equipment directing spray between the rows and use shields to prevent spray contact with the crop plants. Add a non-ionic surfactant at $8 \mathrm{fl}$. $0 \mathrm{z}$. per $100 \mathrm{gals}$. of spray mix. Do not apply more than 3 times per season. A Special Local Needs (24c) label for Florida.

\begin{tabular}{lllll}
\hline \hline $\begin{array}{l}\text { Pelargonic Acid } \\
\text { (Scythe) }\end{array}$ & Cucurbits (melons; cucumber, & Preplant & $3-10 \% \mathrm{v} / \mathrm{v}$ & $3-10 \% \mathrm{v} / \mathrm{v}$ \\
& gourd, pumpkin, squash, & Preemergence & & \\
& muskmelon and watermelon) & Directed-Shielded & &
\end{tabular}

Remarks: Product is a contact, non-selective, foliar applied herbicide. There is no residual activity. May be tank mixed with soil residual compounds. Consult the label for rates and other information.

\begin{tabular}{|c|c|c|}
\hline Sethoxydim (Poast) & Cucurbits: all & Postemergence \\
\hline
\end{tabular}

Remarks: Controls actively growing grass weeds. A total of 3 pts. product per acre may be applied in one season. Do not apply within 14 days of harvest. Apply in 5 to 20 gals. of water adding 2 pts. of crop oil concentrate per acre. Unsatisfactory results may occur if applied to grasses under stress. Use $0.188 \mathrm{lb}$. ai. (1 pt.) on seedling grasses and up to $0.28 \mathrm{lb}$. ai. (1.5 pts.) on perennial grasses emerging from rhizomes, etc. Consult label for grass species and growth stage for best control. 
Table 7. Disease management for cucumber.

\begin{tabular}{|c|c|c|c|c|c|c|}
\hline Chemical & $\begin{array}{l}\text { Fungicide } \\
\text { Group }\end{array}$ & $\frac{\text { Maximum }}{\text { Application }}$ & $\begin{array}{l}\text { Rate/Acre/ } \\
\text { Crop }\end{array}$ & $\begin{array}{l}\text { Min. Days } \\
\text { to Harvest }\end{array}$ & Pertinent Diseases & Remarks \\
\hline \multirow[t]{2}{*}{$\begin{array}{l}\text { Acrobat 50WP } \\
\text { (Dimethomorph) }\end{array}$} & 40 & $6.40 z$ & $320 z$ & 0 & Downy mildew & $\begin{array}{l}\text { Limit is } 5 \text { appl./crop. Tank mix } \\
\text { with another fungicide. Harvest } \\
\text { after spray is dry. }\end{array}$ \\
\hline & & & & & Phytophthora blight & \\
\hline $\begin{array}{l}\text { Aliette 80WDG } \\
\text { (Fosetyl-Al) } \\
\text { Amistar 80DF } \\
\text { (Azoxystrobin) }\end{array}$ & $\begin{array}{l}33 \\
11\end{array}$ & $\begin{array}{l}5 \mathrm{lb} \\
5 \mathrm{oz}\end{array}$ & $\begin{array}{l}35 \mathrm{lb} \\
1.88 \mathrm{lb}\end{array}$ & $\begin{array}{l}12 \mathrm{hr} \\
1\end{array}$ & $\begin{array}{l}\text { Downy mildew } \\
\text { Downy mildew } \\
\text { Powdery mildew } \\
\text { Gummy stem blight } \\
\text { Anthracnose } \\
\text { Alternaria leaf spot } \\
\text { Certain leaf spots } \\
\text { Belly Rot }\end{array}$ & $\begin{array}{l}\text { Limit is } 7 \text { appl./crop. Do not } \\
\text { tank mix with copper fungi- } \\
\text { cides. } \\
\text { Limit is four applications/crop } \\
\text { for all Qol fungicides. Do not } \\
\text { make more than two consecu- } \\
\text { tive applications. }\end{array}$ \\
\hline $\begin{array}{l}\text { Botran } 75 W \\
\text { (Dicloran) } \\
\text { Bravo Ultrex or } \\
\text { Equus DF } \\
\text { (Chlorothalonil) }\end{array}$ & $\begin{array}{l}14 \\
\text { M5 }\end{array}$ & $\begin{array}{l}1.3 \mathrm{lb} \\
2.7 \mathrm{lb}\end{array}$ & $19 \mathrm{lb}$ & $\begin{array}{l}1 \\
0\end{array}$ & $\begin{array}{l}\text { Sclerotinia } \\
\text { Anthracnose } \\
\text { Scab } \\
\text { Downy mildew } \\
\text { Gummmy stem blight } \\
\text { Powdery mildew }\end{array}$ & $\begin{array}{l}\text { Greenhouse only } \\
\text { Maximum application rate } \\
\text { is lower for certain diseases } \\
\text { including downy mildew }\end{array}$ \\
\hline $\begin{array}{l}\text { Bravo Weather Stik } \\
\text { 6FLs, Equus } 720 \\
\text { SST, Echo } 720 \text {, } \\
\text { (Chlorothalonil) }\end{array}$ & M5 & $3 \mathrm{pt}$ & $21 \mathrm{pt}$ & 0 & Same as Bravo Ultrex & Same as Bravo Ultrex \\
\hline $\begin{array}{l}\text { Echo 90DF } \\
\text { (Chlorothalonil) }\end{array}$ & M5 & $2.5 \mathrm{lb}$ & $17 \mathrm{lb}$ & 0 & Same as Bravo Ultrex & Same as Bravo Ultrex \\
\hline $\begin{array}{l}\text { Cabrio } 2.09 \mathrm{~F} \\
\text { (Pyraclostrobin) }\end{array}$ & 11 & $16 \mathrm{fl} \mathrm{oz}$ & $64 \mathrm{fl} \mathrm{oz}$ & 0 & Same as Amistar & $\begin{array}{l}4 \text { appl. Maximum. Same as } \\
\text { Amistar. }\end{array}$ \\
\hline $\begin{array}{l}\text { Curzate 60DF } \\
\text { (Cymoxanil) }\end{array}$ & 27 & $3.2 \mathrm{oz}$ & $\begin{array}{l}\text { See } \\
\text { Remarks }\end{array}$ & 3 & Downy Mildew & $\begin{array}{l}\text { Use only with a labeled rate of } \\
\text { protectant fungicide. No more } \\
\text { than } 9 \text { applications per } 12 \\
\text { months }\end{array}$ \\
\hline $\begin{array}{l}\text { Dithane F45 } \\
\text { Rainshield } \\
\text { (Mancozeb) }\end{array}$ & M3 & $2.4 \mathrm{qt}$ & $19.6 \mathrm{qt}$ & 5 & $\begin{array}{l}\text { Same as Manzate Pro- } \\
\text { Stick }\end{array}$ & \\
\hline $\begin{array}{l}\text { Dithane-DF } \\
\text { Rainshield } \\
\text { (Mancozeb) }\end{array}$ & M3 & $3 \mathrm{lb}$ & $25.6 \mathrm{lb}$ & 5 & $\begin{array}{l}\text { Anthracnose } \\
\text { Gummy stem blight } \\
\text { Downy mildew }\end{array}$ & \\
\hline $\begin{array}{l}\text { Maneb 75DF } \\
\text { (Maneb) }\end{array}$ & M3 & $2 \mathrm{lb}$ & $17.1 \mathrm{lb}$ & 5 & Same as Maneb 80WP & \\
\hline $\begin{array}{l}\text { Manzate Flowable } \\
\text { (Mancozeb) } \\
\text { Manzate Pro-Stick, } \\
\text { Manzate 75DF, } \\
\text { Dithane M-45 } \\
\text { (Mancozeb) }\end{array}$ & $\begin{array}{l}\text { M3 } \\
\text { M3 }\end{array}$ & $\begin{array}{l}2.4 \mathrm{qt} \\
3 \mathrm{lb}\end{array}$ & $\begin{array}{l}19.2 \mathrm{qt} \\
24 \mathrm{lb}\end{array}$ & $\begin{array}{l}5 \\
5\end{array}$ & $\begin{array}{l}\text { Same as Manzate 75DF } \\
\text { Anthracnose } \\
\text { Downy mildew } \\
\text { Gummy stem blight }\end{array}$ & \\
\hline $\begin{array}{l}\text { Maneb 80WP } \\
\text { (Maneb) }\end{array}$ & M3 & $2 \mathrm{lb}$ & $16 \mathrm{lb}$ & 5 & $\begin{array}{l}\text { Scab } \\
\text { Anthracnose } \\
\text { Pythium fruit Rot } \\
\text { Downy Mildew }\end{array}$ & \\
\hline
\end{tabular}


Table 7. Continued.

\begin{tabular}{|c|c|c|c|c|c|c|}
\hline Chemical & $\begin{array}{l}\text { Fungicide } \\
\text { Group }\end{array}$ & $\frac{\text { Maximum }}{\text { Application }}$ & $\begin{array}{l}\text { Rate/Acre/ } \\
\text { Crop }\end{array}$ & $\begin{array}{l}\text { Min. Days } \\
\text { to Harvest }\end{array}$ & Pertinent Diseases & Remarks \\
\hline $\begin{array}{l}\text { Manex 4F } \\
\text { (Maneb) } \\
\text { Flint 50WP } \\
\text { (Trifloxystrobin) }\end{array}$ & $\begin{array}{l}\text { M3 } \\
11\end{array}$ & $\begin{array}{l}1.6 \mathrm{qt} \\
2 \mathrm{oz}\end{array}$ & $\begin{array}{l}12.8 \mathrm{qt} \\
8 \mathrm{oz}\end{array}$ & $\begin{array}{l}5 \\
0\end{array}$ & $\begin{array}{l}\text { Same as Maneb } 80 \\
\text { WP } \\
\text { Powdery mildew } \\
\text { Downy Mildew }\end{array}$ & $\begin{array}{l}\text { Limit is } 4 \text { appl./crop \& alter- } \\
\text { nate chemistry. Maximum } \\
\text { rate is higer for downy mil- } \\
\text { dew suppression. Same as } \\
\text { Amistar. }\end{array}$ \\
\hline $\begin{array}{l}\text { Fosphite, Topaz } \\
\text { (Potassium phos- } \\
\text { phite) }\end{array}$ & & $3 \mathrm{qt}$ & $\begin{array}{l}18 \mathrm{qt} \\
\text { (Topaz) }\end{array}$ & 0 & $\begin{array}{l}\text { Phytophthora, Pythium, } \\
\text { Fusarium, Rhizoctonia, } \\
\text { Downy Mildew }\end{array}$ & $\begin{array}{l}\text { Check label for required mini- } \\
\text { mum gallons per acre, restric- } \\
\text { tions for use following copper } \\
\text { application, plant and environ- } \\
\text { mental conditions that restrict } \\
\text { use, and for compatibility with } \\
\text { other materials. }\end{array}$ \\
\hline $\begin{array}{l}\text { Prophyt } \\
\text { (Potassium phos- } \\
\text { phate) } \\
\text { Gavel 75DF } \\
\text { (Mancozeb; } \\
\text { Zoxamide) }\end{array}$ & M3 \& 22 & $\begin{array}{l}4 \mathrm{pt} \\
2 \mathrm{lb}\end{array}$ & $16 \mathrm{lb}$ & $\begin{array}{l}0 \\
5\end{array}$ & $\begin{array}{l}\text { Downy Mildew, } \\
\text { Phytophthora capsici } \\
\text { Alternaria leaf spot } \\
\text { Downy mildew }\end{array}$ & $\begin{array}{l}\text { Check label for required mini- } \\
\text { mum gallons per acre, plant } \\
\text { and environmental conditions } \\
\text { that restrict use, and for com- } \\
\text { patibility with other materials. } \\
\text { Limit is } 8 \text { appl./crop. }\end{array}$ \\
\hline $\begin{array}{l}\text { Heritage } \\
\text { (Azoxystrobin) }\end{array}$ & 11 & $8.00 \mathrm{z}$ & $3.0 \mathrm{lb}$ & 1 & Same as Amistar & $\begin{array}{l}\text { Do not make more than two } \\
\text { consecutive applications. Do } \\
\text { not make more than } 6 \text { appli- } \\
\text { cations per crop. Same as } \\
\text { Amistar }\end{array}$ \\
\hline $\begin{array}{l}\text { JMS Stylet Oil } \\
\text { ManKocide 61.1DF } \\
\text { (Copper hydroxide; } \\
\text { Mancozeb) }\end{array}$ & M1 \& M3 & $\begin{array}{l}3 \mathrm{qt} \\
2.66 \mathrm{lb}\end{array}$ & $128 \mathrm{lb}$ & $\begin{array}{l}4 \mathrm{hr} \\
5\end{array}$ & $\begin{array}{l}\text { Aphid-transmitted virus- } \\
\text { es, powdery mildew } \\
\text { Angular leaf spot } \\
\text { Downy mildew }\end{array}$ & $\begin{array}{l}\text { See label for specific appl. } \\
\text { Tech. (e.g. use of } 400 \text { psi) }\end{array}$ \\
\hline $\begin{array}{l}\text { Nova 40W } \\
\text { (Myclobutanil) }\end{array}$ & 3 & $50 z$ & $1.5 \mathrm{lb}$ & 0 & Powdery mildew & $\begin{array}{l}\text { Note that a } 30 \text { day plant back } \\
\text { restriction exists. }\end{array}$ \\
\hline $\begin{array}{l}\text { Penncozeb 75DF } \\
\text { (Mancozeb) } \\
\text { Penncozeb 80WP } \\
\text { (Mancozeb) }\end{array}$ & $\begin{array}{l}\text { M3 } \\
\text { M3 }\end{array}$ & $\begin{array}{l}3 \mathrm{lb} \\
3 \mathrm{lb}\end{array}$ & $\begin{array}{l}25.6 \\
24 \mathrm{lb}\end{array}$ & $\begin{array}{l}5 \\
5\end{array}$ & $\begin{array}{l}\text { Same as Penncozeb } \\
80 \text { WP } \\
\text { Anthracnose } \\
\text { Downy mildew } \\
\text { Gummy stem blight } \\
\text { Pythium fruit rot } \\
\text { Scab }\end{array}$ & \\
\hline $\begin{array}{l}\text { Pristine 38WG } \\
\text { (Boscalid;Pyraclost } \\
\text { robin) }\end{array}$ & $7 \& 11$ & $18.5 \mathrm{fl} \mathrm{oz}$ & $74 \mathrm{oz}$ & 0 & Same as Amistar & $\begin{array}{l}\text { Limit is } 4 \text { appl.crop \& alter- } \\
\text { nate chemistry }\end{array}$ \\
\hline $\begin{array}{l}\text { Procure 50WS and } \\
\text { 480SC } \\
\text { (Triflumizole) }\end{array}$ & 3 & $80 z$ & $40 \mathrm{oz}$ & 0 & Powdery Mildew & \\
\hline $\begin{array}{l}\text { Quadris 2.08FL } \\
\text { (Azoxystrobin) }\end{array}$ & 11 & $15.4 \mathrm{fl} \mathrm{oz}$ & $2.88 \mathrm{qt}$ & 1 & Same as Amistar & $\begin{array}{l}\text { Limit is } 4 \text { appl./crop \& alternate } \\
\text { chemistry. Same as Amistar }\end{array}$ \\
\hline $\begin{array}{l}\text { Ranman } \\
\text { (Cyazofamid) }\end{array}$ & 21 & $2.75 \mathrm{fl} \mathrm{oz}$ & $16.5 \mathrm{fl} \mathrm{oz}$ & 0 & $\begin{array}{l}\text { Downy Mildew } \\
\text { Phytophthora blight }\end{array}$ & $\begin{array}{l}\text { Limit is } 6 \text { appl./crop. } \\
\text { Follow resistance management } \\
\text { guidelines on label. }\end{array}$ \\
\hline
\end{tabular}


Table 7. Continued.

\begin{tabular}{|c|c|c|c|c|c|c|}
\hline Chemical & $\begin{array}{l}\text { Fungicide } \\
\text { Group }\end{array}$ & $\frac{\text { Maximum }}{\text { Application }}$ & $\frac{\text { Rate/Acre/ }}{\text { Crop }}$ & $\begin{array}{l}\text { Min. Days } \\
\text { to Harvest }\end{array}$ & Pertinent Diseases & Remarks \\
\hline $\begin{array}{l}\text { Reason 500SC } \\
\text { (Fenamidone) }\end{array}$ & 11 & $5.5 \mathrm{fl} \mathrm{oz}$ & $22 \mathrm{oz}$ & 14 & $\begin{array}{l}\text { Downy Mildew } \\
\text { Alternaria leaf spot }\end{array}$ & $\begin{array}{l}\text { Limit is } 4 \text { appl./crop \& alternate } \\
\text { chemistry }\end{array}$ \\
\hline $\begin{array}{l}\text { Previcur Flex } \\
\text { (Promocarb hydro- } \\
\text { chloride) } \\
\text { Ridomil Gold Bravo } \\
76.4 \mathrm{~W} \\
\text { (Chlorothalonil } \\
\text { Mefenoxam) }\end{array}$ & $\begin{array}{l}\text { U } \\
\text { M5 \& } 4\end{array}$ & $\begin{array}{l}1.2 \mathrm{pt} \\
3 \mathrm{lb}\end{array}$ & $\begin{array}{l}6 \mathrm{pt} \\
12 \mathrm{lb}\end{array}$ & $\begin{array}{l}2 \\
7\end{array}$ & $\begin{array}{l}\text { Downy Mildew } \\
\text { Pythium } \\
\text { Downy mildew } \\
\text { Certain leaf spots } \\
\text { Gummy stem blight } \\
\text { Scab }\end{array}$ & $\begin{array}{l}\text { Use a tank mix partner. See } \\
\text { label for directions using a } \\
\text { contact fungicide and Pythium } \\
\text { suppression } \\
\text { Limit is } 4 \text { appl./crop }\end{array}$ \\
\hline $\begin{array}{l}\text { Ridomil MZ 68WP } \\
\text { (Mancozeb; } \\
\text { Mefenoxam) }\end{array}$ & M3 \& 4 & $2.5 \mathrm{lb}$ & $10 \mathrm{lb}$ & 5 & Downy mildew & Limit is 4 appl./crop. \\
\hline $\begin{array}{l}\text { Ridomil Gold/Copper } \\
64.8 \mathrm{~W} \\
\text { (Copper hydroxide; } \\
\text { Mefenoxam) } \\
\text { Ridomil Gold 4EC } \\
\text { (Mefenoxam) }\end{array}$ & $\begin{array}{l}\mathrm{M} 1 \& 4 \\
4\end{array}$ & $\begin{array}{l}2 \mathrm{lb} \\
2 \mathrm{pt} / \text { treated } \\
\mathrm{A}\end{array}$ & $8 \mathrm{lb}$ & 5 & $\begin{array}{l}\text { Downy mildew } \\
\text { Pythium seedling blight }\end{array}$ & $\begin{array}{l}\text { Limit is } 4 \text { appl./crop } \\
\text { Apply at seeding in a } 7-12 " \\
\text { band on soil over seed furrow }\end{array}$ \\
\hline $\begin{array}{l}\text { Ultra Flourish } \\
\text { (Mefenoxam) }\end{array}$ & 4 & $\begin{array}{l}4 \text { pt/treated } \\
\mathrm{A}\end{array}$ & & & Same Ridomil Gold 4EC & Same Ridomil Gold 4EC \\
\hline $\begin{array}{l}\text { Serenade ASO } \\
\text { (Bacillus subtilis } \\
\text { strain QST 713) }\end{array}$ & & $6 \mathrm{lb}$ & & 0 & $\begin{array}{l}\text { Powdery mildew, } \\
\text { Gummy Stem blight, } \\
\text { Downy mildew }\end{array}$ & $\begin{array}{l}\text { Do not use product alone. } \\
\text { Apply with registered fungicide. }\end{array}$ \\
\hline $\begin{array}{l}\text { Serenade Max } \\
\text { (Bacillus subtilis } \\
\text { strain QST 713) }\end{array}$ & & $3 \mathrm{lb}$ & & 0 & $\begin{array}{l}\text { Powdery mildew, } \\
\text { Gummy Stem blight, } \\
\text { Downy mildew }\end{array}$ & $\begin{array}{l}\text { Do not use product alone. } \\
\text { Apply with registered fungicide. }\end{array}$ \\
\hline $\begin{array}{l}\text { Sonata } \\
\text { (Bacillus pumilus } \\
\text { strain QST 2808) } \\
\text { Tanos 50DF } \\
\text { (Cymoxanil; } \\
\text { Famoxadone) }\end{array}$ & $27 \& 11$ & $\begin{array}{l}4 \mathrm{lb} \\
8 \mathrm{oz}\end{array}$ & $32 \mathrm{oz}$ & $\begin{array}{l}0 \\
3\end{array}$ & $\begin{array}{l}\text { Powdery mildew, Downy } \\
\text { mildew } \\
\text { Downy mildew } \\
\text { Anthracnose }\end{array}$ & $\begin{array}{l}\text { Do not use product alone. } \\
\text { Apply with registered fungicide } \\
\text { Limit is } 4 \text { appl./crop. Must } \\
\text { tankmix with a contact fungi- } \\
\text { cide. Limit is } 72 \text { oz/A maxi- } \\
\text { mum per year. }\end{array}$ \\
\hline $\begin{array}{l}\text { Topsin M 70WP } \\
\text { (Thiophanate-methyl) }\end{array}$ & 1 & $0.5 \mathrm{lb}$. & $3 \mathrm{lb}$ & 1 & $\begin{array}{l}\text { Certain leaf spots, } \\
\text { Powdery mildew, } \\
\text { Gummy stem blight }\end{array}$ & Same as Topsin 4.5 FL \\
\hline $\begin{array}{l}\text { Topsin M WSB } \\
\text { (Thiophanate-methyl) }\end{array}$ & 1 & $0.5 \mathrm{lb}$ & $3 \mathrm{lb}$ & 1 & $\begin{array}{l}\text { Same as Topsin M } \\
\text { 70WP }\end{array}$ & Same as Topsin 4.5 FL \\
\hline $\begin{array}{l}\text { Topsin 4.5FL } \\
\text { (Thiophanate-methyl) }\end{array}$ & 1 & $10 \mathrm{oz}$ & $60 \mathrm{oz}$ & 1 & $\begin{array}{l}\text { Anthracnose, Powdery } \\
\text { Mildew, Gummy stem } \\
\text { blight }\end{array}$ & $\begin{array}{l}\text { Follow resistance management } \\
\text { guidelines on label }\end{array}$ \\
\hline $\begin{array}{l}\text { Thiophanate methyl } \\
\text { 85WDG } \\
\text { (Thiophanate-methyl) }\end{array}$ & 1 & 0.4 & 2.5 & 1 & $\begin{array}{l}\text { Powdery Mildew, } \\
\text { Gummy stem blight }\end{array}$ & Same as Topsin \\
\hline $\begin{array}{l}\text { Various copper for- } \\
\text { mulations }^{1}\end{array}$ & M1 & & & & $\begin{array}{l}\text { Bacterial diseases (See } \\
\text { individual label) }\end{array}$ & See label \\
\hline Sulfur² & & & & & Powdery mildew & See label \\
\hline \multicolumn{7}{|c|}{$\begin{array}{l}1 \text { Badge SC, Basic Copper 53, Champ DP Dry Prill, Champ Formula 2FL, Champion WP, COC DF, COC WP, Copper-Count-N, Cuprofix } \\
\text { Disperss, Cuprofix MZ Disperss, Kocide 101, Kocide 2000, Kocide 4.5LF, Kocide DF, Nordox, Nordox } 75 \text { WG, Nu-Cop 3L, Nu-Cop } 50 \\
\text { WP, Nu-Cop } 50 \text { DF, Stretch, Tenn-Cop 5E }\end{array}$} \\
\hline 2 Dusting Sulfur, Kumı & ulus $\mathrm{DF}, \mathrm{Mi}$ & ro Sulf, Micro & nized Gold, M & licrothiol Dis & s, Sulfur 90W, Thiolux Jet & t, Thiosperse 80 , Wettable Sulfur \\
\hline
\end{tabular}


Table 8. Disease management for cantaloupe.

\begin{tabular}{|c|c|c|c|c|c|c|}
\hline Chemical & $\begin{array}{l}\text { Fungicide } \\
\text { Group }\end{array}$ & $\frac{\text { Maximum }}{\text { Application }}$ & $\frac{\text { ate/Acre/ }}{\text { Crop }}$ & $\begin{array}{l}\text { Min. Days } \\
\text { to Harvest }\end{array}$ & Pertinent Diseases & Remarks \\
\hline $\begin{array}{l}\text { Acrobat 50WP } \\
\text { (Dimethomorph) }\end{array}$ & 40 & $6.40 z$ & $320 z$ & 0 & $\begin{array}{l}\text { Downy mildew } \\
\text { Phytophthora blight }\end{array}$ & $\begin{array}{l}\text { Limit is } 5 \text { appl./crop. Tank mix } \\
\text { with another fungicide. Harvest } \\
\text { after spray is dry. }\end{array}$ \\
\hline $\begin{array}{l}\text { Aliette 80WDG } \\
\text { (Fosetyl-Al) }\end{array}$ & 33 & $5 \mathrm{lb}$ & $35 \mathrm{lb}$ & $12 \mathrm{hr}$ & Downy mildew & $\begin{array}{l}\text { Limit is } 7 \text { appl./crop. Do not tank } \\
\text { mix with copper fungicides. }\end{array}$ \\
\hline $\begin{array}{l}\text { Amistar 80DF } \\
\text { (Azoxystrobin) }\end{array}$ & 11 & $50 z$ & $1.88 \mathrm{lb}$ & 1 & $\begin{array}{l}\text { Downy mildew } \\
\text { Powdery mildew } \\
\text { Gummy stem blight } \\
\text { Anthracnose } \\
\text { Alternaria leaf spot } \\
\text { Certain leaf spots }\end{array}$ & $\begin{array}{l}\text { Limit is } 4 \text { applications/crop for } \\
\text { all Qol fungicides. Do not make } \\
\text { more than two consecutive appli- } \\
\text { cations. }\end{array}$ \\
\hline $\begin{array}{l}\text { Bravo Weather Stik } \\
6 \mathrm{FL} \text {, Echo } 720 \text {, and } \\
\text { Equus } 720 \mathrm{SST} \\
\text { (Chlorothalonil) }\end{array}$ & M5 & $3 \mathrm{pt}$ & $21 \mathrm{pt}$ & 0 & $\begin{array}{l}\text { Gummy stem blight } \\
\text { Anthracnose } \\
\text { Downy mildew } \\
\text { Alternaria leaf spot } \\
\text { Cercospora leaf spot } \\
\text { Powdery Mildew } 1\end{array}$ & $\begin{array}{l}\text { Maximum rate on label is less for } \\
\text { downy mildew and certain other } \\
\text { diseases.. }\end{array}$ \\
\hline $\begin{array}{l}\text { Echo 90DF } \\
\text { (Chlorothalonil) }\end{array}$ & M5 & $2.5 \mathrm{lb}$ & $17 \mathrm{lb}$ & 0 & Same as Echo 720 & Same as Echo 720 \\
\hline $\begin{array}{l}\text { Bravo Ultrex and Equus } \\
\text { DF (Chlorothalonil) }\end{array}$ & s M5 & $2.7 \mathrm{lb}$ & $19 \mathrm{lb}$ & 0 & Same as Echo 720 & Same as Echo 720 \\
\hline $\begin{array}{l}\text { Cabrio 2.09F } \\
\text { (Pyraclostrobin) }\end{array}$ & 11 & $16 \mathrm{fl} \mathrm{oz}$ & $64 \mathrm{fl} \mathrm{oz}$ & 0 & Same as Amistar & $\begin{array}{l}4 \text { appl. Maximum. Same as } \\
\text { Amistar. }\end{array}$ \\
\hline $\begin{array}{l}\text { Curzate 60DF } \\
\text { (Cymoxanil) }\end{array}$ & 27 & $3.20 z$ & $\begin{array}{l}\text { See } \\
\text { Remarks }\end{array}$ & 3 & Downy Mildew & $\begin{array}{l}\text { Use only with a labeled rate of } \\
\text { protectant fungicide. No more } \\
\text { than } 9 \text { applications per } 12 \\
\text { months }\end{array}$ \\
\hline $\begin{array}{l}\text { Flint 50WP } \\
\text { (Trifloxystrobin) }\end{array}$ & 11 & $20 z$ & $80 z$ & 0 & $\begin{array}{l}\text { Powdery mildew } \\
\text { Downy Mildew }\end{array}$ & $\begin{array}{l}\text { Limit is } 4 \text { appl./crop \& alternate } \\
\text { chemistry. Maximum rate is } \\
\text { higer for downy mildew suppres- } \\
\text { sion. Same as Amistar. }\end{array}$ \\
\hline $\begin{array}{l}\text { Gavel 75DF } \\
\text { (Mancozeb; } \\
\text { Zoxamide) }\end{array}$ & $\begin{array}{l}\text { M3 \& } \\
22\end{array}$ & $2 \mathrm{lb}$ & $16 \mathrm{lb}$ & 5 & $\begin{array}{l}\text { Alternaria leaf spot } \\
\text { Downy mildew }\end{array}$ & $\begin{array}{l}\text { Limit is } 8 \text { appl./crop. Some can- } \\
\text { taloupe varieties are sensitive, } \\
\text { check label. }\end{array}$ \\
\hline $\begin{array}{l}\text { Heritage } \\
\text { (Azoxystrobin) }\end{array}$ & 11 & $8.00 z$ & $3.0 \mathrm{lb}$ & 1 & Same as Amistar & $\begin{array}{l}\text { Do not make more than two } \\
\text { consecutive applications. Do not } \\
\text { make more than } 6 \text { applications } \\
\text { per crop. Same as Amistar }\end{array}$ \\
\hline $\begin{array}{l}\text { Quadris 2.08FL } \\
\text { (Azoxystrobin) }\end{array}$ & 11 & $15.4 \mathrm{fl} \mathrm{oz}$ & $2.88 \mathrm{qt}$ & 1 & Same as Amistar & $\begin{array}{l}\text { Limit is } 4 \text { appl./crop \& alternate } \\
\text { chemistry. Same as Amistar }\end{array}$ \\
\hline $\begin{array}{l}\text { Fosphite, Topaz } \\
\text { (Potassium phosphite) }\end{array}$ & & 3 qt & $\begin{array}{l}18 \mathrm{qt} \\
\text { (Topaz) }\end{array}$ & 0 & $\begin{array}{l}\text { Phytophthora, Pythium, } \\
\text { Fusarium, Rhizoctonia, } \\
\text { Downy Mildew }\end{array}$ & $\begin{array}{l}\text { Check label for required minimum } \\
\text { gallons per acre, restrictions for } \\
\text { use following copper application, } \\
\text { plant and environmental condi- } \\
\text { tions that restrict use, and for } \\
\text { compatibility with other materials. }\end{array}$ \\
\hline $\begin{array}{l}\text { Prophyt } \\
\text { (Potassium phosphate) }\end{array}$ & & $4 \mathrm{pt}$ & & 0 & $\begin{array}{l}\text { Downy Mildew, } \\
\text { Phytophthora capsici }\end{array}$ & $\begin{array}{l}\text { Check label for required minimum } \\
\text { gallons per acre, plant and envi- } \\
\text { ronmental conditions that restrict } \\
\text { use, and for compatibility with } \\
\text { other materials. }\end{array}$ \\
\hline
\end{tabular}


Table 8. Contiinued.

\begin{tabular}{|c|c|c|c|c|c|c|}
\hline Chemical & $\begin{array}{l}\text { Fungicide } \\
\text { Group }\end{array}$ & $\frac{\text { Maximum }}{\text { Application }}$ & $\frac{\text { late/Acre/ }}{\text { Crop }}$ & $\begin{array}{l}\text { Min. Days } \\
\text { to Harvest }\end{array}$ & Pertinent Diseases & Remarks \\
\hline $\begin{array}{l}\text { ManKocide 61.1DF } \\
\text { Copper (hydroxide ; } \\
\text { Mancozeb) }\end{array}$ & $\begin{array}{l}\text { M1 \& } \\
\text { M3 }\end{array}$ & $2.5 \mathrm{lb}$ & $128 \mathrm{lb}$ & 5 & $\begin{array}{l}\text { Angular leaf spot } \\
\text { Bacterial fruit blotch } \\
\text { Downy mildew }\end{array}$ & \\
\hline $\begin{array}{l}\text { Maneb 75DF } \\
\text { (Maneb) }\end{array}$ & M3 & $2 \mathrm{lb}$ & $17.1 \mathrm{lb}$ & 5 & $\begin{array}{l}\text { Alternaria leaf spot } \\
\text { Anthracnose } \\
\text { Cercospora leaf spot } \\
\text { Downy mildew } \\
\text { Gummy stem blight }\end{array}$ & $\begin{array}{l}\text { Limit is } 7 \text { appl./crop. Do not } \\
\text { tank mix with copper fungicides. } \\
\text { Some cantaloupe varieties may be } \\
\text { sensitive to EBCD products, check } \\
\text { label or Extension resources for } \\
\text { this information. }\end{array}$ \\
\hline $\begin{array}{l}\text { Manex 4F } \\
\text { (Maneb) }\end{array}$ & M3 & $1.6 \mathrm{qt}$ & $12.8 \mathrm{qt}$ & 5 & Same as Maneb 75 DF & Same as Maneb 75 DF \\
\hline $\begin{array}{l}\text { Maneb 80WP } \\
\text { (Maneb) }\end{array}$ & M3 & $2 \mathrm{lb}$ & $16 \mathrm{lb}$ & 5 & Same as Maneb 75 DF & Same as Maneb 75 DF \\
\hline $\begin{array}{l}\text { Penncozeb 80WP, } \\
\text { Manate 75DF, Manzate } \\
\text { Pro-Stick (Mancozeb) }\end{array}$ & M3 & $3 \mathrm{lb}$ & $24 \mathrm{lb}$ & 5 & Same as Maneb 75 DF & Same as Maneb 75 DF \\
\hline $\begin{array}{l}\text { Manzate FL } \\
\text { (Mancozeb) }\end{array}$ & M3 & $2.4 \mathrm{qt}$ & $19.2 \mathrm{qt}$ & 5 & Same as Maneb 75 DF & Same as Maneb 75 DF \\
\hline $\begin{array}{l}\text { Manzate 75DF, } \\
\text { Penncozeb 75DF } \\
\text { (Mancozeb) }\end{array}$ & M3 & $3 \mathrm{lb}$ & $25.6 \mathrm{lb}$ & 5 & Same as Maneb 75DF & Same as Maneb 75DF \\
\hline $\begin{array}{l}\text { Dithane-DF Rainshield, } \\
\text { (Mancozeb) }\end{array}$ & , M3 & $3 \mathrm{lb}$ & $25.6 \mathrm{lb}$ & 5 & $\begin{array}{l}\text { Alternaria leaf spot } \\
\text { Anthracnose } \\
\text { Downy mildew } \\
\text { Gummy stem blight }\end{array}$ & Same as Maneb 75DF \\
\hline $\begin{array}{l}\text { Dithane M45 } \\
\text { (Mancozeb) }\end{array}$ & M3 & $3 \mathrm{lb}$ & $24 \mathrm{lb}$ & 5 & $\begin{array}{l}\text { Same as Dithane-DF } \\
\text { Rainshield }\end{array}$ & Same as Maneb 75DF \\
\hline $\begin{array}{l}\text { Dithane F45 Rainshield, } \\
\text { (Mancozeb) }\end{array}$ & d, $\quad$ M3 & $2.4 \mathrm{qt}$ & $19.2 \mathrm{qt}$ & 5 & $\begin{array}{l}\text { Same as Dithane-DF } \\
\text { Rainshield }\end{array}$ & Same as Maneb 75DF \\
\hline JMS Stylet Oil & & $3 \mathrm{qt}$ & & $4 \mathrm{hr}$ & $\begin{array}{l}\text { Aphid-transmitted } \\
\text { viruses, powdery mil- } \\
\text { dew }\end{array}$ & $\begin{array}{l}\text { See label for specific appl. Tech. } \\
\text { (e.g. use of } 400 \mathrm{psi})\end{array}$ \\
\hline $\begin{array}{l}\text { Nova 40W } \\
\text { (Myclobutanil) }\end{array}$ & 3 & $50 \mathrm{z}$ & $1.5 \mathrm{lb}$ & 0 & Powdery mildew & $\begin{array}{l}\text { Note that a } 30 \text { day plant back } \\
\text { restriction exists. }\end{array}$ \\
\hline $\begin{array}{l}\text { Pristine 38WG } \\
\text { (Boscalid; } \\
\text { Pyraclostrobin) }\end{array}$ & $7 \& 11$ & $18.5 \mathrm{oz}$ & $74 \mathrm{oz}$ & 0 & Same as Amsitar & $\begin{array}{l}\text { Limit is } 4 \text { appl./crop \& alternate } \\
\text { chemistry }\end{array}$ \\
\hline $\begin{array}{l}\text { Procure 50WS and } \\
480 S C \\
\text { (Triflumizole) }\end{array}$ & 3 & $80 z$ & $40 \mathrm{oz}$ & 0 & Powdery Mildew & \\
\hline $\begin{array}{l}\text { Ranman } \\
\text { (Cyazofamid) }\end{array}$ & 21 & $2.75 \mathrm{fl} \mathrm{oz}$ & $16.5 \mathrm{fl} \mathrm{oz}$ & 0 & $\begin{array}{l}\text { Downy Mildew } \\
\text { Phytophthora blight }\end{array}$ & $\begin{array}{l}\text { Limit is } 6 \text { appl./crop. } \\
\text { Follow resistance management } \\
\text { guidelines on label. }\end{array}$ \\
\hline $\begin{array}{l}\text { Reason 500SC } \\
\text { (Fenamidone) }\end{array}$ & 11 & $5.5 \mathrm{fl} \mathrm{oz}$ & $220 z$ & 14 & $\begin{array}{l}\text { Downy Mildew } \\
\text { Alternaria leaf spot }\end{array}$ & $\begin{array}{l}\text { Limit is } 4 \text { appl./crop \& alternate } \\
\text { chemistry }\end{array}$ \\
\hline $\begin{array}{l}\text { Previcur Flex } \\
\text { (Promocarb hydrochlo- } \\
\text { ride) }\end{array}$ & U & $1.2 \mathrm{pt}$ & $6 \mathrm{pt}$ & 2 & $\begin{array}{l}\text { Downy Mildew } \\
\text { Pythium }\end{array}$ & $\begin{array}{l}\text { Use a tank mix partner. See label } \\
\text { for directions using a contact fun- } \\
\text { gicide and Pythium suppression }\end{array}$ \\
\hline
\end{tabular}


Table 8. Contiinued.

\begin{tabular}{|c|c|c|c|c|c|c|}
\hline Chemical & $\begin{array}{l}\text { Fungicide } \\
\text { Group }\end{array}$ & $\frac{\text { Maximum R }}{\text { Application }}$ & $\frac{\text { late/Acre/ }}{\text { Crop }}$ & $\begin{array}{l}\text { Min. Days } \\
\text { to Harvest }\end{array}$ & Pertinent Diseases & Remarks \\
\hline $\begin{array}{l}\text { Ridomil Gold MZ } \\
\text { 68WP } \\
\text { (Mancozeb; } \\
\text { Mefenoxam) }\end{array}$ & M3 \& 4 & $2.5 \mathrm{lb}$ & $10 \mathrm{lb}$ & 5 & Downy mildew & Limit is 4 appl./crop \\
\hline $\begin{array}{l}\text { Ridomil Gold/Copper } \\
64.8 \mathrm{~W} \\
\text { (Copper hydroxide; } \\
\text { Mefenoxam) }\end{array}$ & M1 \& 4 & $2 \mathrm{lb}$ & $8 \mathrm{lb}$ & 5 & Downy mildew & Limit is 4 appl./crop \\
\hline $\begin{array}{l}\text { Ridomil Gold Bravo } \\
76.4 \mathrm{~W} \\
\text { (Mancozeb; } \\
\text { Mefenoxam) }\end{array}$ & M3 \& 4 & $3 \mathrm{lb}$ & $12 \mathrm{lb}$ & 7 & $\begin{array}{l}\text { Downy mildew } \\
\text { Certain leaf spots } \\
\text { Gummy stem blight }\end{array}$ & Limit is 4 appl./crop \\
\hline $\begin{array}{l}\text { Ridomil Gold 4EC } \\
\text { (Mefenoxam) }\end{array}$ & 4 & $2 \mathrm{pt} /$ treated $\mathrm{A}$ & & & Pythium seedling blight & $\begin{array}{l}\text { Apply at seeding in a } 7-12 \text { " band } \\
\text { on soil over seed furrow. }\end{array}$ \\
\hline $\begin{array}{l}\text { Ultra Flourish } \\
\text { (Mefenoxam) }\end{array}$ & 4 & $4 \mathrm{pt} /$ treated $\mathrm{A}$ & & & Same Ridomil Gold 4EC & Same Ridomil Gold 4EC \\
\hline $\begin{array}{l}\text { Serenade ASO } \\
\text { (Bacillus subtilis strain } \\
\text { QST 713) }\end{array}$ & & $6 \mathrm{lb}$ & & 0 & $\begin{array}{l}\text { Powdery mildew, } \\
\text { Gummy Stem blight, } \\
\text { Downy mildew }\end{array}$ & $\begin{array}{l}\text { Do not use product alone. Apply } \\
\text { with registered fungicide. }\end{array}$ \\
\hline $\begin{array}{l}\text { Serenade Max } \\
\text { (Bacillus subtilis strain } \\
\text { QST 713) }\end{array}$ & & $3 \mathrm{lb}$ & & 0 & $\begin{array}{l}\text { Powdery mildew, } \\
\text { Gummy Stem blight, } \\
\text { Downy mildew }\end{array}$ & $\begin{array}{l}\text { Do not use product alone. Apply } \\
\text { with registered fungicide. }\end{array}$ \\
\hline $\begin{array}{l}\text { Sonata } \\
\text { (Bacillus pumilus strain } \\
\text { QST 2808) }\end{array}$ & & $4 \mathrm{lb}$ & & 0 & $\begin{array}{l}\text { Powdery mildew, } \\
\text { Downy mildew }\end{array}$ & $\begin{array}{l}\text { Do not use product alone. Apply } \\
\text { with registered fungicide }\end{array}$ \\
\hline Sulfur ${ }^{2}$ & M2 & & & & Powdery mildew & $\begin{array}{l}\text { See label. Do not use in warm } \\
\text { weather }\end{array}$ \\
\hline $\begin{array}{l}\text { Tanos 50DF } \\
\text { (Cymoxanil; } \\
\text { Famoxadone) }\end{array}$ & $27 \& 11$ & $180 z$ & & 3 & $\begin{array}{l}\text { Downy mildew } \\
\text { Anthracnose }\end{array}$ & $\begin{array}{l}\text { Limit is } 4 \text { appl./crop. Must } \\
\text { tankmix with a contact fungicide. } \\
\text { Limit is } 72 \text { oz/A maximum per } \\
\text { year. }\end{array}$ \\
\hline $\begin{array}{l}\text { Thiophanate methyl } \\
\text { 85WDG } \\
\text { (Thiophanate-methyl) }\end{array}$ & 1 & $0.4 \mathrm{lb}$ & $2.5 \mathrm{lb}$ & 1 & $\begin{array}{l}\text { Anthracnose, Powdery } \\
\text { Mildew, Gummy stem } \\
\text { blight }\end{array}$ & $\begin{array}{l}\text { Follow resistance management } \\
\text { guidelines on label }\end{array}$ \\
\hline $\begin{array}{l}\text { Topsin 4.5FL } \\
\text { (Thiophanate-methyl) }\end{array}$ & 1 & $10 \mathrm{oz}$ & $60 \mathrm{oz}$ & 1 & $\begin{array}{l}\text { Anthracnose, Powdery } \\
\text { Mildew, Gummy stem } \\
\text { blight }\end{array}$ & $\begin{array}{l}\text { Follow resistance management } \\
\text { guidelines on label }\end{array}$ \\
\hline $\begin{array}{l}\text { Topsin M70WP } \\
\text { (Thiophanate-methyl) }\end{array}$ & 1 & $0.5 \mathrm{lb}$. & $3 \mathrm{lb}$ & 1 & $\begin{array}{l}\text { Certain leaf spots, } \\
\text { Powdery mildew, } \\
\text { Gummy stem blight } 4\end{array}$ & Same as Topsin 4.5 FL \\
\hline $\begin{array}{l}\text { Topsin M WSB } \\
\text { (Thiophanate-methyl) }\end{array}$ & 1 & $0.5 \mathrm{lb}$ & $3 \mathrm{lb}$ & 1 & $\begin{array}{l}\text { Same as Topsin M } \\
\text { 70WP }\end{array}$ & Same as Topsin 4.5 FL \\
\hline $\begin{array}{l}\text { Various copper formu- } \\
\text { lations }^{3}\end{array}$ & & & & & $\begin{array}{l}\text { Bacterial diseases (See } \\
\text { individual label) }\end{array}$ & See label \\
\hline \multicolumn{7}{|c|}{$\begin{array}{l}{ }^{1} \text { Sphaerotheca only } \\
2 \text { Kumulus DF, Micro Sulf, Micronized Gold, Microthiol Disperss, Sulfur 90W, Thiolux Jet, Wettable Sulfur } \\
{ }^{3} \text { Badge SC, Basic Copper 53, Champ DP Dry Prill, Champ Formula 2 FL, Champion WP, COC DF, COC WP, Copper-Count-N, Cuprofix } \\
\text { Disperss, Cuprofix MZ Disperss, Kocide 101, Kocide 2000, Kocide 4.5 LF, Kocide DF, Nordox, Nordox } 75 \text { WG, Nu-Cop 3L, Nu-Cop } 50 \\
\text { WP, Nu-Cop } 50 \text { DF, Stretch, Tenn-Cop 5E }\end{array}$} \\
\hline
\end{tabular}


Table 9. Disease management for pumpkin.

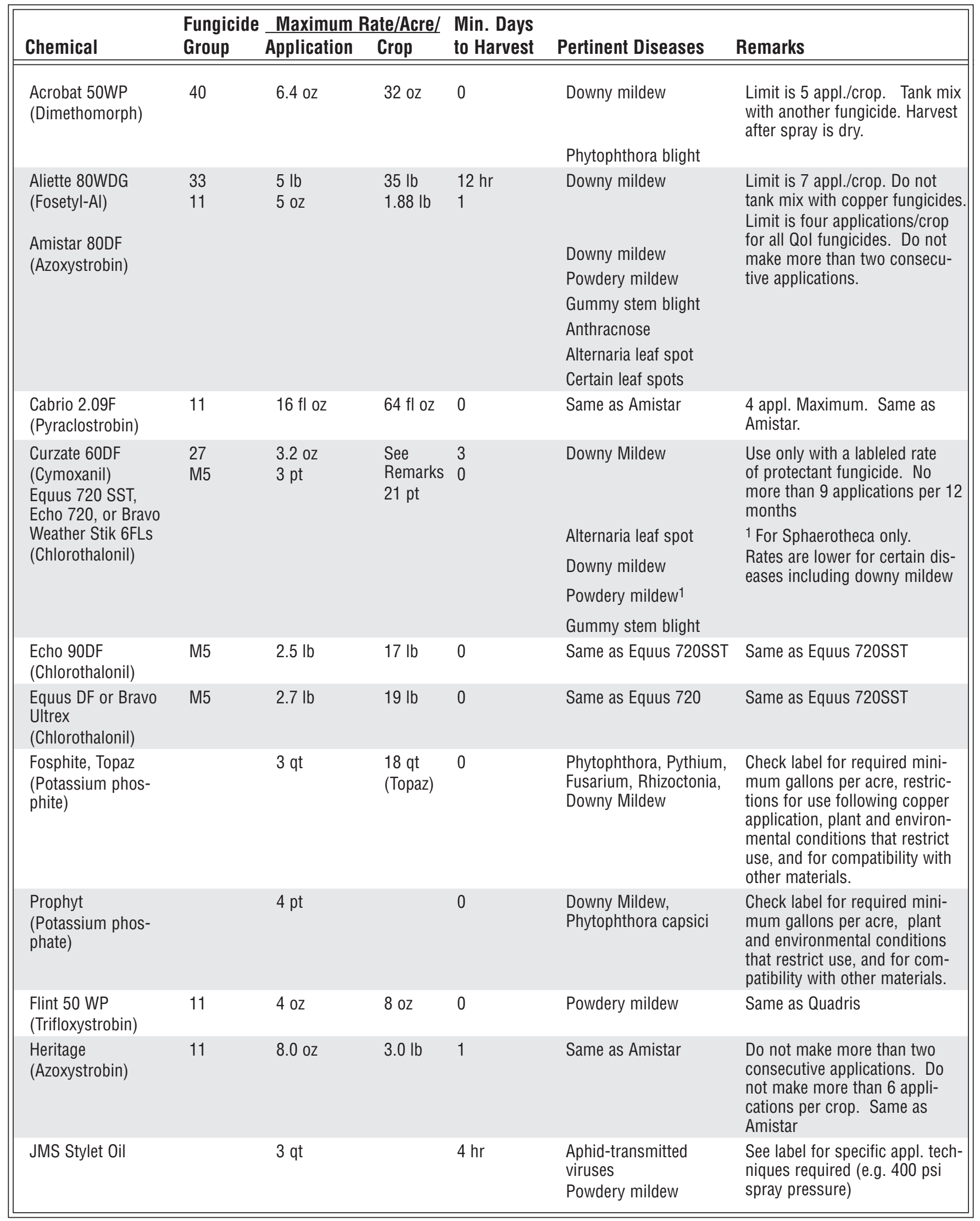


Table 9. Continued.

\begin{tabular}{|c|c|c|c|c|c|c|}
\hline Chemical & $\begin{array}{l}\text { Fungicide } \\
\text { Group }\end{array}$ & $\frac{\text { Maximum Ra }}{\text { Application }}$ & $\frac{\text { ate/Acre/ }}{\text { Crop }}$ & $\begin{array}{l}\text { Min. Days } \\
\text { to Harvest }\end{array}$ & Pertinent Diseases & Remarks \\
\hline $\begin{array}{l}\text { Maneb 80WP } \\
\text { (Maneb) }\end{array}$ & M3 & $2 \mathrm{lb}$ & $16 \mathrm{lb}$ & 5 & Downy mildew & \\
\hline $\begin{array}{l}\text { Manex } \\
\text { (Maneb) }\end{array}$ & M3 & $1.6 \mathrm{qt}$ & $12.8 \mathrm{qt}$ & 5 & Downy mildew & \\
\hline $\begin{array}{l}\text { Maneb 75DF } \\
\text { (Maneb) } \\
\text { Nova 40W } \\
\text { (Myclobutanil) }\end{array}$ & $\begin{array}{l}\mathrm{M} 3 \\
3\end{array}$ & $\begin{array}{l}2 \mathrm{lb} \\
5 \mathrm{oz}\end{array}$ & $\begin{array}{l}17.1 \mathrm{lb} \\
1.5 \mathrm{lb}\end{array}$ & $\begin{array}{l}5 \\
0\end{array}$ & $\begin{array}{l}\text { Downy mildew } \\
\text { Powdery mildew }\end{array}$ & $\begin{array}{l}\text { Note that a } 30 \text { day plant back } \\
\text { restriction exists. }\end{array}$ \\
\hline $\begin{array}{l}\text { Pristine } \\
\text { Boscalid; } \\
\text { Pyraclostrobin) }\end{array}$ & $7 \& 11$ & $18.5 \mathrm{oz}$ & $74 \mathrm{oz}$ & 0 & $\begin{array}{l}\text { Downy Mildew, } \\
\text { Alternaria, Gummy stem } \\
\text { blight, Powdery Mildew }\end{array}$ & $\begin{array}{l}\text { Limit is four applications/crop } \\
\text { for all Qol fungicides. Do not } \\
\text { make more than two consecu- } \\
\text { tive applications. }\end{array}$ \\
\hline $\begin{array}{l}\text { Procure 50WS and } \\
480 S C \\
\text { (Triflumizole) }\end{array}$ & 3 & $80 z$ & $40 \mathrm{oz}$ & 0 & Powdery Mildew & \\
\hline $\begin{array}{l}\text { Quadris } 2.08 \mathrm{FL} \\
\text { (Azoxystrobin) }\end{array}$ & 11 & $15.4 \mathrm{fl} \mathrm{oz}$ & $2.88 \mathrm{qt}$ & 1 & Same as Equus $720 \mathrm{SST}$ & $\begin{array}{l}\text { Limit is four applications/crop } \\
\text { for all Qol fungicides. Do not } \\
\text { make more than two consecu- } \\
\text { tive applications. }\end{array}$ \\
\hline $\begin{array}{l}\text { Ranman } \\
\text { (Cyazofamid) }\end{array}$ & 21 & $2.75 \mathrm{fl} \mathrm{oz}$ & $\begin{array}{l}16.5 \mathrm{fl} \\
0 \mathrm{z}\end{array}$ & 0 & $\begin{array}{l}\text { Downy Mildew } \\
\text { Phytophthora blight }\end{array}$ & $\begin{array}{l}\text { Limit is } 6 \text { appl./crop. } \\
\text { Follow resistance management } \\
\text { guidelines on label. }\end{array}$ \\
\hline $\begin{array}{l}\text { Reason 500SC } \\
\text { (Fenamidone) }\end{array}$ & 11 & $5.5 \mathrm{fl} \mathrm{oz}$ & $22 \mathrm{oz}$ & 14 & $\begin{array}{l}\text { Downy Mildew } \\
\text { Alternaria leaf spot }\end{array}$ & $\begin{array}{l}\text { Limit is } 4 \text { appl./crop \& alternate } \\
\text { chemistry }\end{array}$ \\
\hline $\begin{array}{l}\text { Previcur Flex } \\
\text { (Promocarb hydro- } \\
\text { chloride) }\end{array}$ & $U$ & $1.2 \mathrm{pt}$ & $6 \mathrm{pt}$ & 2 & $\begin{array}{l}\text { Downy Mildew } \\
\text { Pythium }\end{array}$ & $\begin{array}{l}\text { Use a tank mix partner. See } \\
\text { label for directions using a } \\
\text { contact fungicide and Pythium } \\
\text { suppression }\end{array}$ \\
\hline $\begin{array}{l}\text { Ridomil Gold Copper } \\
64.8 \text { W } \\
\text { (Copper hydroxide; } \\
\text { Mefenoxam) } \\
\text { Ridomil Gold 4EC } \\
\text { (Mefenoxam) }\end{array}$ & $\begin{array}{l}\text { M1 \& } 4 \\
4\end{array}$ & $\begin{array}{l}2 \mathrm{lb} \\
2 \mathrm{pt} / \text { treated A }\end{array}$ & $8 \mathrm{lb}$ & 5 & $\begin{array}{l}\text { Downy mildew } \\
\text { Pythium seedling blight }\end{array}$ & $\begin{array}{l}\text { Limit is } 4 \text { appl./crop } \\
\text { Apply at seeding in a } 7-12 \text { " band } \\
\text { on soil over seed furrow. }\end{array}$ \\
\hline $\begin{array}{l}\text { Ultra Flourish } \\
\text { (Mefenoxam) } \\
\text { Ridomil Gold Bravo } \\
76.4 \mathrm{~W} \\
\text { (Chlorothalonil } \\
\text { Mefenoxam) }\end{array}$ & $\begin{array}{l}4 \\
\text { M5 \& } 4\end{array}$ & $\begin{array}{l}4 \mathrm{pt} / \text { treated } \mathrm{A} \\
3 \mathrm{lb}\end{array}$ & $12 \mathrm{lb}$ & 7 & $\begin{array}{l}\text { Downy mildew } \\
\text { Gummy stem blight }\end{array}$ & $\begin{array}{l}\text { Same Ridomil Gold } 4 \mathrm{EC} \\
\text { Limit is } 4 \text { appl./crop }\end{array}$ \\
\hline $\begin{array}{l}\text { Sulfur } \\
\text { (numerous brands) }{ }^{1}\end{array}$ & M2 & & & 1 & Powdery mildew & \\
\hline $\begin{array}{l}\text { Serenade ASO } \\
\text { (Bacillus subtilis } \\
\text { stain QST 713) }\end{array}$ & & $6 \mathrm{lb}$ & & 0 & $\begin{array}{l}\text { Powdery mildew, } \\
\text { Gummy Stem blight, } \\
\text { Downy mildew }\end{array}$ & $\begin{array}{l}\text { Do not use product alone. } \\
\text { Apply with registered fungicide. }\end{array}$ \\
\hline $\begin{array}{l}\text { Serenade Max } \\
\text { (Bacillus sutilis } \\
\text { strain QST 713) }\end{array}$ & & $3 \mathrm{lb}$ & & 0 & $\begin{array}{l}\text { Powdery mildew, } \\
\text { Gummy Stem blight, } \\
\text { Downy mildew }\end{array}$ & $\begin{array}{l}\text { Do not use product alone. } \\
\text { Apply with registered fungicide. }\end{array}$ \\
\hline
\end{tabular}


Table 9. Continued.

\begin{tabular}{|c|c|c|c|c|c|c|}
\hline \multirow[b]{2}{*}{ Chemical } & \multicolumn{3}{|c|}{ Fungicide Maximum Rate/Acre/ } & \multirow{2}{*}{$\begin{array}{l}\text { Min. Days } \\
\text { to Harvest }\end{array}$} & \multirow[b]{2}{*}{ Pertinent Diseases } & \multirow[b]{2}{*}{ Remarks } \\
\hline & Group & Application & Crop & & & \\
\hline \multirow{4}{*}{$\begin{array}{l}\text { Sonata } \\
\text { (Bacillus pumilus } \\
\text { strain QST 2808) } \\
\text { Tanos 50DF } \\
\text { (Cymoxanil; } \\
\text { Famoxadone) }\end{array}$} & \multirow{4}{*}{$27 \& 11$} & \multirow{4}{*}{$\begin{array}{l}4 \mathrm{lb} \\
8 \mathrm{oz}\end{array}$} & & \multirow{4}{*}{$\begin{array}{l}0 \\
3\end{array}$} & \multirow{2}{*}{$\begin{array}{l}\text { Powdery mildew, Downy } \\
\text { mildew }\end{array}$} & \multirow{4}{*}{$\begin{array}{l}\text { Do not use product alone. } \\
\text { Apply with registered fungicide } \\
\text { Limit is } 4 \text { appl./crop. Must } \\
\text { tankmix with a contact fungi- } \\
\text { cide. Limit is } 72 \text { oz/A maximum } \\
\text { per year. }\end{array}$} \\
\hline & & & & & & \\
\hline & & & & & \multirow{2}{*}{$\begin{array}{l}\text { Downy mildew } \\
\text { Anthracnose }\end{array}$} & \\
\hline & & & & & & \\
\hline $\begin{array}{l}\text { Topsin 4.5FL } \\
\text { (Thiophanate- } \\
\text { methyl) }\end{array}$ & 1 & $10 \mathrm{oz}$ & $60 \mathrm{oz}$ & 1 & $\begin{array}{l}\text { Anthracnose, Gummy } \\
\text { Stem , Powdery Mildew }\end{array}$ & $\begin{array}{l}\text { Follow resistance management } \\
\text { guidelines on label }\end{array}$ \\
\hline $\begin{array}{l}\text { Topsin M 70W, } \\
\text { Topsin M WSB } \\
\text { (Thiophanate- } \\
\text { methyl) }\end{array}$ & 1 & $0.5 \mathrm{lb}$ & $3 \mathrm{lb}$ & 1 & Same as Topsin 4.5 FL & Same as Topsin 4.5 FL \\
\hline $\begin{array}{l}\text { Thiophanate methyl } \\
\text { 85WDG } \\
\text { (Thiophanate- } \\
\text { methyl) }\end{array}$ & 1 & 0.4 & 2.5 & 1 & $\begin{array}{l}\text { Anthracnose, Powdery } \\
\text { Mildew, Gummy stem } \\
\text { blight }\end{array}$ & $\begin{array}{l}\text { Follow resistance management } \\
\text { guidelines on label }\end{array}$ \\
\hline $\begin{array}{l}\text { Various copper for- } \\
\text { mulations }^{2}\end{array}$ & M1 & & & & $\begin{array}{l}\text { Bacterial diseases (See } \\
\text { individual label) }\end{array}$ & See label \\
\hline $\begin{array}{l}1 \text { Dusting Sulfur, Mic } \\
2 \text { Badge, Basic Coppe } \\
\text { Disperss, Kocide } 10 \\
\text { Stretch, Tenn-Cop }\end{array}$ & $\begin{array}{l}\text { ronized Go } \\
\text { r 53, Chan } \\
1 \text { 1, Kocide } \\
\text { E }\end{array}$ & $\begin{array}{l}\text { 1, Microthiol D } \\
\text { o DP Dry Prill, } \\
\text { 000, Kocide } 4\end{array}$ & $\begin{array}{l}\text { rss, Sulfur } \\
\text { mp Formu } \\
\text { Kocide D }\end{array}$ & $\begin{array}{l}\text { 90W, Thiolux } \\
\text { ula } 2 \text { FL, Cham } \\
\text { F, Nordox, No }\end{array}$ & $\begin{array}{l}\text { et. } \\
\text { on WP, COC DF, COC WP, c } \\
\text { ox } 75 \text { WG, Nu-Cop 3L, Nu- }\end{array}$ & $\begin{array}{l}\text { Copper-Count-N, Cuprofix } \\
\text {-Cop 50DF, Nu-Cop 50WP, }\end{array}$ \\
\hline
\end{tabular}


Table 10. Disease management for squash.

\begin{tabular}{|c|c|c|c|c|c|c|}
\hline Chemical & $\begin{array}{l}\text { Fungicide } \\
\text { Group }\end{array}$ & $\frac{\text { Maximum R }}{\text { Application }}$ & $\begin{array}{l}\text { ate/Acre/ } \\
\text { Crop }\end{array}$ & $\begin{array}{l}\text { Min. Days } \\
\text { to Harvest }\end{array}$ & Pertinent Diseases & Remarks \\
\hline \multirow[t]{2}{*}{$\begin{array}{l}\text { Acrobat } 50 \text { WP } \\
\text { (Dimethomorph) }\end{array}$} & 40 & $\begin{array}{l}\text { Application } \\
\quad 6.4 \mathrm{oz}\end{array}$ & $\begin{array}{l}\text { Season } \\
32 \mathrm{oz}\end{array}$ & 0 & Downy mildew & $\begin{array}{l}\text { Limit is } 5 \text { appl./crop. Tank mix } \\
\text { with another fungicide. Harvest } \\
\text { after spray is dry. }\end{array}$ \\
\hline & & & & & Phytophthora blight & \\
\hline \multirow[t]{7}{*}{$\begin{array}{l}\text { Aliette 80WDG } \\
\text { (Fosetyl-AI) } \\
\text { Amistar 80DF } \\
\text { (Azoxystrobin) }\end{array}$} & $\begin{array}{l}33 \\
11\end{array}$ & $\begin{array}{l}5 \mathrm{lb} \\
5 \mathrm{oz}\end{array}$ & $\begin{array}{l}35 \mathrm{lb} \\
1.88 \mathrm{lb}\end{array}$ & $\begin{array}{c}12 \mathrm{hr} \\
1\end{array}$ & Downy mildew & $\begin{array}{l}\text { Limit is } 7 \text { appl./crop. Do not tank } \\
\text { mix with copper fungicides. } \\
\text { Limit is four applications/crop } \\
\text { for all Qol fungicides. Do not } \\
\text { make more than two consecutive } \\
\text { applications. }\end{array}$ \\
\hline & & & & & Downy mildew & \\
\hline & & & & & Powdery mildew & \\
\hline & & & & & Gummy stem blight & \\
\hline & & & & & Anthracnose & \\
\hline & & & & & Alternaria leaf spot & \\
\hline & & & & & Certain leaf spots & \\
\hline $\begin{array}{l}\text { Cabrio 2.09F } \\
\text { (Pyraclostrobin) }\end{array}$ & 11 & $16 \mathrm{fl} \mathrm{oz}$ & $64 \mathrm{fl} \mathrm{oz}$ & 0 & Same as Amistar & $\begin{array}{l}4 \text { appl. Maximum. Same as } \\
\text { Amistar. }\end{array}$ \\
\hline $\begin{array}{l}\text { Curzate 60DF } \\
\text { (Cymoxanil) }\end{array}$ & 27 & $3.20 z$ & $\begin{array}{c}\text { See } \\
\text { Remarks }\end{array}$ & 3 & Downy Mildew & $\begin{array}{l}\text { Use only with a lableled rate } \\
\text { of protectant fungicide. No } \\
\text { more than } 9 \text { applications per } 12 \\
\text { months }\end{array}$ \\
\hline $\begin{array}{l}\text { Dithane F45 } \\
\text { Rainshield,Manzate } \\
\text { FL (Mancozeb) }\end{array}$ & M3 & $2.4 \mathrm{qt}$ & 19.2 qt & 5 & Downy mildew & Summer squash only \\
\hline $\begin{array}{l}\text { Dithane M45WP, } \\
\text { Manzate 75DF, } \\
\text { Manzate Pro-Stick, } \\
\text { Penncozeb 80WP } \\
\text { (Mancozeb) }\end{array}$ & M3 & $3 \mathrm{lb}$ & $24 \mathrm{lb}$ & 5 & Downy mildew & Summer squash only \\
\hline $\begin{array}{l}\text { Dithane DF Rainshield } \\
\text { Penncozeb 75DF } \\
\text { (Mancozeb) }\end{array}$ & M3 & $3 \mathrm{lb}$ & $25.6 \mathrm{lb}$ & 5 & Downy mildew & Summer squash only \\
\hline $\begin{array}{l}\text { Maneb 75DF } \\
\text { (Maneb) }\end{array}$ & M3 & $2 \mathrm{lb}$ & $17.1 \mathrm{lb}$ & 5 & Downy mildew & \\
\hline $\begin{array}{l}\text { Maneb 80WP } \\
\text { (Maneb) }\end{array}$ & M3 & $2 \mathrm{lb}$ & $16 \mathrm{lb}$ & 5 & Downy mildew & \\
\hline \multirow{5}{*}{$\begin{array}{l}\text { Manex } 4 \mathrm{~F} \\
\text { Echo } 720 \text { or Equus } \\
7206 \text { FLs, Bravo } \\
\text { Weather Stik } 6 \mathrm{~F} \\
\text { (Chlorothalonil) }\end{array}$} & $\begin{array}{l}\text { M3 } \\
\text { M5 }\end{array}$ & $\begin{array}{l}1.6 \mathrm{qt} \\
3 \mathrm{pt}\end{array}$ & $\begin{array}{l}12.8 \mathrm{qt} \\
21 \mathrm{pt}\end{array}$ & $\begin{array}{l}5 \\
0\end{array}$ & Downy mildew & $\begin{array}{l}\text { Recommended maximum rate is } \\
\text { lower for downy mildew }\end{array}$ \\
\hline & & & & & Alternaria leaf spot & \\
\hline & & & & & Downy mildew & \\
\hline & & & & & Gummy stem blight & \\
\hline & & & & & Powdery mildew ${ }^{1}$ & \\
\hline $\begin{array}{l}\text { Bravo Ultrex or } \\
\text { Equus DF } \\
\text { (Chlorothalonil) }\end{array}$ & M5 & $2.7 \mathrm{lb}$ & $19.0 \mathrm{lb}$ & 0 & Same as Echo 720 & Same as Echo 720 \\
\hline $\begin{array}{l}\text { Echo 90DF } \\
\text { (Chlorothalonil) }\end{array}$ & M5 & $2.5 \mathrm{lb}$ & $17 \mathrm{lb}$ & 0 & Same as Echo 720 & Same as Echo 720 \\
\hline
\end{tabular}


Table 10. Continued.

\begin{tabular}{|c|c|c|c|c|c|c|}
\hline Chemical & $\begin{array}{l}\text { Fungicide } \\
\text { Group }\end{array}$ & $\frac{\text { Maximum }}{\text { Application }}$ & $\begin{array}{l}\text { iate/Acre/ } \\
\text { Crop }\end{array}$ & $\begin{array}{l}\text { Min. Days } \\
\text { to Harvest }\end{array}$ & Pertinent Diseases & Remarks \\
\hline $\begin{array}{l}\text { Fosphite, Topaz } \\
\text { (Potassium phos- } \\
\text { phite) }\end{array}$ & & 3 qt & $\begin{array}{l}18 \mathrm{qt} \\
\text { (Topaz) }\end{array}$ & 0 & $\begin{array}{l}\text { Phytophthora, Pythium, } \\
\text { Fusarium, Rhizoctonia, } \\
\text { Downy Mildew }\end{array}$ & $\begin{array}{l}\text { Check label for required mini- } \\
\text { mum gallons per acre, restric- } \\
\text { tions for use following copper } \\
\text { application, plant and environ- } \\
\text { mental conditions that restrict } \\
\text { use, and for compatibility with } \\
\text { other materials. }\end{array}$ \\
\hline $\begin{array}{l}\text { Prophyt } \\
\text { (Potassium phos- } \\
\text { phate) } \\
\text { Flint 50WP } \\
\text { (Tfifloxystrobin) }\end{array}$ & 11 & $\begin{array}{l}4 \mathrm{pt} \\
2 \mathrm{oz}\end{array}$ & $80 z$ & $\begin{array}{l}0 \\
0\end{array}$ & $\begin{array}{l}\text { Downy Mildew, } \\
\text { Phytophthora capsici } \\
\text { Powdery mildew }\end{array}$ & $\begin{array}{l}\text { Check label for required mini- } \\
\text { mum gallons per acre, plant and } \\
\text { environmental conditions that } \\
\text { restrict use, and for compatibility } \\
\text { with other materials. } \\
\text { Limit is } 4 \text { appl./crop \& alternate } \\
\text { chemistry. Maximum rate is } \\
\text { higer for downy mildew suppres- } \\
\text { sion. Same as Amistar. }\end{array}$ \\
\hline & & & & & Downy Mildew & \\
\hline $\begin{array}{l}\text { Gavel 75DF } \\
\text { (Mancozeb; } \\
\text { Zoxamide) }\end{array}$ & M3 \& 22 & $2 \mathrm{lb}$ & $16 \mathrm{lb}$ & 5 & $\begin{array}{l}\text { Alternaria Leaf spot, } \\
\text { Downy Mildew }\end{array}$ & Limit is 8 applications per crop \\
\hline $\begin{array}{l}\text { Heritage } \\
\text { (Azoxystrobin) }\end{array}$ & 11 & $8.00 z$ & $3.0 \mathrm{lb}$ & 1 & Same as Amistar & $\begin{array}{l}\text { Do not make more than two } \\
\text { consecutive applications. Do not } \\
\text { make more than } 6 \text { applications } \\
\text { per crop. Same as Amistar }\end{array}$ \\
\hline $\begin{array}{l}\text { JMS Stylet Oil } \\
\text { ManKocide 61.1 DF } \\
\text { (Copper hydroxide; } \\
\text { Mancozeb) }\end{array}$ & M1 \&M3 & $\begin{array}{l}3 \mathrm{qt} \\
4 \mathrm{lb}\end{array}$ & $128 \mathrm{lb}$ & $\begin{array}{c}4 \mathrm{hr} \\
5\end{array}$ & $\begin{array}{l}\text { Aphid-transmitted } \\
\text { viruses } \\
\text { Powdery mildew } \\
\text { Downy mildew } \\
\text { Powdery mildew }\end{array}$ & $\begin{array}{l}\text { See label for specific appl. tech- } \\
\text { niques required (e.g. } 400 \text { psi } \\
\text { spray pressure) } \\
\text { Summer Squash only }\end{array}$ \\
\hline $\begin{array}{l}\text { Nova 40W } \\
\text { (Myclobutanil) }\end{array}$ & 3 & $50 z$ & $1.5 \mathrm{lb}$ & 0 & Powdery mildew & $\begin{array}{l}\text { Note that a } 30 \text { day plant back } \\
\text { restriction exists. }\end{array}$ \\
\hline $\begin{array}{l}\text { Pristine 38WG } \\
\text { (Boscalid; } \\
\text { Pyraclostrobin) }\end{array}$ & $7 \& 11$ & $18.5 \mathrm{oz}$ & $740 z$ & 0 & Same as Amistar & Same as Amistar \\
\hline $\begin{array}{l}\text { Quadris 2.08FL } \\
\text { (Azoxystrobin) }\end{array}$ & 11 & $15.4 \mathrm{fl} \mathrm{oz}$ & $2.88 \mathrm{qt}$ & 1 & Same as Amistar & $\begin{array}{l}\text { Limit is } 4 \text { appl./crop \& alternate } \\
\text { chemistry. Same as Amistar }\end{array}$ \\
\hline $\begin{array}{l}\text { Procure 50WS and } \\
480 S C \\
\text { (Triflumizole) }\end{array}$ & 3 & $80 z$ & $40 \mathrm{oz}$ & 0 & Powdery Mildew & \\
\hline $\begin{array}{l}\text { Ranman } \\
\text { (Cyazofamid) }\end{array}$ & 21 & $2.75 \mathrm{fl} \mathrm{oz}$ & $16.5 \mathrm{fl} \mathrm{oz}$ & 0 & $\begin{array}{l}\text { Downy Mildew } \\
\text { Phytophthora blight }\end{array}$ & $\begin{array}{l}\text { Limit is } 6 \text { appl./crop. } \\
\text { Follow resistance management } \\
\text { guidelines on label. }\end{array}$ \\
\hline $\begin{array}{l}\text { Reason 500SC } \\
\text { (Fenamidone) }\end{array}$ & 11 & $5.5 \mathrm{fl} \mathrm{oz}$ & $220 z$ & 14 & $\begin{array}{l}\text { Downy Mildew } \\
\text { Alternaria leaf spot }\end{array}$ & $\begin{array}{l}\text { Limit is } 4 \text { appl./crop \& alternate } \\
\text { chemistry }\end{array}$ \\
\hline $\begin{array}{l}\text { Previcur Flex } \\
\text { (Promocarb hydro- } \\
\text { chloride) } \\
\text { Ridomil Gold Bravo } \\
76.4 \mathrm{~W} \\
\text { (Chlorothalonil; } \\
\text { Mefenoxam) }\end{array}$ & U5 \& 4 & $1.2 \mathrm{pt}$ & $\begin{array}{l}6 \mathrm{pt} \\
12 \mathrm{lb}\end{array}$ & $\begin{array}{l}2 \\
7\end{array}$ & $\begin{array}{l}\text { Downy Mildew } \\
\text { Pythium } \\
\text { Downy mildew } \\
\text { Certain leaf spots } \\
\text { Gummy stem blight }\end{array}$ & $\begin{array}{l}\text { Use a tank mix partner. See label } \\
\text { for directions using a contact } \\
\text { fungicide and Pythium suppres- } \\
\text { sion } \\
\text { Limit is } 4 \text { appl./crop }\end{array}$ \\
\hline
\end{tabular}


Table 11. Disease management for watermelon.

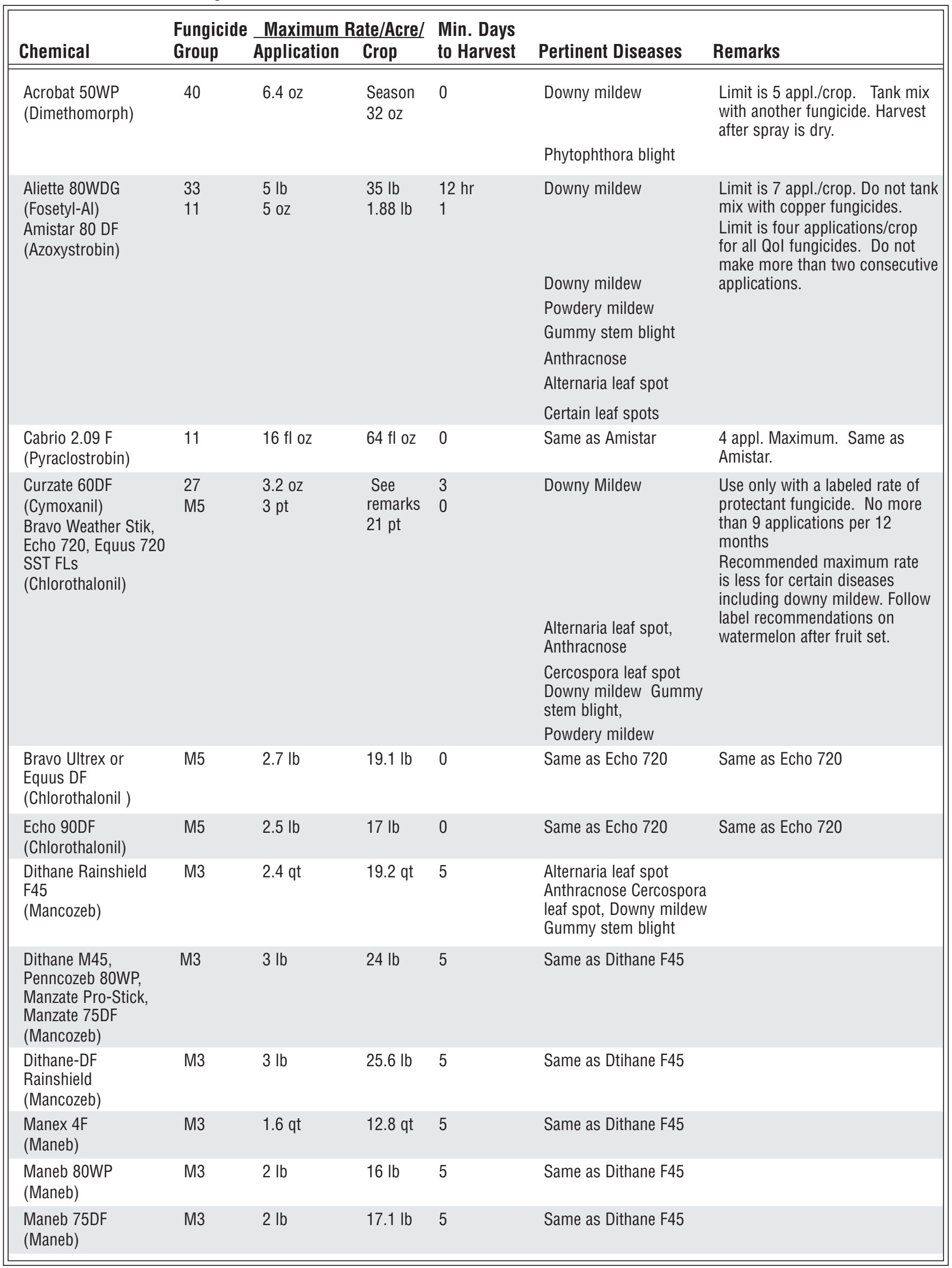


Table 11. Continued.

\begin{tabular}{|c|c|c|c|c|c|c|}
\hline Chemical & $\begin{array}{l}\text { Fungicide } \\
\text { Group }\end{array}$ & $\frac{\text { Maximum }}{\text { Application }}$ & $\frac{\text { ate/Acre/ }}{\text { Crop }}$ & $\begin{array}{l}\text { Min. Days } \\
\text { to Harvest }\end{array}$ & Pertinent Diseases & Remarks \\
\hline $\begin{array}{l}\text { Manzate Flowable 4F } \\
\text { (Mancozeb) }\end{array}$ & M3 & $2.4 \mathrm{qt}$ & $19.2 \mathrm{qt}$ & 5 & Same as Dithane F45 & \\
\hline \multirow{3}{*}{$\begin{array}{l}\text { Penncozeb 75DF } \\
\text { (Mancozeb) } \\
\text { Flint 50WP } \\
\text { (Trifloxystrobin) }\end{array}$} & M3 & $3 \mathrm{lb}$ & $24 \mathrm{lb}$ & 5 & Same as Dithane F45 & \\
\hline & 11 & $20 z$ & $80 z$ & 0 & Powdery mildew & $\begin{array}{l}\text { Limit is } 4 \text { appl./crop \& alternate } \\
\text { chemistry. Maximum rate } \\
\text { is higer for downy mildew } \\
\text { suppression. Same as Amistar. }\end{array}$ \\
\hline & & & & & Downy Mildew & \\
\hline $\begin{array}{l}\text { Gavel 75DF } \\
\text { (Mancozeb; } \\
\text { Zoxamide) }\end{array}$ & M3 \& 22 & $2 \mathrm{lb}$ & $16 \mathrm{lb}$ & 5 & $\begin{array}{l}\text { Alternaria Leaf spot, } \\
\text { Downy Mildew }\end{array}$ & Limit is 8 applications per crop \\
\hline $\begin{array}{l}\text { Heritage } \\
\text { (Azoxystrobin) }\end{array}$ & 11 & $8.0 \mathrm{oz}$ & $3.0 \mathrm{lb}$ & 1 & Same as Amistar & $\begin{array}{l}\text { Do not make more than two } \\
\text { consecutive applications. Do not } \\
\text { make more than } 6 \text { applications } \\
\text { per crop. Same as Amistar }\end{array}$ \\
\hline JMS Stylet Oil & & $3 \mathrm{qt}$ & & $4 \mathrm{hr}$ & $\begin{array}{l}\text { Aphid-transmitted } \\
\text { viruses, powdery } \\
\text { mildew }\end{array}$ & $\begin{array}{l}\text { See label for specific appl. } \\
\text { techniques required (e.g. use of } \\
400 \text { psi.) }\end{array}$ \\
\hline $\begin{array}{l}\text { Fosphite, Topaz } \\
\text { (Potassium phos- } \\
\text { phite) }\end{array}$ & & $3 \mathrm{qt}$ & $\begin{array}{l}18 \mathrm{qt} \\
\text { (Topaz) }\end{array}$ & 0 & $\begin{array}{l}\text { Phytophthora, Pythium, } \\
\text { Fusarium, Rhizoctonia, } \\
\text { Downy Mildew }\end{array}$ & $\begin{array}{l}\text { Check label for required } \\
\text { minimum gallons per acre, } \\
\text { restrictions for use following } \\
\text { copper application, plant and } \\
\text { environmental conditions that } \\
\text { restrict use, and for compatibility } \\
\text { with other materials. }\end{array}$ \\
\hline $\begin{array}{l}\text { Prophyt } \\
\text { (Potassium phos- } \\
\text { phate) } \\
\text { ManKocide 61DF } \\
\text { (Copper hydroxide ; } \\
\text { Mancozeb) }\end{array}$ & M1 \& M3 & $\begin{array}{l}4 \mathrm{pt} \\
2.66 \mathrm{Ib}\end{array}$ & $128 \mathrm{lb}$ & $\begin{array}{l}0 \\
5\end{array}$ & $\begin{array}{l}\text { Angular leaf spot } \\
\text { Downy mildew } \\
\text { Bacterial fruit blotch }\end{array}$ & $\begin{array}{l}\text { Check label for required } \\
\text { minimum gallons per acre, } \\
\text { plant and environmental } \\
\text { conditions that restrict use, } \\
\text { and for compatibility with other } \\
\text { materials. }\end{array}$ \\
\hline $\begin{array}{l}\text { Nova 40W } \\
\text { (Myclobutanil) }\end{array}$ & 3 & $50 z$ & $1.5 \mathrm{lb}$ & 0 & Powdery mildew & $\begin{array}{l}\text { Note that a } 30 \text { day plant back } \\
\text { restriction exists. }\end{array}$ \\
\hline $\begin{array}{l}\text { Procure 50WS and } \\
480 S C \\
\text { (Triflumizole) }\end{array}$ & 3 & $80 z$ & $40 \mathrm{oz}$ & 0 & Powdery Mildew & \\
\hline $\begin{array}{l}\text { Pristine 38WG } \\
\text { (Boscalid; } \\
\text { Pyraclostrobin) }\end{array}$ & $7 \& 11$ & $18.5 \mathrm{oz}$ & $74 \mathrm{oz}$ & 0 & Same as Amistar & $\begin{array}{l}\text { Limit is } 4 \text { appl./crop \& alternate } \\
\text { chemistry. Same as Amistar }\end{array}$ \\
\hline $\begin{array}{l}\text { Quadris 2.08FL } \\
\text { (Azoxystrobin) }\end{array}$ & 11 & $15.4 \mathrm{fl} \mathrm{oz}$ & $2.88 \mathrm{qt}$ & 1 & Same as Amistar & $\begin{array}{l}\text { Limit is } 4 \text { appl./crop \& alternate } \\
\text { chemistry. Same as Amistar }\end{array}$ \\
\hline $\begin{array}{l}\text { Ranman } \\
\text { (Cyazofamid) }\end{array}$ & 21 & $2.75 \mathrm{fl} \mathrm{oz}$ & $\begin{array}{l}16.5 \mathrm{fl} \\
0 \mathrm{z}\end{array}$ & 0 & $\begin{array}{l}\text { Downy Mildew } \\
\text { Phytophthora blight }\end{array}$ & $\begin{array}{l}\text { Limit is } 6 \text { appl./crop. } \\
\text { Follow resistance management } \\
\text { guidelines on label. }\end{array}$ \\
\hline $\begin{array}{l}\text { Reason 500SC } \\
\text { (Fenamidone) }\end{array}$ & 11 & $5.5 \mathrm{fl} \mathrm{oz}$ & $22 \mathrm{oz}$ & 14 & $\begin{array}{l}\text { Downy Mildew } \\
\text { Alternaria leaf spot }\end{array}$ & $\begin{array}{l}\text { Limit is } 4 \text { appl./crop \& alternate } \\
\text { chemistry }\end{array}$ \\
\hline
\end{tabular}


Table 11. Continued.

\begin{tabular}{|c|c|c|c|c|c|c|}
\hline \multirow[b]{2}{*}{ Chemical } & \multirow{2}{*}{$\begin{array}{l}\text { Fungicide } \\
\text { Group }\end{array}$} & \multicolumn{2}{|c|}{ Maximum Rate/Acre/ } & \multirow{2}{*}{$\begin{array}{l}\text { Min. Days } \\
\text { to Harvest }\end{array}$} & \multirow[b]{2}{*}{ Pertinent Diseases } & \multirow[b]{2}{*}{ Remarks } \\
\hline & & Application & Crop & & & \\
\hline $\begin{array}{l}\text { Previcur Flex } \\
\text { (Promocarb hydro- } \\
\text { chloride) } \\
\text { Ridomil Gold Bravo } \\
76.4 \mathrm{~W} \\
\text { (Chlorothalonil; } \\
\text { Mefenoxam) }\end{array}$ & $\begin{array}{l}\text { U } \\
\text { M5 \& } 4\end{array}$ & $\begin{array}{l}1.2 \mathrm{pt} \\
3 \mathrm{lb}\end{array}$ & $\begin{array}{l}6 \mathrm{pt} \\
12 \mathrm{lb}\end{array}$ & $\begin{array}{l}2 \\
7\end{array}$ & $\begin{array}{l}\text { Downy Mildew } \\
\text { Pythium } \\
\text { Downy mildew } \\
\text { Certain leaf spots } \\
\text { Gummy stem blight }\end{array}$ & $\begin{array}{l}\text { Use a tank mix partner. See } \\
\text { label for directions using a } \\
\text { contact fungicide and Pythium } \\
\text { suppression } \\
\text { Limit is } 4 \text { appl./crop }\end{array}$ \\
\hline $\begin{array}{l}\text { Ridomil MZ 68WP } \\
\text { (Mancozeb; } \\
\text { Mefenoxam) }\end{array}$ & M3 \& 4 & $2.5 \mathrm{lb}$ & $10 \mathrm{lb}$ & 5 & Downy mildew & Limit is 4 appl./crop \\
\hline $\begin{array}{l}\text { Ridomil/Copper 70W } \\
\text { (Copper hydroxide; } \\
\text { Mefenoxam) } \\
\text { Ridomil Gold 4EC } \\
\text { (Mefenoxam) }\end{array}$ & $\begin{array}{l}\text { M1 \& } 4 \\
4\end{array}$ & $\begin{array}{l}2 \mathrm{lb} \\
2 \mathrm{pt} / \text { treated } \mathrm{A}\end{array}$ & $8 \mathrm{lb}$ & 5 & $\begin{array}{l}\text { Downy mildew } \\
\text { Pythium Seedling blight }\end{array}$ & $\begin{array}{l}\text { Limit is } 4 \text { appl./crop } \\
\text { Apply at seeding in a } 7-12 \text { " band } \\
\text { on soil over seed furrow }\end{array}$ \\
\hline $\begin{array}{l}\text { Ultra Flourish } \\
\text { (Menfenoxam) }\end{array}$ & 4 & $4 \mathrm{pt} /$ treated $\mathrm{A}$ & & & Same Ridomil Gold 4EC & Same Ridomil Gold 4EC \\
\hline $\begin{array}{l}\text { Serenade ASO } \\
\text { (Bacillus subtilis } \\
\text { strain QST 713) }\end{array}$ & & $6 \mathrm{qt}$ & & 0 & $\begin{array}{l}\text { Downy mildew, Gummy } \\
\text { Stem }\end{array}$ & $\begin{array}{l}\text { Do not use product alone. Mix } \\
\text { with a registered fungicide }\end{array}$ \\
\hline $\begin{array}{l}\text { Serenade Max } \\
\text { (Bacillus subtilis } \\
\text { strain QST 713) }\end{array}$ & & $3 \mathrm{lb}$ & & 0 & $\begin{array}{l}\text { Downy mildew, Gummy } \\
\text { Stem }\end{array}$ & $\begin{array}{l}\text { Do not use product alone. Mix } \\
\text { with a registered fungicide }\end{array}$ \\
\hline $\begin{array}{l}\text { Sonata } \\
\text { (Bacillus pumilus } \\
\text { strain QST 2808) } \\
\text { Tanos 50DF } \\
\text { (Cymoxanil; } \\
\text { Famoxadone) }\end{array}$ & $27 \& 11$ & $\begin{array}{l}4 \mathrm{qt} \\
8 \mathrm{oz}\end{array}$ & & $\begin{array}{l}0 \\
3\end{array}$ & $\begin{array}{l}\text { Downy mildew, Gummy } \\
\text { Stem } \\
\text { Downy mildew } \\
\text { Anthracnose }\end{array}$ & $\begin{array}{l}\text { Do not use product alone. Mix } \\
\text { with a registered fungicide } \\
\text { Limit is } 4 \text { appl./crop. Must } \\
\text { tankmix with a contact fungicide. } \\
\text { Limit is } 72 \text { oz/A maximum per } \\
\text { year. }\end{array}$ \\
\hline $\begin{array}{l}\text { Thiophanate methyl } \\
\text { 85WDG } \\
\text { (Thiophanate-methyl) }\end{array}$ & 1 & 0.4 & 2.5 & 1 & $\begin{array}{l}\text { Anthracnose, Powdery } \\
\text { Mildew, Gummy stem } \\
\text { blight }\end{array}$ & $\begin{array}{l}\text { Follow resistance management } \\
\text { guidelines on label }\end{array}$ \\
\hline $\begin{array}{l}\text { Topsin M WSB } \\
\text { (Thiophanate-methyl) }\end{array}$ & 1 & $0.5 \mathrm{lb}$ & $3 \mathrm{lb}$ & 1 & $\begin{array}{l}\text { Same as Topsin M } \\
\text { 70WP }\end{array}$ & Same as Topsin 4.5 FL \\
\hline $\begin{array}{l}\text { Topsin 4.5FL } \\
\text { (Thiophanate-methyl) }\end{array}$ & 1 & $10 \mathrm{oz}$ & $600 z$ & 1 & $\begin{array}{l}\text { Anthracnose, Powdery } \\
\text { Mildew, Gummy stem } \\
\text { blight }\end{array}$ & $\begin{array}{l}\text { Follow resistance management } \\
\text { guidelines on label }\end{array}$ \\
\hline $\begin{array}{l}\text { Topsin M70WP } \\
\text { (Thiophanate-methyl) }\end{array}$ & 1 & $05 \mathrm{lb}$ & $3 \mathrm{lb}$ & 1 & $\begin{array}{l}\text { Certain leaf spots, } \\
\text { Powdery mildew, } \\
\text { Gummy stem blight }\end{array}$ & Same as Topsin 4.5 FL \\
\hline $\begin{array}{l}\text { Various copper for- } \\
\text { mulations }^{1}\end{array}$ & M1 & & & & $\begin{array}{l}\text { Bacterial diseases (See } \\
\text { individual label) }\end{array}$ & See label \\
\hline $\begin{array}{l}1 \text { Badge SC, Basic Cop } \\
\text { Disperss, Cuprofix M } \\
\text { WP, Nu-Cop } 50 \text { DF, S }\end{array}$ & $\begin{array}{l}\text { pper 53, Cha } \\
\text { MZ Disperss, } \\
\text { Stretch, Tenr }\end{array}$ & $\begin{array}{l}\text { amp DP Dry Prill, } \\
\text {, Kocide 101, Koc } \\
\text { n-Cop 5E }\end{array}$ & $\begin{array}{l}\text { Champ Fo } \\
\text { cide } 2000 \text {, }\end{array}$ & $\begin{array}{l}\text { rmula 2FL, } \\
\text { Kocide 4.5L }\end{array}$ & $\begin{array}{l}\text { רpion WP, COC DF, COC V } \\
\text { cide DF, Nordox, Nordox }\end{array}$ & $\begin{array}{l}\text { NP, Copper-Count-N, Cuprofix } \\
75 \text { WG, Nu-Cop 3L, Nu-Cop } 50\end{array}$ \\
\hline 2 Kumulus DF, Micro S & Sulf, Microni & ized Gold, Microt & thiol Disper & rss, Sulfur $90 \mathrm{~V}$ & , Thiolux Jet, Wettable Sult & \\
\hline
\end{tabular}


Table 12. Selected insecticides approved for use on insects attacking cucumbers.

\begin{tabular}{|c|c|c|c|c|c|c|}
\hline $\begin{array}{l}\text { Trade Name } \\
\text { (Common Name) }\end{array}$ & $\begin{array}{l}\text { Rate } \\
\text { (product/acre) }\end{array}$ & $\begin{array}{l}\text { REI } \\
\text { (hours) }\end{array}$ & $\begin{array}{l}\text { Days to } \\
\text { Harvest }\end{array}$ & Insects & $\begin{array}{l}\text { MOA } \\
\text { Code }^{1}\end{array}$ & Notes \\
\hline $\begin{array}{l}\text { Acramite-50WS } \\
\text { (bifenazate) }\end{array}$ & $0.75-1.0 \mathrm{lb}$ & 12 & 3 & twospotted spider mite & 25 & One application per season. \\
\hline $\begin{array}{l}\text { Admire } 2 \mathrm{~F} \\
\text { (imidacloprid) }\end{array}$ & $\begin{array}{l}0.1 \mathrm{fl} \mathrm{oz} / 1000 \\
\text { plants }\end{array}$ & 12 & 21 & aphids, whiteflies & $4 \mathrm{~A}$ & $\begin{array}{l}\text { Planthouse: } 1 \text { application to } \\
\text { transplants. See label. }\end{array}$ \\
\hline Admire Pro & $\begin{array}{l}0.44 \mathrm{fl} \\
0 \mathrm{z} / 10,000 \\
\text { plants }\end{array}$ & & & & & \\
\hline $\begin{array}{l}\text { Admire 2F } \\
\text { (imidacloprid) }\end{array}$ & $\begin{array}{l}1.4 \mathrm{fl} \mathrm{oz} / 1000 \\
\text { plants }\end{array}$ & 12 & 0 (soil) & aphids, whiteflies & $4 \mathrm{~A}$ & $\begin{array}{l}\text { Mature plants in greenhouse, } \\
\text { one application. Do not apply to } \\
\text { immature plants. }\end{array}$ \\
\hline Admire Pro & $0.6 \mathrm{oz} / 1000$ & & & & & \\
\hline $\begin{array}{l}\text { Admire 2F } \\
\text { (imidacloprid) }\end{array}$ & $16-24$ oz & 12 & 21 & $\begin{array}{l}\text { aphids, cucumber beetles, } \\
\text { leafhoppers, thrips, white- } \\
\text { flies }\end{array}$ & $4 \mathrm{~A}$ & $\begin{array}{l}\text { Will not control thrips in flow- } \\
\text { ers. }\end{array}$ \\
\hline Admire Pro & $7-10.5 \mathrm{fl} \mathrm{oz}$ & & & & & \\
\hline $\begin{array}{l}\text { Agree WG } \\
\text { (Bacillus thuringiensis } \\
\text { subspecies aizawai) }\end{array}$ & $0.5-2.0 \mathrm{lb}$ & 4 & 0 & $\begin{array}{l}\text { lepidopteran larvae (cater- } \\
\text { pillar pests) }\end{array}$ & 11B1 & $\begin{array}{l}\text { Apply when larvae are small for } \\
\text { best control. OMRI-listed². }\end{array}$ \\
\hline $\begin{array}{l}\text { *Agri-Mek } 0.15 \text { EC } \\
\text { (abamectin) }\end{array}$ & $8-16 \mathrm{fl} \mathrm{oz}$ & 12 & 7 & leafminers, spider mites & 6 & $\begin{array}{l}\text { Minimum } 7 \text {-day intervals. No } \\
\text { more than } 2 \text { sequential applica- } \\
\text { tions. }\end{array}$ \\
\hline $\begin{array}{l}\text { *Ambush 25W } \\
\text { (permethrin) }\end{array}$ & $6.4-12.80 z$ & 12 & 0 & $\begin{array}{l}\text { cabbage looper, cucumber } \\
\text { beetles (adults), cut- } \\
\text { worms, leafminers, lygus } \\
\text { bug, melonworm, pickle- } \\
\text { worm, rindworms, squash } \\
\text { bug, squash vine borer, } \\
\text { stink bugs }\end{array}$ & 3 & $\begin{array}{l}\text { Do not apply more than } 1.6 \mathrm{lb} \\
\text { active ingredient per acre, per } \\
\text { season. (102.4 oz) }\end{array}$ \\
\hline $\begin{array}{l}\text { *Asana XL (0.66 EC) } \\
\text { (esfenvalerate) }\end{array}$ & $5.8-9.6 \mathrm{fl} \mathrm{oz}$ & 12 & 3 & $\begin{array}{l}\text { cabbage looper, corn ear- } \\
\text { worm, cucumber beetles } \\
\text { (adults), cutworms (seed- } \\
\text { ling spray), grasshoppers, } \\
\text { leafhoppers, lygus bug, } \\
\text { pickleworm, rindworms, } \\
\text { squash bug, squash vine } \\
\text { borer, stink bugs }\end{array}$ & 3 & $\begin{array}{l}\text { Do not apply more than } 0.25 \\
\text { Ib a.i. per acre per season or } 5 \\
\text { applications at high rate. }\end{array}$ \\
\hline $\begin{array}{l}\text { Aza-Direct } \\
\text { (azadirachtin) }\end{array}$ & $\begin{array}{l}1-2 \text { pts, } \\
\text { up to } 3.5 \text { pts, } \\
\text { if needed }\end{array}$ & 4 & 0 & $\begin{array}{l}\text { aphids, beetles, caterpil- } \\
\text { lars, leafhoppers, leafmin- } \\
\text { ers, mites, stink bugs, } \\
\text { thrips, weevils, whiteflies }\end{array}$ & 26 & $\begin{array}{l}\text { Antifeedant, repellent, insect } \\
\text { growth regulator. OMRI-listed }{ }^{2} \text {. }\end{array}$ \\
\hline $\begin{array}{l}\text { Azatin XL } \\
\text { (azadirachtin) }\end{array}$ & $5-21 \mathrm{fl} \mathrm{oz}$ & 4 & 0 & $\begin{array}{l}\text { aphids, beetles, caterpil- } \\
\text { lars, leafhoppers, leafmin- } \\
\text { ers, thrips, weevils, } \\
\text { whiteflies }\end{array}$ & 26 & $\begin{array}{l}\text { Antifeedant, repellent, insect } \\
\text { growth regulator. }\end{array}$ \\
\hline $\begin{array}{l}\text { Baythroid } 2 \\
\text { (cyfluthrin) }\end{array}$ & 0.8-2.8 fl oz & 12 & 0 & $\begin{array}{l}\text { armyworm, cabbage } \\
\text { looper, corn earworm, } \\
\text { cucumber beetles, cut- } \\
\text { worms, grasshoppers, } \\
\text { melonworm, pickleworm, } \\
\text { rindworms, tobacco bud- } \\
\text { worm }\end{array}$ & 3 & $\begin{array}{l}\text { Apply no more than } 4 \text { times per } \\
\text { season. }\end{array}$ \\
\hline
\end{tabular}


Table 12. Continued.

\begin{tabular}{|c|c|c|c|c|c|c|}
\hline $\begin{array}{l}\text { Trade Name } \\
\text { (Common Name) }\end{array}$ & $\begin{array}{l}\text { Rate } \\
\text { (product/acre) }\end{array}$ & $\begin{array}{l}\text { REI } \\
\text { (hours) }\end{array}$ & $\begin{array}{l}\text { Days to } \\
\text { Harvest }\end{array}$ & Insects & $\begin{array}{l}\text { MOA } \\
\text { Code }^{1}\end{array}$ & Notes \\
\hline $\begin{array}{l}\text { Biobit HP } \\
\text { (Bacillus thuringiensis } \\
\text { subspecies kurstaki) }\end{array}$ & $0.5-2.0 \mathrm{lb}$ & 4 & 0 & $\begin{array}{l}\text { caterpillars (will not con- } \\
\text { trol large armyworms) }\end{array}$ & 11B2 & $\begin{array}{l}\text { Treat when larvae are young. } \\
\text { Good coverage is essential. } \\
\text { Can be used in the greenhouse. } \\
\text { OMRI-listed?2. }^{2} \text {. }\end{array}$ \\
\hline $\begin{array}{l}\text { BotaniGard } 22 \text { WP, ES } \\
\text { (Beauveria bassiana) }\end{array}$ & $\begin{array}{l}\text { WP: } \\
0.5-2 \mathrm{lb} / 100 \mathrm{gal} \\
\text { ES: } \\
0.5-2 \mathrm{gt} / 100 \\
\text { gal }\end{array}$ & 4 & 0 & aphids, thrips, whiteflies & -- & $\begin{array}{l}\text { May be used in greenhouses. } \\
\text { Contact dealer for recommen- } \\
\text { dations if an adjuvant must be } \\
\text { used. Not compatible in tank } \\
\text { mix with fungicides. }\end{array}$ \\
\hline $\begin{array}{l}\text { *Capture } 2 \text { EC } \\
\text { (bifenthrin) }\end{array}$ & $2.6-6.4 \mathrm{fl} \mathrm{oz}$ & 12 & 3 & $\begin{array}{l}\text { aphids, armyworms, } \\
\text { cabbage looper, corn ear- } \\
\text { worm, cucumber beetles, } \\
\text { cutworms, grasshoppers, } \\
\text { leafhoppers, melonworm, } \\
\text { mites, pickleworm, plant } \\
\text { bugs, rindworms, squash } \\
\text { bug, squash vine borer, } \\
\text { stink bugs, tobacco bud- } \\
\text { worm }\end{array}$ & 3 & $\begin{array}{l}\text { Do not apply more than } 19.2 \\
\text { ounces of product per acre per } \\
\text { season. Do not make more than } \\
2 \text { applications after bloom. }\end{array}$ \\
\hline $\begin{array}{l}\text { Courier 70WP, 40SC } \\
\text { (buprofezin) }\end{array}$ & $\begin{array}{l}\text { 70WP: } 6-9 \text { oz } \\
\text { 40SC: } 9-13.6 \\
\text { fl oz }\end{array}$ & 12 & 7 & whitefly nymphs & 16 & $\begin{array}{l}\text { Insect growth regulator. Do not } \\
\text { make more than } 2 \text { applications } \\
\text { per season per crop. Do not } \\
\text { plant food crops except those } \\
\text { on the label within } 120 \text { days fol- } \\
\text { lowing application. }\end{array}$ \\
\hline $\begin{array}{l}\text { Crymax WDG } \\
\text { (Bacillus thuringiensis } \\
\text { subspecies kurstaki) }\end{array}$ & $0.5-2.0 \mathrm{lb}$ & 4 & 0 & caterpillars & 11B2 & $\begin{array}{l}\text { Use high rate for armyworms. } \\
\text { Treat when larvae are young. }\end{array}$ \\
\hline $\begin{array}{l}\text { *Danitol } \\
\text { (fenpropathrin) }\end{array}$ & $10.67 \mathrm{fl} \mathrm{oz}$ & 24 & 7 & $\begin{array}{l}\text { banded cucumber beetle, } \\
\text { cabbage looper, fall army- } \\
\text { worm, green stinkbugs, } \\
\text { plant bugs, spider mites, } \\
\text { striped cucumber beetle. } \\
\text { Tank-mix with endosulfan } \\
\text { to control aphids, thrips, } \\
\text { and whiteflies. }\end{array}$ & 3 & $\begin{array}{l}\text { Do not apply more often than } \\
\text { every } 7 \text { days. Do not exceed } 0.8 \\
\text { Ib active ingredient per acre per } \\
\text { season. }\end{array}$ \\
\hline $\begin{array}{l}\text { Deliver } \\
\text { (Bacillus thuringiensis } \\
\text { subspecies kurstaki) }\end{array}$ & $0.25-1.5 \mathrm{lb}$ & 4 & 0 & caterpillars & 11B2 & $\begin{array}{l}\text { Use higher rates for army- } \\
\text { worms. OMRI-listed². }\end{array}$ \\
\hline $\begin{array}{l}\text { Dicofol 4E } \\
\text { (dicofol) }\end{array}$ & $0.75 \mathrm{pt}$ & 12 & 2 & twospotted mites & 20 & $\begin{array}{l}\text { Do not apply more than twice a } \\
\text { season. }\end{array}$ \\
\hline $\begin{array}{l}\text { DiPel DF } \\
\text { (Bacillus thuringiensis } \\
\text { subspecies kurstaki) }\end{array}$ & $0.5-2.0 \mathrm{lb}$ & 4 & 0 & caterpillars & 11B2 & $\begin{array}{l}\text { Treat when larvae are young. } \\
\text { Good coverage is essential. } \\
\text { OMRI-listed². }\end{array}$ \\
\hline $\begin{array}{l}\text { Endosulfan } 3 \text { EC } \\
\text { (endosulfan) }\end{array}$ & $0.66-1.33 \mathrm{qt}$ & 24 & 2 & $\begin{array}{l}\text { aphids, cabbage looper, } \\
\text { cucumber beetles, fall } \\
\text { armyworm, flea beetles, } \\
\text { melonworm, pickleworm, } \\
\text { squash beetle, squash } \\
\text { bug, squash vine borer, } \\
\text { whiteflies }\end{array}$ & 2 & $\begin{array}{l}\text { Do not make more than } 6 \text { appli- } \\
\text { cations per year or exceed } 3.0 \\
\text { lb active ingredient per acre per } \\
\text { year. }\end{array}$ \\
\hline
\end{tabular}


Table 12. Continued.

\begin{tabular}{|c|c|c|c|c|c|c|}
\hline $\begin{array}{l}\text { Trade Name } \\
\text { (Common Name) }\end{array}$ & $\begin{array}{l}\text { Rate } \\
\text { (product/acre) }\end{array}$ & $\begin{array}{l}\text { REI } \\
\text { (hours) }\end{array}$ & $\begin{array}{l}\text { Days to } \\
\text { Harvest }\end{array}$ & Insects & $\begin{array}{l}\text { MOA } \\
\text { Code }^{1}\end{array}$ & Notes \\
\hline $\begin{array}{l}\text { Entrust } \\
\text { (spinosad) }\end{array}$ & $1.25-2.50 z$ & 4 & 1 & $\begin{array}{l}\text { armyworms, cabbage } \\
\text { looper, leafminers, mel- } \\
\text { onworm, pickleworm, } \\
\text { rindworms, thrips }\end{array}$ & 5 & $\begin{array}{l}\text { Do not apply more then } 6 \text { times } \\
\text { (or } 9 \text { oz per acre per crop). } \\
\text { OMRI-listed². }\end{array}$ \\
\hline $\begin{array}{l}\text { Esteem Ant Bait } \\
\text { (pyriproxyfen) }\end{array}$ & $1.5-2.0 \mathrm{lb}$ & 12 & 1 & red imported fire ant & $7 \mathrm{D}$ & $\begin{array}{l}\text { Apply when ants are actively } \\
\text { foraging. }\end{array}$ \\
\hline $\begin{array}{l}\text { Extinguish } \\
\text { ((S)-methoprene) }\end{array}$ & $1.0-1.5 \mathrm{lb}$ & 4 & 0 & fire ants & $7 \mathrm{~A}$ & $\begin{array}{l}\text { Slow-acting IGR (insect growth } \\
\text { regulator). Best applied early } \\
\text { spring and fall where crop will } \\
\text { be grown. Colonies will be } \\
\text { reduced after three weeks and } \\
\text { eliminated after } 8 \text { to } 10 \text { weeks. } \\
\text { May be applied by ground } \\
\text { equipment or aerially. }\end{array}$ \\
\hline $\begin{array}{l}\text { Fulfill } \\
\text { (pymetrozine) }\end{array}$ & $2.75 \mathrm{oz}$ & 12 & 0 & $\begin{array}{l}\text { green peach aphid, melon } \\
\text { aphid, suppression of } \\
\text { whiteflies }\end{array}$ & $9 B$ & $\begin{array}{l}\text { Minimum of } 7 \text { days between } \\
\text { applications. Maximum } 5.5 \text { oz/ } \\
\text { acre/season. }\end{array}$ \\
\hline $\begin{array}{l}\text { Intrepid 2F } \\
\text { (methoxyfenozide) }\end{array}$ & $4-10 \mathrm{fl} \mathrm{oz}$ & 4 & 3 & $\begin{array}{l}\text { beet armyworm, cab- } \\
\text { bage looper, melonworm, } \\
\text { pickleworm, rindworm, } \\
\text { southern armyworm, true } \\
\text { armyworm, yellowstriped } \\
\text { armyworm }\end{array}$ & 18 & $\begin{array}{l}\text { Do not make more than } 4 \text { appli- } \\
\text { cations per seaon. }\end{array}$ \\
\hline $\begin{array}{l}\text { Javelin WG } \\
\text { (Bacillus thuringiensis } \\
\text { subspecies kurstaki) }\end{array}$ & $0.12-1.5 \mathrm{lb}$ & 4 & 0 & $\begin{array}{l}\text { most caterpillars, but } \\
\text { not Spodoptera species } \\
\text { (armyworms). }\end{array}$ & $11 \mathrm{~B} 2$ & $\begin{array}{l}\text { Treat when larvae are young. } \\
\text { Thorough coverage is essential. } \\
\text { OMRI-listed?2. }\end{array}$ \\
\hline $\begin{array}{l}\text { Kelthane } 50 \text { WSP } \\
\text { (Bacillus thuringiensis } \\
\text { subspecies kurstaki) }\end{array}$ & $1.25 \mathrm{lb}$ & 48 & 2 & mites & 20 & $\begin{array}{l}\text { Do not apply more than twice } \\
\text { per season. }\end{array}$ \\
\hline $\begin{array}{l}\text { Knack IGR } \\
\text { (pyriproxyfen) }\end{array}$ & $8-10 \mathrm{fl} \mathrm{oz}$ & 12 & 7 & whiteflies (immatures) & $7 \mathrm{D}$ & $\begin{array}{l}\text { Do not apply more than twice } \\
\text { per season. }\end{array}$ \\
\hline $\begin{array}{l}\text { Kryocide } \\
\text { (cryolite) }\end{array}$ & $8-12 \mathrm{lb}$ & 12 & 14 & $\begin{array}{l}\text { cabbage looper, cucumber } \\
\text { beetles, flea beetles, mel- } \\
\text { onworm, pickleworm }\end{array}$ & - $9 \mathrm{~A}$ & $\begin{array}{l}\text { Do not exceed } 48 \mathrm{Ib} / \text { acre per } \\
\text { season. Minimum of } 10 \text { days } \\
\text { between applications. }\end{array}$ \\
\hline $\begin{array}{l}\text { *Lannate LV; }{ }^{*} \mathbf{S P} \\
\text { (methomyl) }\end{array}$ & $\begin{array}{l}\text { LV: } 1.5-3.0 \mathrm{pt} \\
\text { SP: } 0.5-1.0 \mathrm{lb}\end{array}$ & 48 & $\begin{array}{l}1-1.5 \mathrm{pt} \\
(\mathrm{LV}) \\
\text { or } 0.5 \mathrm{lb} \\
\text { (SP) } \\
3->1.5 \\
\text { pt or } 0.5 \\
\text { lb }\end{array}$ & $\begin{array}{l}\text { aphids, beet armyworm, } \\
\text { cucumber beetles, cut- } \\
\text { worms, fall armyworm, } \\
\text { flea beetles, loopers, } \\
\text { melonworm, pickleworm, } \\
\text { tobacco budworm, varie- } \\
\text { gated cutworm, yellow- } \\
\text { striped armyworm }\end{array}$ & $1 \mathrm{~A}$ & \\
\hline $\begin{array}{l}\text { Lepinox WDG } \\
\text { (Bacillus thuringiensis } \\
\text { subspecies kurstaki) }\end{array}$ & $1.0-2.0 \mathrm{lb}$ & 12 & 0 & $\begin{array}{l}\text { for most caterpillars, } \\
\text { including beet armyworm } \\
\text { (see label) }\end{array}$ & 11B2 & $\begin{array}{l}\text { Treat when larvae are small. } \\
\text { Thorough coverage is essential. }\end{array}$ \\
\hline $\begin{array}{l}\text { Malathion } 8 \mathrm{~F} \\
\text { (malathion) }\end{array}$ & $1.75 \mathrm{pt}$ & 12 & 1 & $\begin{array}{l}\text { aphids, cucumber beetles, } \\
\text { leafminers, mites, pick- } \\
\text { leworm, squash vine borer }\end{array}$ & 1B & $\begin{array}{l}\text { Do not apply unless plants are } \\
\text { dry. Can be used in greenhouse }\end{array}$ \\
\hline $\begin{array}{l}\text { *MSR Spray } \\
\text { Concentrate (oxy- } \\
\text { demeton-methyl) }\end{array}$ & $1.5-2 \mathrm{pt}$ & 48 & 3 & aphids, mites & 1B & $\begin{array}{l}\text { Do not apply more than } 2 \text { times } \\
\text { per season. }\end{array}$ \\
\hline
\end{tabular}


Chapter 27: Cucurbit Production in Florida

Table 12. Continued.

\begin{tabular}{|c|c|c|c|c|c|c|}
\hline $\begin{array}{l}\text { Trade Name } \\
\text { (Common Name) }\end{array}$ & $\begin{array}{l}\text { Rate } \\
\text { (product/acre) }\end{array}$ & $\begin{array}{l}\text { REI } \\
\text { (hours) }\end{array}$ & $\begin{array}{l}\text { Days to } \\
\text { Harvest }\end{array}$ & Insects & $\begin{array}{l}\text { MOA } \\
\text { Code }^{1}\end{array}$ & Notes \\
\hline $\begin{array}{l}\text { M-Pede } \mathbf{4 9 \%} \text { EC } \\
\text { (Soap, insecticidal) }\end{array}$ & $1-2 \%$ V/V & 12 & 0 & $\begin{array}{l}\text { aphids, leafhoppers, } \\
\text { mites, thrips, whiteflies }\end{array}$ & -- & OMRI-listed². \\
\hline $\begin{array}{l}\text { Neemix } 4.5 \\
\text { (azadirachtin) }\end{array}$ & $4-16 \mathrm{fl} \mathrm{oz}$ & 12 & 0 & $\begin{array}{l}\text { fall armyworm, leafmin- } \\
\text { ers, melonworm, pickle- } \\
\text { worm, rindworms, squash } \\
\text { bug, squash vine borer, } \\
\text { tobacco budworm, white- } \\
\text { flies }\end{array}$ & 26 & $\begin{array}{l}\text { IGR and feeding repellant. } \\
\text { Greenhouse and field use. } \\
\text { OMRI-listed?2. }\end{array}$ \\
\hline $\begin{array}{l}\text { Oberon 2SC } \\
\text { (spiromesifen) }\end{array}$ & $7.0-8.5 \mathrm{fl} \mathrm{oz}$ & 12 & 7 & $\begin{array}{l}\text { twospotted spidermite, } \\
\text { whiteflies }\end{array}$ & 23 & $\begin{array}{l}\text { Maximum amount per crop: } \\
25.5 \mathrm{fl} \text { oz/acre. No more than } 3 \\
\text { applications. }\end{array}$ \\
\hline $\begin{array}{l}\text { Oils, Insecticidal } \\
\text { SunSpray } 98.8 \% \\
\text { Ultra-Fine } \\
\text { JMS Stylet Oil } \\
\text { Others }\end{array}$ & $\begin{array}{l}3-6 \mathrm{qts} / 100 \mathrm{gal} \\
\text { (JMS) }\end{array}$ & 4 & 0 & $\begin{array}{l}\text { aphids, leafhoppers, } \\
\text { leafminers, mites, thrips, } \\
\text { whiteflies, aphid transmit- } \\
\text { ted viruses (JMS) }\end{array}$ & -- & $\begin{array}{l}\text { Organic Stylet-Oil is } \\
\text { OMRI-listed². }\end{array}$ \\
\hline $\begin{array}{l}\text { Platinum } \\
\text { (thiamethoxam) }\end{array}$ & $5-8 \mathrm{fl} \mathrm{oz}$ & 12 & 30 & $\begin{array}{l}\text { aphids, flea beetles, white- } \\
\text { flies }\end{array}$ & $-4 \mathrm{~A}$ & $\begin{array}{l}\text { For most crops that are not on } \\
\text { the label, a } 120 \text {-day plant-back } \\
\text { interval must be observed. }\end{array}$ \\
\hline $\begin{array}{l}\text { *Pounce } 3.2 \text { EC (per- } \\
\text { methrin) }\end{array}$ & $4-80 z$ & 12 & 0 & $\begin{array}{l}\text { aphids, cabbage looper, } \\
\text { cucumber beetles (adults), } \\
\text { cutworms, leafhoppers, } \\
\text { leafminers, lygus bug, } \\
\text { melonworm, pickleworm, } \\
\text { rindworms, squash bug, } \\
\text { squash vine borer, stink } \\
\text { bugs }\end{array}$ & 3 & \\
\hline $\begin{array}{l}\text { Pyrellin EC } \\
\text { (pyrethrin + rotenone) }\end{array}$ & $1-2 \mathrm{pt}$ & 12 & 12 hours & $\begin{array}{l}\text { aphids, cucumber beetles, } \\
\text { flea beetles, leafhoppers, } \\
\text { leafminers, loopers, lygus } \\
\text { bug, mites, squash bug, } \\
\text { squash vine borer, stink } \\
\text { bugs, thrips, whiteflies }\end{array}$ & 3 & \\
\hline $\begin{array}{l}\text { Sevin 80S, 4F, } \\
\text { XLR Plus } \\
\text { (carbaryl) }\end{array}$ & $\begin{array}{l}\text { 80S: } 0.63-1.25 \\
\text { lb } \\
\text { 4F, XLR: } 0.5- \\
1 \text { qt }\end{array}$ & 12 & 3 & $\begin{array}{l}\text { cucumber beetles, flea } \\
\text { beetles, leafhoppers, } \\
\text { melonworm, pickleworm, } \\
\text { squash bug }\end{array}$ & $1 \mathrm{~A}$ & $\begin{array}{l}\text { Do not apply more than } 6 \text { qt or } \\
7.5 \mathrm{lb} \text { per acre per crop. }\end{array}$ \\
\hline $\begin{array}{l}\text { SpinTor } 2 \text { SC } \\
\text { (spinosad) }\end{array}$ & $4-8 \mathrm{fl} \mathrm{oz}$ & 4 & 1 & $\begin{array}{l}\text { armyworms, cabbage } \\
\text { looper, leafminers, mel- } \\
\text { onworm, pickleworm, } \\
\text { rindworms, thrips }\end{array}$ & 5 & $\begin{array}{l}\text { Do not apply more than } 29 \text { oz } \\
\text { per acre per season. }\end{array}$ \\
\hline $\begin{array}{l}\text { *Telone C-35 (dichlo- } \\
\text { ropropene + chloro- } \\
\text { picrin) }\end{array}$ & See label & $\begin{array}{l}5 \text { days } \\
\text { (see } \\
\text { label) }\end{array}$ & preplant & symphylans, wireworms & -- & $\begin{array}{l}\text { See supplemental label for use } \\
\text { restrictions in south and central } \\
\text { Florida. }\end{array}$ \\
\hline \multicolumn{7}{|l|}{$\begin{array}{l}\text { *Telone II } \\
\text { (dichloropropene) }\end{array}$} \\
\hline $\begin{array}{l}\text { Trigard } \\
\text { (cyromazine) }\end{array}$ & $2.66 \mathrm{oz}$ & 12 & 0 & leafminers & 17 & $\begin{array}{l}\text { Do not make more than } 6 \text { appli- } \\
\text { cations. }\end{array}$ \\
\hline $\begin{array}{l}\text { Trilogy } \\
\text { (extract of neem oil) }\end{array}$ & $0.5-2.0 \%$ V/N & 4 & 0 & $\begin{array}{l}\text { aphids, mites, suppres- } \\
\text { sion of thrips and white- } \\
\text { flies }\end{array}$ & 26 & $\begin{array}{l}\text { Apply morning or evening to } \\
\text { reduce potential for leaf burn. } \\
\text { Toxic to bees exposed to direct } \\
\text { treatment. OMRI-listed? }\end{array}$ \\
\hline
\end{tabular}


Table 12. Continued.

\begin{tabular}{|c|c|c|c|c|c|c|}
\hline $\begin{array}{l}\text { Trade Name } \\
\text { (Common Name) }\end{array}$ & $\begin{array}{l}\text { Rate } \\
\text { (product/acre) }\end{array}$ & $\begin{array}{l}\text { REI } \\
\text { (hours) }\end{array}$ & $\begin{array}{l}\text { Days to } \\
\text { Harvest }\end{array}$ & Insects & $\begin{array}{l}\text { MOA } \\
\text { Code } 1\end{array}$ & Notes \\
\hline $\begin{array}{l}\text { Venom } \\
\text { (dinotefuran) }\end{array}$ & $\begin{array}{l}\text { foliar: } 1-4 \text { oz } \\
\text { soil: } 5-6 \text { oz }\end{array}$ & 12 & $\begin{array}{l}1 \text { - foliar } \\
21 \text { - soil }\end{array}$ & $\begin{array}{l}\text { green peach aphid, } \\
\text { leafhoppers, leafmin- } \\
\text { ers, melon aphid, thrips, } \\
\text { whiteflies }\end{array}$ & $4 \mathrm{~A}$ & $\begin{array}{l}\text { Do not apply more than } 6 \text { oz } \\
\text { per acre per season (foliar) or } \\
12 \text { oz per acre per season (soil) } \\
\text { Do not use both application } \\
\text { methods. }\end{array}$ \\
\hline $\begin{array}{l}\text { *Vydate L } \\
\text { (oxamyl) }\end{array}$ & $2-4 \mathrm{pt}$ & 48 & 1 & aphids, leafminers, thrips & $1 \mathrm{~A}$ & \\
\hline $\begin{array}{l}\text { Xentari DF } \\
\text { (Bacillus thuringiensis } \\
\text { subspecies aizawai) }\end{array}$ & $0.5-2.0 \mathrm{lb}$ & 4 & 0 & caterpillars & $11 \mathrm{~B} 1$ & $\begin{array}{l}\text { Treat when larvae are young. } \\
\text { Thorough coverage is essential. } \\
\text { May be used in the greenhouse. } \\
\text { Can be used in organic produc- } \\
\text { tion. }\end{array}$ \\
\hline
\end{tabular}

The pesticide information presented in this table was current with federal and state regulations at the time of revision. The user is responsible for determining the intended use is consistent with the label of the product being used. Use pesticides safely. Read and follow label instructions.

1 Mode of Action codes for vegetable pest insecticides from the Insecticide Resistance Action Committee (IRAC) Mode of Action Classification v.3.3 October 2003. 1A. Acetylcholine esterase inhibitors, Carbamates 1B. Acetylcholine esterase inhibitors, Organophosphates

2A. GABA-gated chloride channel antagonists

3. Sodium channel modulators

4A. Nicotinic Acetylcholine receptor agonists/antagonists, Neonicotinoids

5. Nicotinic Acetylcholine receptor agonists (not group 4)

6. Chloride channel activators

7A. Juvenile hormone mimics, Juvenile hormone analogues

7D. Juvenile hormone mimics, Pyriproxifen

9A. Compounds of unknown or non-specific mode of action (selective feeding blockers), Cryolite

9B. Compounds of unknown or non-specific mode of action (selective feeding blockers), Pymetrozine

11B1. Microbial disruptors of insect midgut membranes, B.t. var aizawai

11B2. Microbial disruptors of insect midgut membranes, B.t. var kurstaki

12B. Inhibitors of oxidative phosphorylation, disruptors of ATP formation, Organotin miticide

15. Inhibitors of chitin biosynthesis, type 0, Lepidopteran

16. Inhibitors of chitin biosynthesis, type 1, Homopteran

17. Inhibitors of chitin biosynthesis, type 2, Dipteran

18. Ecdysone agonist/disruptor

20. Site II electron transport inhibitors

21. Site I electron transport inhibitors

22. Voltage-dependent sodium channel blocker

23. Inhibitors of lipid biosynthesis

25. Neuroactive (unknown mode of action)

26. Unknown mode of action, Azadirachtin

2 OMRI-listed: Listed by the Organic Materials Review Institute for use in organic production.

* Restricted Use Pesticide 
Table 13. Selected insecticides approved for use on insects attacking squash.

\begin{tabular}{|c|c|c|c|c|c|c|}
\hline $\begin{array}{l}\text { Trade Name } \\
\text { (Common Name) }\end{array}$ & $\begin{array}{l}\text { Rate } \\
\text { (product/acre) }\end{array}$ & $\begin{array}{l}\text { REI } \\
\text { (hours) }\end{array}$ & $\begin{array}{l}\text { Days to } \\
\text { Harvest }\end{array}$ & Insects & $\begin{array}{l}\text { MOA } \\
\text { Code }^{1}\end{array}$ & Notes \\
\hline $\begin{array}{l}\text { Acramite 50ws } \\
\text { (bifenazate) }\end{array}$ & $0.75-1.0 \mathrm{lb}$ & 12 & 3 & twospotted spider mite & 25 & One application per season. \\
\hline $\begin{array}{l}\text { Admire } 2 \mathrm{~F} \\
\text { (imidacloprid) }\end{array}$ & $16-24$ oz & 12 & 21 & $\begin{array}{l}\text { aphids, cucumber beetles, } \\
\text { leafhoppers, thrips, white- } \\
\text { flies }\end{array}$ & $4 \mathrm{~A}$ & Will not control thrips in flowers. \\
\hline Admire Pro & $7.0-10.5 \mathrm{oz}$ & & & & & \\
\hline $\begin{array}{l}\text { Agree WG } \\
\text { (Bacillus thuringiensis } \\
\text { subspecies aizawai) }\end{array}$ & $0.5-2.0 \mathrm{lb}$ & 4 & 0 & $\begin{array}{l}\text { lepidopteran larvae (cater- } \\
\text { pillar pests) }\end{array}$ & $11 \mathrm{~B} 1$ & $\begin{array}{l}\text { Apply when larvae are small for } \\
\text { best control. } \\
\text { OMRI-listed². }\end{array}$ \\
\hline $\begin{array}{l}\text { *Agri-Mek } 0.15 \text { EC } \\
\text { (abamectin) }\end{array}$ & $8-16 \mathrm{fl} \mathrm{oz}$ & 12 & 7 & leafminers, spider mites & 6 & $\begin{array}{l}\text { Minimum 7-day intervals. No } \\
\text { more than } 2 \text { sequential applica- } \\
\text { tions. }\end{array}$ \\
\hline $\begin{array}{l}\text { *Ambush 25W } \\
\text { (permethrin) }\end{array}$ & $6.4-12.80 z$ & 12 & 0 & $\begin{array}{l}\text { cabbage loopers, cucum- } \\
\text { ber beetles, cutworms, } \\
\text { leafminers, Lygus bug, } \\
\text { melonworms, pickle- } \\
\text { worms, plant bugs, rind- } \\
\text { worm complex, squash } \\
\text { bug, squash vine borer, } \\
\text { stink bugs }\end{array}$ & 3 & $\begin{array}{l}\text { Do not apply more than } 1.6 \mathrm{lb} \\
\text { ai/acre per season. (102.4 oz) }\end{array}$ \\
\hline $\begin{array}{l}\text { *Asana XL (0.66 EC) } \\
\text { (esfenvalerate) }\end{array}$ & $5.8-9.6 \mathrm{fl} \mathrm{oz}$ & 12 & 3 & $\begin{array}{l}\text { cabbage looper, corn ear- } \\
\text { worm, cucumber beetles } \\
\text { (adults), cutworms (seed- } \\
\text { ling spray), grasshoppers, } \\
\text { leafhoppers, Lygus bug, } \\
\text { pickleworms, rindworm } \\
\text { complex, squash bug, } \\
\text { squash vine borer, stink } \\
\text { bugs }\end{array}$ & 3 & $\begin{array}{l}\text { Do not apply more than } 0.25 \mathrm{lb} \\
\text { ai/acre per season ( } 5 \text { applications } \\
\text { at high rate). }\end{array}$ \\
\hline $\begin{array}{l}\text { Aza-Direct } \\
\text { (azadirachtin) }\end{array}$ & $\begin{array}{l}1-2 \mathrm{pts}, \text { up } \\
\text { to } 3.5 \mathrm{pts} \text {, if } \\
\text { needed }\end{array}$ & 4 & 0 & $\begin{array}{l}\text { aphids, beetles, caterpil- } \\
\text { lars, leafhoppers, leafmin- } \\
\text { ers, mites, stink bugs, } \\
\text { thrips, weevils, whiteflies }\end{array}$ & 26 & $\begin{array}{l}\text { Antifeedant, repellant, insect } \\
\text { growth regulator. OMRI-listed }{ }^{2} \text {. }\end{array}$ \\
\hline $\begin{array}{l}\text { Azatin XL } \\
\text { (azadirachtin) }\end{array}$ & $5-21 \mathrm{fl} \mathrm{oz}$ & 4 & 0 & $\begin{array}{l}\text { aphids, beetles, caterpil- } \\
\text { lars, leafhoppers, leafmin- } \\
\text { ers, thrips, weevils, } \\
\text { whiteflies }\end{array}$ & 26 & $\begin{array}{l}\text { Antifeedant, repellant, insect } \\
\text { growth regulator. }\end{array}$ \\
\hline $\begin{array}{l}\text { Baythroid } 2 \\
\text { (cyfluthrin) }\end{array}$ & $0.8-2.8 \mathrm{fl} \mathrm{oz}$ & 12 & 0 & $\begin{array}{l}\text { armyworm, cabbage } \\
\text { looper, corn earworm, } \\
\text { cucumber beetles, cut- } \\
\text { worms, grasshoppers, } \\
\text { melonworm, pickleworm, } \\
\text { rindworms, tobacco bud- } \\
\text { worm }\end{array}$ & 3 & $\begin{array}{l}\text { Apply no more than } 4 \text { times per } \\
\text { season. }\end{array}$ \\
\hline $\begin{array}{l}\text { Biobit HP } \\
\text { (Bacillus thuringiensis } \\
\text { subspecies kurstaki) }\end{array}$ & $0.5-2.0 \mathrm{lb}$ & 4 & 0 & $\begin{array}{l}\text { caterpillars (will not con- } \\
\text { trol large armyworms) }\end{array}$ & $11 \mathrm{~B} 2$ & $\begin{array}{l}\text { Treat when larvae are young. } \\
\text { Good coverage is essential. } \\
\text { Can be used in the greenhouse. } \\
\text { OMRI-listed? }\end{array}$ \\
\hline $\begin{array}{l}\text { BotaniGard } 22 \text { WP, ES } \\
\text { (Beauveria bassiana) }\end{array}$ & $\begin{array}{l}\text { WP: } \\
0.5-2 \mathrm{lb} / 100 \mathrm{gal} \\
\text { ES: } \\
0.5-2 \mathrm{qt} / 100 \mathrm{gal}\end{array}$ & 4 & 0 & aphids, thrips, whiteflies & -- & $\begin{array}{l}\text { May be used in greenhouses. } \\
\text { Contact dealer for recommen- } \\
\text { dations if an adjuvant must be } \\
\text { used. Not compatible in tank mix } \\
\text { with fungicides. }\end{array}$ \\
\hline
\end{tabular}


Table 13. Continued.

\begin{tabular}{|c|c|c|c|c|c|c|}
\hline $\begin{array}{l}\text { Trade Name } \\
\text { (Common Name) }\end{array}$ & $\begin{array}{l}\text { Rate } \\
\text { (product/acre) }\end{array}$ & $\begin{array}{l}\text { REI } \\
\text { (hours) }\end{array}$ & $\begin{array}{l}\text { Days to } \\
\text { Harvest }\end{array}$ & Insects & $\begin{array}{l}\text { MOA } \\
\text { Code }^{1}\end{array}$ & Notes \\
\hline $\begin{array}{l}\text { *Capture } 2 \text { EC } \\
\text { (bifenthrin) }\end{array}$ & 2.6-6.4 fl oz & 12 & 3 & $\begin{array}{l}\text { aphids, armyworms, } \\
\text { cabbage looper, corn ear- } \\
\text { worm, cucumber beetles, } \\
\text { cutworms, grasshoppers, } \\
\text { leafhoppers, melonworm, } \\
\text { pickleworm, plant bugs, } \\
\text { rindworms, squash bug, } \\
\text { squash vine borer, stink } \\
\text { bugs, tobacco budworm }\end{array}$ & 3 & $\begin{array}{l}\text { Do not apply more than } 19.2 \\
\text { ounces of product per acre per } \\
\text { season. Do not make more than } \\
2 \text { applications after bloom. }\end{array}$ \\
\hline $\begin{array}{l}\text { Courier 70WP, 40SC } \\
\text { (buprofezin) }\end{array}$ & $\begin{array}{l}\text { 70WP: } \\
\text { 6-9 oz } \\
\text { 40SC: } \\
9-13.6 \mathrm{fl} \mathrm{oz}\end{array}$ & 12 & 7 & whitefly nymphs & 16 & $\begin{array}{l}\text { Insect growth regulator. Do not } \\
\text { make more than } 2 \text { applications } \\
\text { per season per crop. Do not plant } \\
\text { food crops except those on the } \\
\text { label within } 120 \text { days following } \\
\text { application. }\end{array}$ \\
\hline $\begin{array}{l}\text { Crymax WDG } \\
\text { (Bacillus thuringiensis } \\
\text { subspecies kurstaki) }\end{array}$ & $0.5-2.0 \mathrm{lb}$ & 4 & 0 & caterpillars & 11B2 & $\begin{array}{l}\text { Use high rate for armyworms. } \\
\text { Treat when larvae are young. }\end{array}$ \\
\hline $\begin{array}{l}\text { *Danitol } \\
\text { (fenpropathrin) }\end{array}$ & $10.67 \mathrm{fl} \mathrm{oz}$ & 24 & 7 & $\begin{array}{l}\text { banded cucumber beetle, } \\
\text { cabbage looper, fall army- } \\
\text { worm, southern green } \\
\text { stink bug, spider mites, } \\
\text { striped cucumber beetle, } \\
\text { yellowstriped armyworm. } \\
\text { Tank-mix with endosulfan } \\
\text { to control aphids, thrips, } \\
\text { and whiteflies. }\end{array}$ & 3 & $\begin{array}{l}\text { Do not apply more often than } \\
\text { every } 7 \text { days. Do not exceed } 0.8 \\
\text { lb ai. per acre per season. ( } 42.67 \\
\text { fl oz) }\end{array}$ \\
\hline $\begin{array}{l}\text { Deliver } \\
\text { (Bacillus thuringiensis } \\
\text { subspecies kurstaki) }\end{array}$ & $0.25-1.5 \mathrm{lb}$ & 4 & 0 & caterpillars & 11B2 & $\begin{array}{l}\text { Use higher rates for armyworms. } \\
\text { OMRI-listed². }\end{array}$ \\
\hline $\begin{array}{l}\text { Dibrom } 8 \text { EC } \\
\text { (naled) } \\
\text { summer squash only }\end{array}$ & $1 \mathrm{pt}$ & 48 & 1 & $\begin{array}{l}\text { aphids, armyworms, } \\
\text { cucumber beetles, loop- } \\
\text { ers, mites, thrips }\end{array}$ & 1B & $\begin{array}{l}\text { Apply no more than } 1 \mathrm{pt} \text { per acre } \\
\text { in Florida. Do not apply when } \\
\text { temperature is over } 90^{\circ} \mathrm{F} \text {. }\end{array}$ \\
\hline $\begin{array}{l}\text { Dicofol 4E } \\
\text { (dicofol) }\end{array}$ & $0.75 \mathrm{pt}$ & 12 & 2 & twospotted mites & 20 & $\begin{array}{l}\text { No more than } 2 \text { applications per } \\
\text { season. }\end{array}$ \\
\hline $\begin{array}{l}\text { DiPel DF } \\
\text { (Bacillus thuringiensis } \\
\text { subspecies kurstaki) }\end{array}$ & $0.5-2.0 \mathrm{lb}$ & 4 & 0 & caterpillars & 11B2 & $\begin{array}{l}\text { Treat when larvae are young. } \\
\text { Good coverage is essential. } \\
\text { OMRI-listed?2. }\end{array}$ \\
\hline $\begin{array}{l}\text { Endosulfan } 3 \text { EC } \\
\text { (endosulfan) }\end{array}$ & $0.66-1.33$ qt & 24 & 2 & $\begin{array}{l}\text { aphids, cabbage looper, } \\
\text { cucumber beetles, flea } \\
\text { beetles, melonworm, } \\
\text { pickleworm, squash bee- } \\
\text { tle, squash bug, squash } \\
\text { vine borer, whiteflies }\end{array}$ & 2 & $\begin{array}{l}\text { Do not make more than } 6 \text { appli- } \\
\text { cations per year or exceed } 3.0 \\
\text { lb active ingredient per acre per } \\
\text { year. }\end{array}$ \\
\hline $\begin{array}{l}\text { Entrust } \\
\text { (spinosad) }\end{array}$ & $1.25-2.5 \mathrm{oz}$ & 4 & 3 & $\begin{array}{l}\text { armyworms, cabbage } \\
\text { looper, leafminers, mel- } \\
\text { onworm, pickleworm, } \\
\text { rindworms, thrips }\end{array}$ & 5 & $\begin{array}{l}\text { Do not apply more than } 6 \text { times } \\
\text { or } 9 \text { oz per acre/crop. OMRI- } \\
\text { listed }^{2} \text {. }\end{array}$ \\
\hline $\begin{array}{l}\text { Esteem Ant Bait } \\
\text { (pyriproxyfen) }\end{array}$ & $1.5-2.0 \mathrm{lb}$ & 12 & 1 & red imported fire ant & $7 \mathrm{D}$ & $\begin{array}{l}\text { Apply when ants are actively } \\
\text { foraging. }\end{array}$ \\
\hline
\end{tabular}


Chapter 27: Cucurbit Production in Florida

Table 13. Continued.

\begin{tabular}{|c|c|c|c|c|c|c|}
\hline $\begin{array}{l}\text { Trade Name } \\
\text { (Common Name) }\end{array}$ & $\begin{array}{l}\text { Rate } \\
\text { (product/acre) }\end{array}$ & $\begin{array}{l}\text { REI } \\
\text { (hours) }\end{array}$ & $\begin{array}{l}\text { Days to } \\
\text { Harvest }\end{array}$ & Insects & $\begin{array}{l}\text { MOA } \\
\text { Code }^{1}\end{array}$ & Notes \\
\hline $\begin{array}{l}\text { Extinguish } \\
\text { ((S)-methprene) }\end{array}$ & $1.0-1.5 \mathrm{lb}$ & 4 & 0 & fire ants & $7 \mathrm{~A}$ & $\begin{array}{l}\text { Slow-acting IGR (insect growth } \\
\text { regulator). Best applied early } \\
\text { spring and fall where crop will be } \\
\text { grown. Colonies will be reduced } \\
\text { after three weeks and eliminated } \\
\text { after } 8 \text { to } 10 \text { weeks. May be } \\
\text { applied by ground equipment or } \\
\text { aerially. }\end{array}$ \\
\hline $\begin{array}{l}\text { Fulfill } \\
\text { (pymetrozine) }\end{array}$ & $2.75 \mathrm{oz}$ & 12 & 0 & $\begin{array}{l}\text { green peach aphid, melon } \\
\text { aphid, suppression of } \\
\text { whiteflies }\end{array}$ & $9 B$ & $\begin{array}{l}\text { Minimum of } 7 \text { days between } \\
\text { applications. Two applications } \\
\text { only. }\end{array}$ \\
\hline $\begin{array}{l}\text { Intrepid 2F } \\
\text { (methoxyfenozide) }\end{array}$ & $4-10 \mathrm{fl} \mathrm{oz}$ & 4 & 3 & $\begin{array}{l}\text { beet armyworm, cab- } \\
\text { bage looper, melonworm, } \\
\text { pickleworm, rindworm, } \\
\text { southern armyworm, true } \\
\text { armyworm, yellowstriped } \\
\text { armyworm }\end{array}$ & 18 & $\begin{array}{l}\text { Do not apply more than } 4 \text { appli- } \\
\text { cations per season. }\end{array}$ \\
\hline $\begin{array}{l}\text { Javelin WG } \\
\text { (Bacillus thuringiensis } \\
\text { subspecies kurstaki) }\end{array}$ & $0.12-1.5 \mathrm{lb}$ & 4 & 0 & $\begin{array}{l}\text { most caterpillars, but } \\
\text { not Spodoptera species } \\
\text { (armyworms) }\end{array}$ & $11 \mathrm{~B} 2$ & $\begin{array}{l}\text { Treat when larvae are young. } \\
\text { Thorough coverage is essential. } \\
\text { OMRI-listed?2. }\end{array}$ \\
\hline $\begin{array}{l}\text { Kelthane 50WSP } \\
\text { (dicofol) }\end{array}$ & $1.25 \mathrm{lb}$ & 48 & 2 & mites & 20 & $\begin{array}{l}\text { Do not apply more than twice per } \\
\text { season. }\end{array}$ \\
\hline $\begin{array}{l}\text { Knack IGR } \\
\text { (pyriproxyfen) }\end{array}$ & $8-10 \mathrm{fl} \mathrm{oz}$ & 12 & 7 & whiteflies (immatures) & $7 \mathrm{D}$ & $\begin{array}{l}\text { Do not apply more than twice per } \\
\text { season. }\end{array}$ \\
\hline $\begin{array}{l}\text { Kryocide } \\
\text { (cryolite) }\end{array}$ & $8-16 \mathrm{lb}$ & 12 & 7 & $\begin{array}{l}\text { cabbage looper, Diabrotica } \\
\text { beetles, flea beetles, mel- } \\
\text { onworm, pickleworm }\end{array}$ & $9 \mathrm{~A}$ & $\begin{array}{l}\text { Do not exceed } 64 \mathrm{lb} / \text { acre per } \\
\text { season. }\end{array}$ \\
\hline $\begin{array}{l}\text { *Lannate LV; *SP } \\
\text { (methomyl) } \\
\text { summer squash only }\end{array}$ & $\begin{array}{l}\text { LV: } 1.5-3.0 \mathrm{pt} \\
\text { SP: } 0.5-1.0 \mathrm{lb}\end{array}$ & 48 & $\begin{array}{l}1 \text { or } 3 \text {, } \\
\text { depend- } \\
\text { ing on } \\
\text { rate } \\
\text { used }\end{array}$ & $\begin{array}{l}\text { aphids, beet armyworm, } \\
\text { cucumber beetles, fall } \\
\text { armyworm, flea beetles, } \\
\text { granulate cutworms, loop- } \\
\text { ers, melonworm, pickle- } \\
\text { worm, tobacco budworm, } \\
\text { yellowstriped armyworm }\end{array}$ & $1 \mathrm{~A}$ & \\
\hline $\begin{array}{l}\text { Lepinox WDG } \\
\text { (Bacillus thuringiensis } \\
\text { subspecies kurstaki) }\end{array}$ & $1.0-2.0 \mathrm{lb}$ & 12 & 0 & $\begin{array}{l}\text { for most caterpillars, } \\
\text { including beet armyworm } \\
\text { (see label) }\end{array}$ & $11 \mathrm{~B} 2$ & $\begin{array}{l}\text { Treat when larvae are small. } \\
\text { Thorough coverage is essential. }\end{array}$ \\
\hline $\begin{array}{l}\text { Malathion } 8 \mathrm{~F} \\
\text { (malathion) }\end{array}$ & $1.75 \mathrm{pt}$ & 12 & 1 & $\begin{array}{l}\text { aphids, cucumber beetles, } \\
\text { leafminers, mites, pickle- } \\
\text { worm, squash vine borer }\end{array}$ & $1 \mathrm{~B}$ & $\begin{array}{l}\text { Do not apply unless plants are } \\
\text { dry. }\end{array}$ \\
\hline $\begin{array}{l}\text { *MSR Spray } \\
\text { Concentrate (oxy- } \\
\text { demeton-methyl) }\end{array}$ & $1.5-2.0 \mathrm{pt}$ & 48 & $\begin{array}{l}3 \text { - sum- } \\
\text { mer } \\
14- \\
\text { winter }\end{array}$ & aphids & $1 \mathrm{~B}$ & Apply only once per season. \\
\hline $\begin{array}{l}\text { M-Pede } 49 \% \text { EC } \\
\text { (Soap, insecticidal) }\end{array}$ & $1-2 \%$ V/V & 12 & 0 & $\begin{array}{l}\text { aphids, leafhoppers, } \\
\text { mites, plant bugs, thrips, } \\
\text { whiteflies }\end{array}$ & -- & OMRI-listed². \\
\hline $\begin{array}{l}\text { Neemix } 4.5 \text { (azadi- } \\
\text { rachtin) }\end{array}$ & $4-16 \mathrm{fl} \mathrm{oz}$ & 12 & 0 & $\begin{array}{l}\text { fall armyworm, leafmin- } \\
\text { ers, melonworm, pickle- } \\
\text { worm, rindworm complex, } \\
\text { squash bug, squash vine } \\
\text { borer, tobacco budworm, } \\
\text { whiteflies }\end{array}$ & 26 & $\begin{array}{l}\text { IGR and feeding repellent. } \\
\text { Greenhouse and field use. OMRI- } \\
\text { listed?2. }^{2}\end{array}$ \\
\hline $\begin{array}{l}\text { Oberon 2SC } \\
\text { (spiromesifen) }\end{array}$ & $7.0-8.5 \mathrm{fl} \mathrm{oz}$ & 12 & 7 & $\begin{array}{l}\text { twospotted spider mite, } \\
\text { whiteflies }\end{array}$ & 23 & $\begin{array}{l}\text { Maximum amount per season: } \\
25.5 \mathrm{fl} \text { oz. No more than } 3 \text { appli- } \\
\text { cations. }\end{array}$ \\
\hline
\end{tabular}


Table 13. Continued.

\begin{tabular}{|c|c|c|c|c|c|c|}
\hline $\begin{array}{l}\text { Trade Name } \\
\text { (Common Name) }\end{array}$ & $\begin{array}{l}\text { Rate } \\
\text { (product/acre) }\end{array}$ & $\begin{array}{l}\text { REI } \\
\text { (hours) }\end{array}$ & $\begin{array}{l}\text { Days to } \\
\text { Harvest }\end{array}$ & Insects & $\begin{array}{l}\text { MOA } \\
\text { Code }^{1}\end{array}$ & Notes \\
\hline $\begin{array}{l}\text { Oils, Insecticidal } \\
\text { SunSpray } 98.8 \% \\
\text { Ultra-Fine } \\
\text { JMS Stylet 0il } \\
\text { Others }\end{array}$ & $\begin{array}{l}3-6 \mathrm{qts} / 100 \mathrm{gal} \\
\text { (JMS) }\end{array}$ & 4 & 0 & $\begin{array}{l}\text { aphids, leafhoppers, } \\
\text { leafminers, mites, thrips, } \\
\text { whiteflies (pest controlled } \\
\text { vary by specific product). }\end{array}$ & -- & 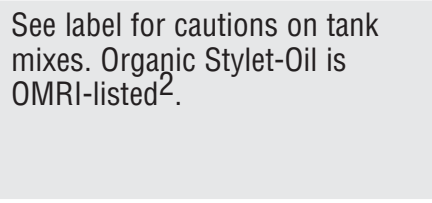 \\
\hline $\begin{array}{l}\text { Platinum } \\
\text { (thiamethoxam) }\end{array}$ & $5-8 \mathrm{fl} \mathrm{oz}$ & 12 & 30 & $\begin{array}{l}\text { aphids, flea beetles, } \\
\text { whiteflies }\end{array}$ & $4 \mathrm{~A}$ & $\begin{array}{l}\text { For most crops that are not on } \\
\text { the label, a } 120 \text {-day plant-back } \\
\text { interval must be observed. }\end{array}$ \\
\hline $\begin{array}{l}\text { *Pounce } 3.2 \text { EC (per- } \\
\text { methrin) }\end{array}$ & $4-80 z$ & 12 & 0 & $\begin{array}{l}\text { aphids, cabbage looper, } \\
\text { cucumber beetles, cut- } \\
\text { worms, leafhoppers, } \\
\text { leafminers, lygus bug, } \\
\text { melonworm, pickleworm, } \\
\text { plant bugs, rindworm } \\
\text { complex, squash bug, } \\
\text { squash vine borer, stink } \\
\text { bugs }\end{array}$ & 3 & \\
\hline $\begin{array}{l}\text { Prokil Cryolite } 96 \\
\text { (cryolite) }\end{array}$ & 8-16 lb & 12 & $\begin{array}{l}14 \\
\text { - winter } \\
7 \text { - sum- } \\
\text { mer }\end{array}$ & $\begin{array}{l}\text { cabbage looper, Diabrotica } \\
\text { beetles, flea beetles, mel- } \\
\text { onworm, pickleworm }\end{array}$ & $9 A$ & \\
\hline $\begin{array}{l}\text { Pyrellin EC } \\
\text { (pyrethrin + rotenone) }\end{array}$ & $1-2 \mathrm{pt}$ & 12 & $\begin{array}{l}12 \\
\text { hours }\end{array}$ & $\begin{array}{l}\text { aphids, cabbage looper, } \\
\text { cucumber beetles, flea } \\
\text { beetles, leafhoppers, } \\
\text { leafminers, loopers, lygus } \\
\text { bug, mites, plant bugs, } \\
\text { squash bug, squash vine } \\
\text { borer, stink bugs, thrips, } \\
\text { whiteflies }\end{array}$ & 3,21 & \\
\hline $\begin{array}{l}\text { Sevin 80S, 4F, } \\
\text { XLR Plus } \\
\text { (carbaryl) }\end{array}$ & $\begin{array}{l}\text { 80S: } 0.63-1.25 \\
\text { lb } \\
\text { 4F, XLR Plus: } \\
0.5-1.0 \text { qt }\end{array}$ & 12 & 3 & $\begin{array}{l}\text { cucumber beetles, flea } \\
\text { beetles, leafhoppers, } \\
\text { melonworm, pickleworm, } \\
\text { squash bug }\end{array}$ & $1 \mathrm{~A}$ & $\begin{array}{l}\text { Do not apply more than } 7.5 \mathrm{lb} \text { or } \\
6 \text { qt per acre per crop. }\end{array}$ \\
\hline $\begin{array}{l}\text { SpinTor } 2 \text { SC } \\
\text { (spinosad) }\end{array}$ & $4-8 \mathrm{fl} \mathrm{oz}$ & 4 & 3 & $\begin{array}{l}\text { armyworms, cabbage } \\
\text { looper, leafminers, mel- } \\
\text { onworm, pickleworm, } \\
\text { rindworms, thrips }\end{array}$ & 5 & $\begin{array}{l}\text { Do not use more than } 3 \text { times } \\
\text { in a } 21 \text {-day period. Rotate to a } \\
\text { different class of product for } 21 \\
\text { days. }\end{array}$ \\
\hline $\begin{array}{l}{ }^{*} \text { Telone C-35 (dichloro- } \\
\text { propene + chloropicrin) }\end{array}$ & See label & $\begin{array}{l}5 \text { days } \\
\text { (see } \\
\text { label) }\end{array}$ & preplant & symphylans, wireworms & -- & $\begin{array}{l}\text { See supplemental label for use } \\
\text { restrictions in south and central } \\
\text { Florida. }\end{array}$ \\
\hline \multicolumn{7}{|l|}{$\begin{array}{l}\text { *Telone II } \\
\text { (dichloropropene) }\end{array}$} \\
\hline $\begin{array}{l}\text { Trigard } \\
\text { (cyromazine) }\end{array}$ & $2.66 \mathrm{oz}$ & 12 & 0 & leafminers & 17 & $\begin{array}{l}\text { Do not make more than } 6 \text { appli- } \\
\text { cations. }\end{array}$ \\
\hline $\begin{array}{l}\text { Trilogy } \\
\text { (extract of neem oil) }\end{array}$ & $0.5-2.0 \% \mathrm{~V} N$ & 4 & 0 & $\begin{array}{l}\text { aphids, mites, suppres- } \\
\text { sion of thrips and white- } \\
\text { flies }\end{array}$ & 26 & $\begin{array}{l}\text { Apply morning or evening to } \\
\text { reduce potential for leaf burn. } \\
\text { Toxic to bees exposed to direct } \\
\text { treatment. OMRI-listed?2. }\end{array}$ \\
\hline $\begin{array}{l}\text { Venom } \\
\text { (dinotefuran) }\end{array}$ & $\begin{array}{l}\text { foliar: } 1-4 \text { oz } \\
\text { soil: } 5-6 \text { oz }\end{array}$ & 12 & $\begin{array}{l}1-\text { foliar } \\
21-\text { soil }\end{array}$ & $\begin{array}{l}\text { green peach aphid, leaf- } \\
\text { hopper, leafminers, melon } \\
\text { aphid, thrips, whiteflies }\end{array}$ & $4 \mathrm{~A}$ & $\begin{array}{l}\text { Do not apply more than } 6 \text { oz/acre } \\
\text { per season (foliar) or } 12 \text { oz/acre } \\
\text { (soil). Use only one application } \\
\text { method (soil or foliar, not both). }\end{array}$ \\
\hline
\end{tabular}


Table 13. Continued.

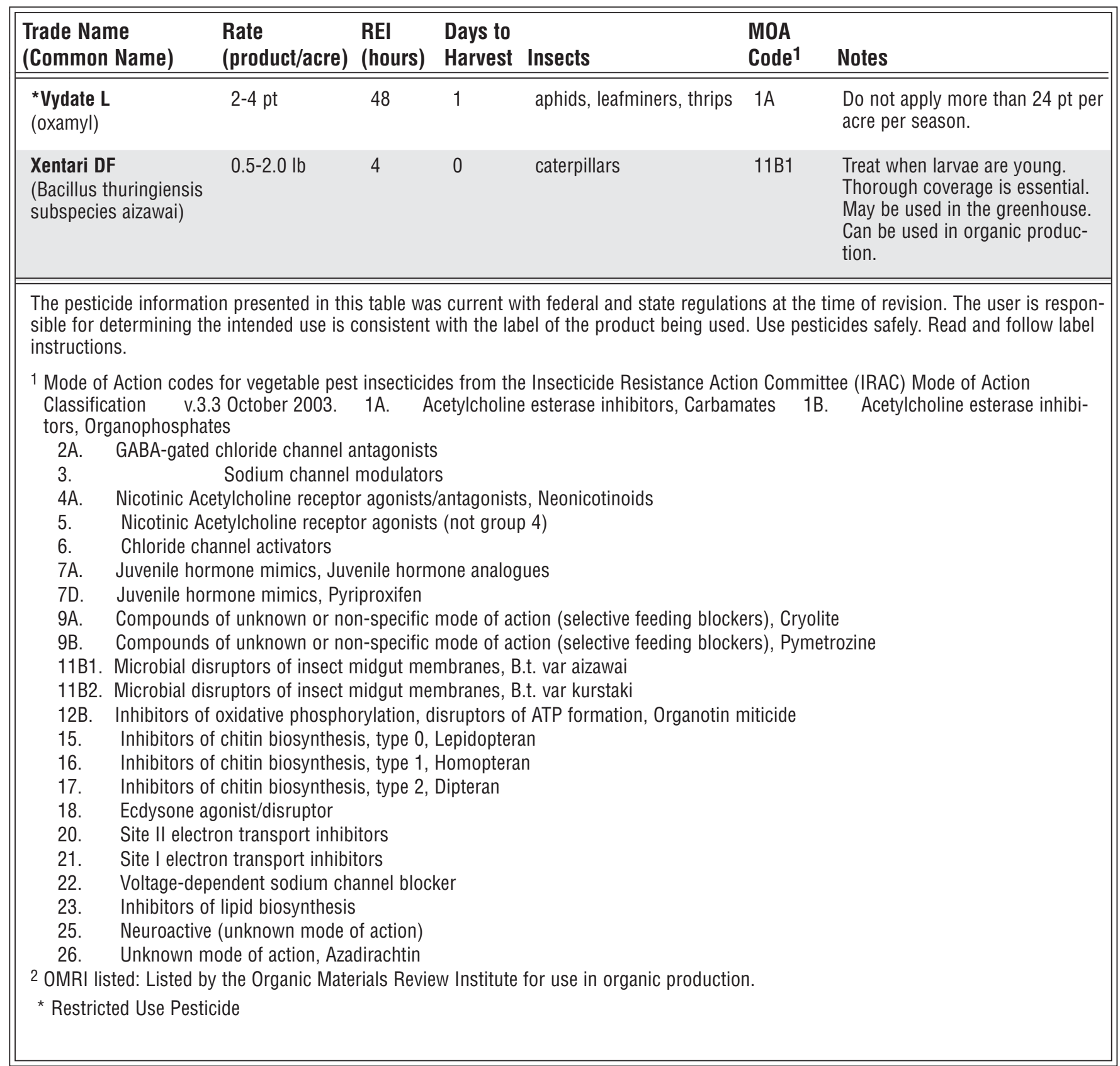


Table 14. Selected insecticides approved for use on insects attacking cantaloupes.

\begin{tabular}{|c|c|c|c|c|c|c|}
\hline $\begin{array}{l}\text { Trade Name } \\
\text { (Common Name) }\end{array}$ & $\begin{array}{l}\text { Rate } \\
\text { (product/acre) }\end{array}$ & $\begin{array}{l}\text { REI } \\
\text { (hours) }\end{array}$ & $\begin{array}{l}\text { Days to } \\
\text { Harvest }\end{array}$ & Insects & $\begin{array}{l}\text { MOA } \\
\text { Code }^{1}\end{array}$ & Notes \\
\hline $\begin{array}{l}\text { Acramite-50WS } \\
\text { (bifenazate) }\end{array}$ & $0.75-1.0 \mathrm{lb}$ & 12 & 3 & twospotted spider mite & 25 & One application per season. \\
\hline $\begin{array}{l}\text { Admire } 2 \mathrm{~F} \\
\text { (imidacloprid) }\end{array}$ & $16-24 \mathrm{fl} \mathrm{oz}$ & 12 & 21 (soil) & $\begin{array}{l}\text { aphids, cucumber bee- } \\
\text { tles, leafhoppers, thrips, } \\
\text { whiteflies }\end{array}$ & $4 \mathrm{~A}$ & Will not control thrips in flowers. \\
\hline Admire Pro & $7.0-10.5 \mathrm{fl} \mathrm{oz}$ & & & & & \\
\hline $\begin{array}{l}\text { Admire 2F } \\
\text { (imidacloprid) }\end{array}$ & $\begin{array}{l}0.1 \mathrm{fl} 0 \mathrm{oz} / 1000 \\
\text { plants }\end{array}$ & 12 & 21 & aphids, whiteflies & $4 \mathrm{~A}$ & $\begin{array}{l}\text { Planthouse - See label, } 1 \text { appli- } \\
\text { cation. }\end{array}$ \\
\hline Admire Pro & $\begin{array}{l}0.44 \mathrm{fl} \\
0 \mathrm{z} / 10,000 \\
\text { plants }\end{array}$ & & & & & \\
\hline $\begin{array}{l}\text { Agree WG } \\
\text { (Bacillus thuringiensis } \\
\text { subspecies aizawai) }\end{array}$ & $0.5-2.0 \mathrm{lb}$ & 4 & 0 & $\begin{array}{l}\text { lepidopteran larvae (cat- } \\
\text { erpillar pests) }\end{array}$ & $11 \mathrm{~B} 1$ & $\begin{array}{l}\text { Apply when larvae are small for } \\
\text { best control. OMRI-listed². }\end{array}$ \\
\hline $\begin{array}{l}\text { *Agri-Mek 0.15 EC } \\
\text { (abamectin) }\end{array}$ & 8-16 fl oz & 12 & 7 & leafminers, spider mites & 6 & $\begin{array}{l}\text { Minimum 7-day intervals, no } \\
\text { more than } 2 \text { sequential applica- } \\
\text { tions. }\end{array}$ \\
\hline $\begin{array}{l}\text { *Ambush 25W } \\
\text { (permethrin) }\end{array}$ & $6.4-12.80 z$ & 12 & 0 & $\begin{array}{l}\text { cabbage looper, cucum- } \\
\text { ber beetles, cutworms, } \\
\text { leafminers, Lygus bug, } \\
\text { melonworm, pickleworm, } \\
\text { plant bugs, rindworms, } \\
\text { squash vine borer, stink } \\
\text { bugs }\end{array}$ & 3 & $\begin{array}{l}\text { Do not apply more than } 102.4 \mathrm{oz} \\
\text { acre per season. }\end{array}$ \\
\hline $\begin{array}{l}\text { *Asana XL (0.66 EC) } \\
\text { (esfenvalerate) }\end{array}$ & $5.8-9.6 \mathrm{fl} \mathrm{oz}$ & 12 & 3 & $\begin{array}{l}\text { cabbage looper, corn ear- } \\
\text { worm, cucumber beetles } \\
\text { (adults), cutworms } \\
\text { (seedling spray), grass- } \\
\text { hoppers, leafhoppers, } \\
\text { Lygus bug, pickleworm, } \\
\text { rindworms, squash bug, } \\
\text { squash vine borer, stink } \\
\text { bugs }\end{array}$ & 3 & $\begin{array}{l}\text { Do not apply more than } 0.25 \mathrm{lb} \\
\text { ai/acre per season. ( } 5 \text { applica- } \\
\text { tions at high rate). }\end{array}$ \\
\hline $\begin{array}{l}\text { Aza-Direct } \\
\text { (azadirachtin) }\end{array}$ & $\begin{array}{l}1-2 \text { pts, } \\
\text { up to } 3.5 \text { pts if } \\
\text { needed }\end{array}$ & 4 & 0 & $\begin{array}{l}\text { aphids, beetles, cat- } \\
\text { erpillars, leafhoppers, } \\
\text { leafminers, mites, stink } \\
\text { bugs, thrips, weevils, } \\
\text { whiteflies }\end{array}$ & 26 & $\begin{array}{l}\text { Antifeedant, repellent, insect } \\
\text { growth regulator. OMRI-listed². }\end{array}$ \\
\hline $\begin{array}{l}\text { Azatin XL } \\
\text { (azadirachtin) }\end{array}$ & $5-21 \mathrm{fl} \mathrm{oz}$ & 4 & 0 & $\begin{array}{l}\text { aphids, beetles, cat- } \\
\text { erpillars, leafhoppers, } \\
\text { leafminers, thrips, wee- } \\
\text { vils, whiteflies }\end{array}$ & 26 & $\begin{array}{l}\text { Antifeedant, repellent, insect } \\
\text { growth regulator. }\end{array}$ \\
\hline $\begin{array}{l}\text { Baythroid } 2 \\
\text { (cyfluthrin) }\end{array}$ & $0.8-2.8 \mathrm{fl} \mathrm{oz}$ & 12 & 0 & $\begin{array}{l}\text { armyworm, cabbage } \\
\text { looper, corn earworm, } \\
\text { cucumber beetles, cut- } \\
\text { worms, grasshoppers, } \\
\text { melonworm, pickleworm, } \\
\text { rindworms, tobacco } \\
\text { budworm }\end{array}$ & 3 & $\begin{array}{l}\text { Apply no more than } 4 \text { times per } \\
\text { season. }\end{array}$ \\
\hline $\begin{array}{l}\text { Biobit HP } \\
\text { (Bacillus thuringiensis } \\
\text { subspecies kurstaki) }\end{array}$ & $0.5-2.0 \mathrm{lb}$ & 4 & 0 & $\begin{array}{l}\text { caterpillars (will not con- } \\
\text { trol large armyworms) }\end{array}$ & 11B2 & $\begin{array}{l}\text { Treat when larvae are young. } \\
\text { Good coverage is essential. } \\
\text { Can be used in the greenhouse. } \\
\text { OMRI-listed². }^{2}\end{array}$ \\
\hline
\end{tabular}


Table 14. Cotninued.

\begin{tabular}{|c|c|c|c|c|c|c|}
\hline $\begin{array}{l}\text { Trade Name } \\
\text { (Common Name) }\end{array}$ & $\begin{array}{l}\text { Rate } \\
\text { (product/acre) }\end{array}$ & $\begin{array}{l}\text { REI } \\
\text { (hours) }\end{array}$ & $\begin{array}{l}\text { Days to } \\
\text { Harvest }\end{array}$ & Insects & $\begin{array}{l}\text { MOA } \\
\text { Code }^{1}\end{array}$ & Notes \\
\hline $\begin{array}{l}\text { BotaniGard } 22 \text { WP, ES } \\
\text { (Beauveria bassiana) }\end{array}$ & $\begin{array}{l}\text { WP: } \\
0.5-2.0 \mathrm{lb} / 100 \\
\text { gal } \\
\text { ES: } \\
0.5-2 \text { qt } 100 / \mathrm{gal}\end{array}$ & 4 & 0 & aphids, thrips, whiteflies & -- & $\begin{array}{l}\text { May be used in greenhouses. } \\
\text { Contact dealer for recommen- } \\
\text { dations if an adjuvant must be } \\
\text { used. Not compatible in tank mix } \\
\text { with fungicides. }\end{array}$ \\
\hline $\begin{array}{l}\text { *Capture } 2 \text { EC } \\
\text { (bifenthrin) }\end{array}$ & 2.6-6.4 fl oz & 12 & 3 & $\begin{array}{l}\text { aphids, armyworms, } \\
\text { cabbage looper, corn ear- } \\
\text { worm, cucumber beetles, } \\
\text { cutworms, grasshoppers, } \\
\text { leafhoppers, melonworm, } \\
\text { mites, pickleworm, plant } \\
\text { bugs, rindworms, squash } \\
\text { bug, squash vine borer, } \\
\text { stink bugs, tobacco bud- } \\
\text { worm }\end{array}$ & 3 & $\begin{array}{l}\text { Do not apply more than } 19.2 \\
\text { ounces of product per acre per } \\
\text { season. Do not make more than } \\
2 \text { applications after bloom. }\end{array}$ \\
\hline $\begin{array}{l}\text { Courier 70WP, 40SC } \\
\text { (buprofezin) }\end{array}$ & $\begin{array}{l}\text { 70WP: } 6-9 \text { oz } \\
\text { 40SC: } 9-13.6 \\
\text { fl oz }\end{array}$ & 12 & 7 & whitefly nymphs & 16 & $\begin{array}{l}\text { Insect growth regulator. Do not } \\
\text { make more than } 2 \text { applications } \\
\text { per season per crop. Do not } \\
\text { plant food crops except those on } \\
\text { the label within } 120 \text { days follow- } \\
\text { ing application. }\end{array}$ \\
\hline $\begin{array}{l}\text { Crymax WDG } \\
\text { (Bacillus thuringiensis } \\
\text { subspecies kurstaki) }\end{array}$ & $0.5-2.0 \mathrm{lb}$ & 4 & 0 & caterpillars & 11B2 & $\begin{array}{l}\text { Use high rate for armyworms. } \\
\text { Treat when larvae are young. }\end{array}$ \\
\hline $\begin{array}{l}\text { *Danitol 2.4 EC } \\
\text { (fenpropathrin) }\end{array}$ & $10.67 \mathrm{fl} \mathrm{oz}$ & 24 & 7 & $\begin{array}{l}\text { banded cucumber beetle, } \\
\text { cabbage looper, fall } \\
\text { armyworm, green stink } \\
\text { bug, plant bugs, spider } \\
\text { mites, striped cucumber } \\
\text { beetle, yellow striped } \\
\text { armyworm }\end{array}$ & 3 & $\begin{array}{l}\text { Mix with endosulfan for aphid, } \\
\text { thrips, and whitefly control. }\end{array}$ \\
\hline $\begin{array}{l}\text { Deliver } \\
\text { (Bacillus thuringiensis } \\
\text { subspecies kurstaki) }\end{array}$ & $0.25-1.5 \mathrm{lb}$ & 4 & 0 & caterpillars & 11B2 & $\begin{array}{l}\text { Use higher rates for armyworms } \\
\text { OMRI-listed². }\end{array}$ \\
\hline $\begin{array}{l}\text { Dibrom } 8 \text { EC } \\
\text { (naled) }\end{array}$ & $1 \mathrm{pt}$ & 48 & 1 & $\begin{array}{l}\text { aphids, armyworms, } \\
\text { leafhoppers, leafminers, } \\
\text { loopers }\end{array}$ & $1 \mathrm{~B}$ & $\begin{array}{l}\text { Netted varieties only. Apply no } \\
\text { more than } 2 \mathrm{pt} \text { per acre per } \\
\text { season. Do not apply when tem- } \\
\text { perature is over } 90^{\circ} \text { F. }\end{array}$ \\
\hline \multirow[t]{2}{*}{$\begin{array}{l}\text { *Diazinon } 4 \mathrm{E},{ }^{*} 50 \mathrm{~W} \\
\text { (diazinon) }\end{array}$} & $\begin{array}{l}\text { AG500, 4E: } \\
0.5-1.5 \mathrm{pts} \\
\text { 50W: } 0.5-1.5 \mathrm{lb}\end{array}$ & 24 & 3 (foliar) & $\begin{array}{l}\text { aphids, cucumber } \\
\text { beetles, leafhoppers, } \\
\text { leafminers, melonworm, } \\
\text { mites, thrips }\end{array}$ & 1B & $\begin{array}{l}\text { Will not control organophos- } \\
\text { phate- resistant leafminers. } \\
\text { Limited to } 5 \text { applications. }\end{array}$ \\
\hline & $\begin{array}{l}\text { AG500, 4E: } \\
\text { 2-4 qts } \\
\text { 50W: } 4-8 \mathrm{lb}\end{array}$ & & preplant & cutworms, wireworms & & \\
\hline $\begin{array}{l}\text { Dimethoate } 4 \mathrm{EC}, \\
2.67 \mathrm{EC} \\
\text { (dimethoate) }\end{array}$ & $\begin{array}{l}\text { 4EC: } 1 \mathrm{pt} \\
2.67: 1.5 \mathrm{pts}\end{array}$ & 48 & 3 & $\begin{array}{l}\text { aphids, leafhoppers, } \\
\text { leafminers, thrips }\end{array}$ & 1B & Highly toxic to bees. \\
\hline $\begin{array}{l}\text { DiPel DF } \\
\text { (Bacillus thuringiensis } \\
\text { subspecies kurstaki) }\end{array}$ & $0.5-2.0 \mathrm{lb}$ & 4 & 0 & caterpillars & $11 \mathrm{~B} 2$ & $\begin{array}{l}\text { Treat when larvae are young. } \\
\text { Good coverage is essential. } \\
\text { OMRI-listed?2. }\end{array}$ \\
\hline
\end{tabular}


Table 14. Cotninued.

\begin{tabular}{|c|c|c|c|c|c|c|}
\hline $\begin{array}{l}\text { Trade Name } \\
\text { (Common Name) }\end{array}$ & $\begin{array}{l}\text { Rate } \\
\text { (product/acre) }\end{array}$ & $\begin{array}{l}\text { REI } \\
\text { (hours) }\end{array}$ & $\begin{array}{l}\text { Days to } \\
\text { Harvest }\end{array}$ & Insects & $\begin{array}{l}\text { MOA } \\
\text { Code } 1\end{array}$ & Notes \\
\hline $\begin{array}{l}\text { Endosulfan } 3 \text { EC } \\
\text { (endosulfan) }\end{array}$ & $0.66-1.33$ gts & 24 & 2 & $\begin{array}{l}\text { aphids, armyworms, cab- } \\
\text { bage looper, cucumber } \\
\text { beetles, flea beetles, } \\
\text { loopers, melonworm, } \\
\text { pickleworm, squash bee- } \\
\text { tle, squash bug, squash } \\
\text { vine borer, whiteflies }\end{array}$ & 2 & $\begin{array}{l}\text { Do not make more than six } \\
\text { applications per year or apply } \\
\text { more than } 3 \mathrm{lb} \text { active ingredient } \\
\text { per acre per year. }\end{array}$ \\
\hline $\begin{array}{l}\text { Entrust } \\
\text { (spinosad) }\end{array}$ & $1.25-2.5 \mathrm{oz}$ & 4 & 3 & $\begin{array}{l}\text { armyworms, cabbage } \\
\text { looper, leafminers, mel- } \\
\text { onworm, pickleworm, } \\
\text { rindworms, thrips }\end{array}$ & 5 & $\begin{array}{l}\text { No more than } 6 \text { applications per } \\
\text { crop or } 9 \text { oz per acre per crop. } \\
\text { OMRI-listed². }\end{array}$ \\
\hline $\begin{array}{l}\text { Esteem Ant Bait } \\
\text { (pyriproxyfen) }\end{array}$ & $1.5-2.0 \mathrm{lb}$ & 12 & 1 & red imported fire ant & $7 \mathrm{D}$ & $\begin{array}{l}\text { Apply when ants are actively } \\
\text { foraging. }\end{array}$ \\
\hline $\begin{array}{l}\text { Extinguish } \\
\text { ((S)-methoprene) }\end{array}$ & $1.0-1.5 \mathrm{lb}$ & 4 & 0 & fire ants & $7 \mathrm{~A}$ & $\begin{array}{l}\text { Slow-acting IGR (insect growth } \\
\text { regulator). Best applied early } \\
\text { spring and fall where crop will } \\
\text { be grown. Colonies will be } \\
\text { reduced after three weeks and } \\
\text { eliminated after } 8 \text { to } 10 \text { weeks. } \\
\text { May be applied by ground equip- } \\
\text { ment or aerially. }\end{array}$ \\
\hline $\begin{array}{l}\text { Fulfill } \\
\text { (pymetrozine) }\end{array}$ & $2.75 \mathrm{oz}$ & 12 & 0 & $\begin{array}{l}\text { green peach aphid, } \\
\text { melon aphid, suppres- } \\
\text { sion of whiteflies }\end{array}$ & $9 B$ & $\begin{array}{l}\text { Minimum of } 7 \text { days between } \\
\text { applications. }\end{array}$ \\
\hline $\begin{array}{l}\text { Intrepid 2F } \\
\text { (methoxyfenozide) }\end{array}$ & $4-10 \mathrm{fl} \mathrm{oz}$ & 4 & 3 & $\begin{array}{l}\text { beet armyworms, cab- } \\
\text { bage looper, melonworm, } \\
\text { pickleworm, rindworm, } \\
\text { wouthern armyworm, } \\
\text { true armyworm, yellow- } \\
\text { striped armyworm }\end{array}$ & 18 & $\begin{array}{l}\text { Do not make more than } 4 \text { appli- } \\
\text { cations per season. }\end{array}$ \\
\hline $\begin{array}{l}\text { Javelin WG } \\
\text { (Bacillus thuringiensis } \\
\text { subspecies kurstaki) }\end{array}$ & $0.12-1.50 \mathrm{lb}$ & 4 & 0 & $\begin{array}{l}\text { most caterpillars, but } \\
\text { not Spodoptera species } \\
\text { (armyworms) }\end{array}$ & $11 \mathrm{~B} 2$ & $\begin{array}{l}\text { Treat when larvae are young. } \\
\text { Thorough coverage is essential. } \\
\text { OMRI-listed }^{2} \text {. }\end{array}$ \\
\hline $\begin{array}{l}\text { Kelthane 50WSP } \\
\text { (dicofol) }\end{array}$ & $1.25 \mathrm{lb}$ & 48 & 2 & mites & 20 & $\begin{array}{l}\text { Do not apply more than twice } \\
\text { per season. }\end{array}$ \\
\hline $\begin{array}{l}\text { Knack IGR } \\
\text { (pyriproxyfen) }\end{array}$ & $8-10 \mathrm{fl} \mathrm{oz}$ & 12 & 7 & whiteflies (immatures) & $7 \mathrm{D}$ & $\begin{array}{l}\text { Do not apply more than twice } \\
\text { per season. }\end{array}$ \\
\hline $\begin{array}{l}\text { Kryocide } \\
\text { (cryolite) }\end{array}$ & $8-16 \mathrm{lb}$ & 12 & 14 & $\begin{array}{l}\text { cabbage looper, cucum- } \\
\text { ber beetles, flea beetles, } \\
\text { melonworm, pickleworm }\end{array}$ & $9 \mathrm{~A}$ & $\begin{array}{l}\text { Do not exceed } 64 \mathrm{lb} / \mathrm{acre} \text { per } \\
\text { season. }\end{array}$ \\
\hline $\begin{array}{l}\text { *Lannate LV, *SP } \\
\text { (methomyl) }\end{array}$ & $1.5-3.0 \mathrm{pt}$ & 48 & $\begin{array}{l}1=11 / 2 \\
\text { pts } \\
3=11 / 2+ \\
\text { pts }\end{array}$ & $\begin{array}{l}\text { aphids, beet armyworm, } \\
\text { cucumber beetles, fall } \\
\text { armyworm, flea beetles, } \\
\text { granulate cutworms, } \\
\text { loopers, melonworm, } \\
\text { pickleworm, tobacco } \\
\text { budworm, variegated } \\
\text { cutworm, yellowstriped } \\
\text { armyworm }\end{array}$ & $1 \mathrm{~A}$ & \\
\hline
\end{tabular}


Table 14. Cotninued.

\begin{tabular}{|c|c|c|c|c|c|c|}
\hline $\begin{array}{l}\text { Trade Name } \\
\text { (Common Name) }\end{array}$ & $\begin{array}{l}\text { Rate } \\
\text { (product/acre) }\end{array}$ & $\begin{array}{l}\text { REI } \\
\text { (hours) }\end{array}$ & $\begin{array}{l}\text { Days to } \\
\text { Harvest }\end{array}$ & Insects & $\begin{array}{l}\text { MOA } \\
\text { Code }^{1}\end{array}$ & Notes \\
\hline $\begin{array}{l}\text { Lepinox WDG } \\
\text { (Bacillus thuringiensis } \\
\text { subspecies kurstaki) }\end{array}$ & $1-2 \mathrm{lb}$ & 12 & 0 & $\begin{array}{l}\text { most caterpillars, includ- } \\
\text { ing beet armyworm (see } \\
\text { label) }\end{array}$ & $11 \mathrm{~B} 2$ & $\begin{array}{l}\text { Treat when larvae are small. } \\
\text { Thorough coverage is essential. }\end{array}$ \\
\hline $\begin{array}{l}\text { *MSR Spray } \\
\text { Concentrate (oxy- } \\
\text { demeton-methyl) }\end{array}$ & $1.5-2 \mathrm{pt}$ & 48 & 14 & aphids, mites & 1B & $\begin{array}{l}\text { Do not apply more than } 3 \text { times } \\
\text { per season. }\end{array}$ \\
\hline $\begin{array}{l}\text { M-Pede } \mathbf{4 9 \%} \text { EC } \\
\text { (Soap, insecticidal) }\end{array}$ & $1-2 \%$ V/V & 12 & 0 & $\begin{array}{l}\text { aphids, leafhoppers, } \\
\text { mites, thrips, whiteflies }\end{array}$ & -- & OMRI-listed². \\
\hline $\begin{array}{l}\text { Neemix } 4.5 \\
\text { (azadirachtin) }\end{array}$ & $4-16 \mathrm{fl} \mathrm{oz}$ & 12 & 0 & $\begin{array}{l}\text { fall armyworm, leafmin- } \\
\text { ers, pickleworm, rind- } \\
\text { worms, squash bug, } \\
\text { squash vine borer, tobac- } \\
\text { co budworm, whiteflies }\end{array}$ & 26 & $\begin{array}{l}\text { IGR and feeding repellant. } \\
\text { Greenhouse and field use. } \\
\text { OMRI-listed². }^{2}\end{array}$ \\
\hline $\begin{array}{l}\text { Oberon 2SC } \\
\text { (spiromesifen) }\end{array}$ & $7.0-8.5 \mathrm{fl} \mathrm{oz}$ & 12 & 7 & $\begin{array}{l}\text { twospotted spider mite, } \\
\text { whiteflies }\end{array}$ & 23 & $\begin{array}{l}\text { Maximum amount per crop: } \\
25.5 \mathrm{fl} \text { oz acre. No more than } 3 \\
\text { applications. }\end{array}$ \\
\hline $\begin{array}{l}\text { Platinum } \\
\text { (thiamethoxam) }\end{array}$ & $5-8 \mathrm{fl} \mathrm{oz}$ & 12 & 30 & $\begin{array}{l}\text { aphids, flea beetles, } \\
\text { whiteflies }\end{array}$ & $4 \mathrm{~A}$ & $\begin{array}{l}\text { For most crops that are not on } \\
\text { the label, a 120-day plant-back } \\
\text { interval must be observed. }\end{array}$ \\
\hline $\begin{array}{l}\text { *Pounce } 3.2 \text { EC (per- } \\
\text { methrin) }\end{array}$ & $4-80 z$ & 12 & 0 & $\begin{array}{l}\text { aphids, cabbage looper, } \\
\text { cucumber beetles, cut- } \\
\text { worms, leafhoppers, } \\
\text { leafminers, lygus bug, } \\
\text { melonworm, pickleworm, } \\
\text { plant bugs, rindworms, } \\
\text { squash vine borer, stink } \\
\text { bugs }\end{array}$ & 3 & \\
\hline $\begin{array}{l}\text { Pyrellin EC } \\
\text { (pyrethrin + rotenone) }\end{array}$ & $1-2 \mathrm{pt}$ & 12 & 12 & $\begin{array}{l}\text { aphids, leafhoppers, } \\
\text { leafminers, loopers, } \\
\text { lygus bug, mites, plant } \\
\text { bugs, thrips, whiteflies }\end{array}$ & 3,21 & \\
\hline $\begin{array}{l}\text { Sevin 80S, 4F, XLR } \\
\text { (carbaryl) }\end{array}$ & $\begin{array}{l}\text { 80S: } 0.63-1.25 \\
\text { lb } \\
\text { 4F, XLR: } 0.5- \\
1.0 \text { qt }\end{array}$ & 12 & 3 & $\begin{array}{l}\text { ants, cucumber beetles, } \\
\text { flea beetles, grasshop-- } \\
\text { pers, leafhoppers, mel- } \\
\text { onworm, pickleworm, } \\
\text { squash bug }\end{array}$ & $1 \mathrm{~A}$ & \\
\hline $\begin{array}{l}\text { SpinTor } 2 \text { SC } \\
\text { (spinosad) }\end{array}$ & $4-8 \mathrm{fl} \mathrm{oz}$ & 4 & 3 & $\begin{array}{l}\text { armyworms, cabbage } \\
\text { looper, leafminers, mel- } \\
\text { onworm, pickleworm, } \\
\text { rindworms, thrips }\end{array}$ & 5 & $\begin{array}{l}\text { Do not apply more than } 3 \text { times } \\
\text { in a } 21 \text {-day period. Rotate to a } \\
\text { different class of product for } 21 \\
\text { days. }\end{array}$ \\
\hline Sulfur, others & See label & 24 & 1 & mites & -- & \\
\hline $\begin{array}{l}\text { Sun Spray } 98.8 \% \text {, } \\
\text { JMS Stylet-0il, others } \\
\text { (Oil, insecticidal) }\end{array}$ & $\begin{array}{l}3-6 \mathrm{qts} / 100 \mathrm{gal} \\
\text { (JMS) }\end{array}$ & 4 & 0 & $\begin{array}{l}\text { aphid-transmitted viruses } \\
\text { (JMS), leafhoppers, } \\
\text { leafminers, mites, thrips, } \\
\text { whiteflies }\end{array}$ & -- & $\begin{array}{l}\text { See label for cautions on tank } \\
\text { mixes. Organic Stylet-oil is } \\
\text { OMRI-listed? }\end{array}$ \\
\hline $\begin{array}{l}\text { *Telone C-35 (dichlo- } \\
\text { ropropene + chloro- } \\
\text { picrin) } \\
\text { *Telone II } \\
\text { (dichloropropene) }\end{array}$ & See label & $\begin{array}{l}5 \text { days } \\
\text { (See } \\
\text { label) }\end{array}$ & preplant & symphylans, wireworms & -- & $\begin{array}{l}\text { See supplemental label for use } \\
\text { restrictions in south and central } \\
\text { Florida. }\end{array}$ \\
\hline
\end{tabular}


Table 14. Cotninued.

\begin{tabular}{|c|c|c|c|c|c|c|}
\hline $\begin{array}{l}\text { Trade Name } \\
\text { (Common Name) }\end{array}$ & $\begin{array}{l}\text { Rate } \\
\text { (product/acre) }\end{array}$ & $\begin{array}{l}\text { REI } \\
\text { (hours) }\end{array}$ & $\begin{array}{l}\text { Days to } \\
\text { Harvest }\end{array}$ & Insects & $\begin{array}{l}\text { MOA } \\
\text { Code }^{1}\end{array}$ & Notes \\
\hline $\begin{array}{l}\text { Trigard } \\
\text { (cyromazine) }\end{array}$ & $2.66 \mathrm{oz}$ & 12 & 0 & leafminers & 17 & $\begin{array}{l}\text { Do not make more than } 6 \text { appli- } \\
\text { cations. }\end{array}$ \\
\hline $\begin{array}{l}\text { Trilogy } \\
\text { (extract of neem oil) }\end{array}$ & $0.5-2.0 \% \mathrm{~V} / \mathrm{V}$ & 4 & 0 & $\begin{array}{l}\text { aphids, mites, sup- } \\
\text { pression of thrips and } \\
\text { whiteflies }\end{array}$ & 26 & $\begin{array}{l}\text { Apply morning or evening to } \\
\text { reduce potential for leaf burn. } \\
\text { Toxic to bees exposed to direct } \\
\text { treatment. OMRI-listed². }\end{array}$ \\
\hline $\begin{array}{l}\text { Venom } \\
\text { (dinotefuran) }\end{array}$ & $\begin{array}{l}\text { foliar: } 1-4 \text { oz } \\
\text { soil: } 5-6 \text { oz }\end{array}$ & 12 & $\begin{array}{l}\text { foliar - } 1 \\
\text { soil - } 21\end{array}$ & $\begin{array}{l}\text { green peach aphid, } \\
\text { leafhoppers, leafmin- } \\
\text { ers, melon aphid, thrips, } \\
\text { whiteflies }\end{array}$ & $4 \mathrm{~A}$ & $\begin{array}{l}\text { Do not apply more than } 6 \text { oz per } \\
\text { acre per season (foliar) or } 12 \\
\text { oz per acre per season (soil). } \\
\text { Do not use both application } \\
\text { methods. }\end{array}$ \\
\hline $\begin{array}{l}\text { *Vydate L } \\
\text { (oxamyl) }\end{array}$ & $2-4 \mathrm{pt}$ & 48 & 1 & aphids, leafminers, thrips & $1 \mathrm{~A}$ & \\
\hline $\begin{array}{l}\text { Xentari DF } \\
\text { (Bacillus thuringiensis } \\
\text { subspecies aizawai) }\end{array}$ & $0.5-2.0 \mathrm{lb}$ & 4 & 0 & caterpillars & $11 \mathrm{~B} 1$ & $\begin{array}{l}\text { Treat when larvae are young. } \\
\text { Thorough coverage is essential. } \\
\text { May be used in the greenhouse. } \\
\text { Can be used in organic produc- } \\
\text { tion. }\end{array}$ \\
\hline
\end{tabular}

The pesticide information presented in this table was current with federal and state regulations at the time of revision. The user is responsible for determining the intended use is consistent with the label of the product being used. Use pesticides safely. Read and follow label instructions.

${ }^{1}$ Mode of Action codes for vegetable pest insecticides from the Insecticide Resistance Action Committee (IRAC) Mode of Action Classification v.3.3 October 2003. 1A. Acetylcholine esterase inhibitors, Carbamates 1B. Acetylcholine esterase inhibitors, Organophosphates

2A. GABA-gated chloride channel antagonists

$3 . \quad$ Sodium channel modulators

4A. Nicotinic Acetylcholine receptor agonists/antagonists, Neonicotinoids

5. $\quad$ Nicotinic Acetylcholine receptor agonists (not group 4)

6. Chloride channel activators

7A. Juvenile hormone mimics, Juvenile hormone analogues

7D. Juvenile hormone mimics, Pyriproxifen

9A. Compounds of unknown or non-specific mode of action (selective feeding blockers), Cryolite

9B. Compounds of unknown or non-specific mode of action (selective feeding blockers), Pymetrozine

11B1. Microbial disruptors of insect midgut membranes, B.t. var aizawai

11B2. Microbial disruptors of insect midgut membranes, B.t. var kurstaki

12B. Inhibitors of oxidative phosphorylation, disruptors of ATP formation, Organotin miticide

15. Inhibitors of chitin biosynthesis, type 0, Lepidopteran

16. Inhibitors of chitin biosynthesis, type 1, Homopteran

17. Inhibitors of chitin biosynthesis, type 2, Dipteran

18. Ecdysone agonist/disruptor

20. Site II electron transport inhibitors

21. Site I electron transport inhibitors

22. Voltage-dependent sodium channel blocker

23. Inhibitors of lipid biosynthesis

25. Neuroactive (unknown mode of action)

26. Unknown mode of action, Azadirachtin

2 OMRI listed: Listed by the Organic Materials Review Institute for use in organic production.

* Restricted Use Pesticide 
Table 15. Selected insecticides approved for use on insects attacking watermelon.

\begin{tabular}{|c|c|c|c|c|c|c|}
\hline $\begin{array}{l}\text { Trade Name } \\
\text { (Common Name) }\end{array}$ & $\begin{array}{l}\text { Rate } \\
\text { (product/acre) }\end{array}$ & $\begin{array}{l}\text { REI } \\
\text { (hours) }\end{array}$ & $\begin{array}{l}\text { Days to } \\
\text { Harvest }\end{array}$ & Insects & $\begin{array}{l}\text { MOA } \\
\text { Code }^{1}\end{array}$ & Notes \\
\hline $\begin{array}{l}\text { Acramite-50ws } \\
\text { (bifenazate) }\end{array}$ & $0.75-1.0 \mathrm{lb}$ & 12 & 3 & twospotted spider mite & 25 & One application per season. \\
\hline $\begin{array}{l}\text { Admire } 2 \mathrm{~F} \\
\text { (imidacloprid) }\end{array}$ & $16-24 \mathrm{oz}$ & 12 & 21 (soil) & $\begin{array}{l}\text { aphids, cucumber beetles, } \\
\text { leafhoppers, thrips, white- } \\
\text { flies }\end{array}$ & $4 \mathrm{~A}$ & Will not control thrips in flowers. \\
\hline Admire Pro & $7-10.5 \mathrm{oz}$ & & & & & \\
\hline $\begin{array}{l}\text { Admire } 2 \mathrm{~F} \\
\text { (imidacloprid) }\end{array}$ & $\begin{array}{l}0.1 \mathrm{fl} \mathrm{oz/1000} \\
\text { plants }\end{array}$ & 12 & 21 & aphids, whiteflies & $4 \mathrm{~A}$ & $\begin{array}{l}\text { Planthouse: One application to } \\
\text { transplants. }\end{array}$ \\
\hline Admire Pro & $\begin{array}{l}0.44 \mathrm{fl} \mathrm{oz/} \\
10,000 \text { plants }\end{array}$ & & & & & \\
\hline $\begin{array}{l}\text { Agree WG } \\
\text { (Bacillus thuringiensis } \\
\text { subspecies aizawai) }\end{array}$ & $0.5-2.0 \mathrm{lb}$ & 4 & 0 & $\begin{array}{l}\text { lepidopteran larvae (cater- } \\
\text { pillar pests) }\end{array}$ & $11 \mathrm{~B} 1$ & $\begin{array}{l}\text { Apply when larvae are small for } \\
\text { best control. OMRI-listed². }\end{array}$ \\
\hline $\begin{array}{l}\text { *Agri-Mek } 0.15 \text { EC } \\
\text { (abamectin) }\end{array}$ & $8-16 \mathrm{fl} \mathrm{oz}$ & 12 & 7 & leafminers, spider mites & 6 & $\begin{array}{l}\text { Minimum 7-day int. No more } \\
\text { than } 2 \text { sequential applications. }\end{array}$ \\
\hline $\begin{array}{l}\text { *Ambush 25W } \\
\text { (permethrin) }\end{array}$ & $6.4-12.8 \mathrm{oz}$ & 12 & 0 & $\begin{array}{l}\text { cabbage looper, cucum- } \\
\text { ber beetles, cutworms, } \\
\text { leafminers, lygus bug, } \\
\text { melonworm, pickleworm, } \\
\text { plant bugs, rindworms, } \\
\text { squash vine borer, stink } \\
\text { bugs }\end{array}$ & 3 & $\begin{array}{l}\text { Do not apply more than } 102.4 \mathrm{oz} \\
\text { of product per acre per season. }\end{array}$ \\
\hline $\begin{array}{l}\text { *Asana XL (0.66 EC) } \\
\text { (esfenvalerate) }\end{array}$ & $5.8-9.6 \mathrm{fl} \mathrm{oz}$ & 12 & 3 & $\begin{array}{l}\text { cabbage looper, corn ear- } \\
\text { worm, cucumber beetles } \\
\text { (adults), cutworms (seed- } \\
\text { ling spray), grasshoppers, } \\
\text { leafhoppers, lygus bug, } \\
\text { rindworms, squash bug, } \\
\text { squash vine borer, stink } \\
\text { bugs }\end{array}$ & 3 & $\begin{array}{l}\text { Do not apply more than } 0.25 \mathrm{lb} \\
\text { ai/acre per season, (or } 5 \text { applica- } \\
\text { tions at high rate). }\end{array}$ \\
\hline $\begin{array}{l}\text { Aza-Direct } \\
\text { (azadirachtin) }\end{array}$ & $\begin{array}{l}1-2 \mathrm{pts} \text {, up } \\
\text { to } 3.5 \mathrm{pts} \text {, if } \\
\text { needed }\end{array}$ & 4 & 0 & $\begin{array}{l}\text { aphids, beetles, caterpil- } \\
\text { lars, leafhoppers, leafmin- } \\
\text { ers, mites, stink bugs, } \\
\text { thrips, weevils, whiteflies }\end{array}$ & 26 & $\begin{array}{l}\text { Antifeedant, repellant, insect } \\
\text { growth regulator. OMRI-listed }{ }^{2} \text {. }\end{array}$ \\
\hline $\begin{array}{l}\text { Azatin XL } \\
\text { (azadirachtin) }\end{array}$ & $5-21 \mathrm{fl} \mathrm{oz}$ & 4 & 0 & $\begin{array}{l}\text { aphids, beetles, caterpil- } \\
\text { lars, leafhoppers, leafmin- } \\
\text { ers, thrips, weevils, } \\
\text { whiteflies }\end{array}$ & 26 & $\begin{array}{l}\text { Antifeedant, repellant, insect } \\
\text { growth regulator. }\end{array}$ \\
\hline $\begin{array}{l}\text { Baythroid } 2 \\
\text { (cyfluthrin) }\end{array}$ & $0.8-2.8 \mathrm{fl} \mathrm{oz}$ & 12 & 0 & $\begin{array}{l}\text { armyworm, cabbage } \\
\text { looper, corn earworm, } \\
\text { cucumber beetles, cut- } \\
\text { worms, grasshoppers, } \\
\text { melonworm, pickleworm, } \\
\text { rindworms, tobacco bud- } \\
\text { worm }\end{array}$ & 3 & $\begin{array}{l}\text { Apply no more than } 4 \text { times per } \\
\text { season. }\end{array}$ \\
\hline $\begin{array}{l}\text { Biobit HP } \\
\text { (Bacillus thuringiensis } \\
\text { subspecies kurstaki) }\end{array}$ & $0.5-2.0 \mathrm{lb}$ & 4 & 0 & $\begin{array}{l}\text { caterpillars (will not con- } \\
\text { trol large armyworms) }\end{array}$ & 11B2 & $\begin{array}{l}\text { Treat when larvae are young. } \\
\text { Good coverage is essential. } \\
\text { Can be used in the greenhouse. } \\
\text { OMRI-listed². }\end{array}$ \\
\hline $\begin{array}{l}\text { BotaniGard } 22 \text { WP, ES } \\
\text { (Beauveria bassiana) }\end{array}$ & $\begin{array}{l}\text { WP: } \\
0.5-2 \mathrm{lb} / 100 \mathrm{gal} \\
\text { ES: } \\
0.5-2 \mathrm{gt} / 100 \\
\text { gal }\end{array}$ & 4 & 0 & aphids, thrips, whiteflies & -- & $\begin{array}{l}\text { May be used in greenhouses. } \\
\text { Contact dealer for recommen- } \\
\text { dations if an adjuvant must be } \\
\text { used. Not compatible in tank mix } \\
\text { with fungicides. }\end{array}$ \\
\hline
\end{tabular}


Table 15. Continued.

\begin{tabular}{|c|c|c|c|c|c|c|}
\hline $\begin{array}{l}\text { Trade Name } \\
\text { (Common Name) }\end{array}$ & $\begin{array}{l}\text { Rate } \\
\text { (product/acre) }\end{array}$ & $\begin{array}{l}\text { REI } \\
\text { (hours) }\end{array}$ & $\begin{array}{l}\text { Days to } \\
\text { Harvest }\end{array}$ & Insects & $\begin{array}{l}\text { MOA } \\
\text { Code }^{1}\end{array}$ & Notes \\
\hline $\begin{array}{l}\text { *Capture 2 EC } \\
\text { (bifenthrin) }\end{array}$ & $2.6-6.4 \mathrm{fl} \mathrm{oz}$ & 12 & 3 & $\begin{array}{l}\text { aphids, armyworms, } \\
\text { cabbage looper, corn ear- } \\
\text { worm, cucumber beetles, } \\
\text { cutworms, grasshoppers, } \\
\text { leafhoppers, melonworm, } \\
\text { mites, pickleworm, plant } \\
\text { bugs, rindworms, squash } \\
\text { bug, squash vine borer, } \\
\text { stink bugs, tobacco bud- } \\
\text { worm }\end{array}$ & 3 & $\begin{array}{l}\text { Do not apply more than } 19.2 \\
\text { ounces of product per acre per } \\
\text { season. Do not make more than } \\
2 \text { applications after bloom. }\end{array}$ \\
\hline $\begin{array}{l}\text { Courier 70WP, 40SC } \\
\text { (buprofezin) }\end{array}$ & $\begin{array}{l}\text { 70WP: } 6-9 \text { oz } \\
\text { 40SC: } 9-13.6 \\
\text { fl oz }\end{array}$ & 12 & 7 & whitefly nymphs & 16 & $\begin{array}{l}\text { Insect growth regulator. Do not } \\
\text { make more than } 2 \text { applications } \\
\text { per season per crop. Do not plant } \\
\text { food crops except those on the } \\
\text { label within } 120 \text { days following } \\
\text { application. }\end{array}$ \\
\hline $\begin{array}{l}\text { Crymax WDG } \\
\text { (Bacillus thuringiensis } \\
\text { subspecies kurstaki) }\end{array}$ & $0.5-2.0 \mathrm{lb}$ & 4 & 0 & caterpillars & 11B2 & $\begin{array}{l}\text { Use high rate for armyworms. } \\
\text { Treat when larvae are young. }\end{array}$ \\
\hline $\begin{array}{l}\text { *Danitol 2.4 EC } \\
\text { (fenpropathrin) }\end{array}$ & $10.67 \mathrm{fl} \mathrm{oz}$ & 24 & 7 & $\begin{array}{l}\text { banded cucumber beetle, } \\
\text { cabbage looper, fall army- } \\
\text { worm, green stink bug, } \\
\text { plant bug, striped cucum- } \\
\text { ber beetle, twospotted } \\
\text { spider mite, yellowstriped } \\
\text { armyworm } \\
\text { NOTE: mix with endosul- } \\
\text { fan for aphid, thrips, and } \\
\text { whitefly control. }\end{array}$ & 3 & $\begin{array}{l}\text { Do not exceed } 42.67 \mathrm{fl} \text { oz per } \\
\text { acre per season. }\end{array}$ \\
\hline $\begin{array}{l}\text { Deliver } \\
\text { (Bacillus thuringiensis } \\
\text { subspecies kurstaki) }\end{array}$ & $0.25-1.5 \mathrm{lb}$ & 4 & 0 & caterpillars & $11 \mathrm{~B} 2$ & $\begin{array}{l}\text { Use higher rates for armyworms. } \\
\text { OMRI-listed? }\end{array}$ \\
\hline \multirow[t]{2}{*}{$\begin{array}{l}\text { *Diazinon } 4 \mathrm{E},{ }^{*} 50 \mathrm{~W} \\
\text { (diazinon) }\end{array}$} & $\begin{array}{l}\text { foliar - } \\
\text { AG500, 4E: } \\
0.5-1.5 \mathrm{pt} \\
\text { 50W: } 0.5-1.5 \mathrm{lb}\end{array}$ & 24 & 3 & $\begin{array}{l}\text { aphids, cucumber beetles, } \\
\text { leafhoppers, leafminers, } \\
\text { mites, thrips }\end{array}$ & 1B & $\begin{array}{l}\text { Will not control organophos- } \\
\text { phate- resistant leafminers. Do } \\
\text { not apply more than } 5 \text { times. } \\
\text { (foliar) }\end{array}$ \\
\hline & $\begin{array}{l}\text { preplant - } \\
\text { AG500, 4E: 2- } \\
4 \text { qts } \\
50 W: 4-8 \mathrm{lb}\end{array}$ & & preplant & cutworms, wireworms & & \\
\hline $\begin{array}{l}\text { Dimethoate } 4 \text { EC, } 2.67 \\
\text { EC } \\
\text { (dimethoate) }\end{array}$ & $\begin{array}{l}\text { 4EC: } 0.5-2 \mathrm{pt} \\
2.67: 0.75- \\
1.5 \mathrm{pt}\end{array}$ & 48 & 3 & $\begin{array}{l}\text { aphids, leafhoppers, } \\
\text { leafminers, maggots }\end{array}$ & $1 \mathrm{~B}$ & Highly toxic to bees. \\
\hline $\begin{array}{l}\text { DiPel DF } \\
\text { (Bacillus thuringiensis } \\
\text { subspecies kurstaki) }\end{array}$ & $0.5-2.0 \mathrm{lb}$ & 4 & 0 & caterpillars & 11B2 & $\begin{array}{l}\text { Treat when larvae are young. } \\
\text { Good coverage is essential. } \\
\text { OMRI-listed². }^{2} \text {. }\end{array}$ \\
\hline $\begin{array}{l}\text { Endosulfan } 3 \text { EC } \\
\text { (endosulfan) }\end{array}$ & $0.66-1.33 \mathrm{qt}$ & 24 & 2 & $\begin{array}{l}\text { aphids, cabbage looper, } \\
\text { cucumber beetles, flea } \\
\text { beetles, loopers, melon- } \\
\text { worm, omnivorous lea- } \\
\text { froller, pickleworm, rind- } \\
\text { worms, squash beetle, } \\
\text { squash bug, squash vine } \\
\text { borer, whiteflies }\end{array}$ & 2 & $\begin{array}{l}\text { Do not make more than } 6 \text { appli- } \\
\text { cations per year or exceed } 3.0 \\
\text { lb active ingredient per acre per } \\
\text { year. }\end{array}$ \\
\hline
\end{tabular}


Chapter 27: Cucurbit Production in Florida

Table 15. Continued.

\begin{tabular}{|c|c|c|c|c|c|c|}
\hline $\begin{array}{l}\text { Trade Name } \\
\text { (Common Name) }\end{array}$ & $\begin{array}{l}\text { Rate } \\
\text { (product/acre) }\end{array}$ & $\begin{array}{l}\text { REI } \\
\text { (hours) }\end{array}$ & $\begin{array}{l}\text { Days to } \\
\text { Harvest }\end{array}$ & Insects & $\begin{array}{l}\text { MOA } \\
\text { Code } 1\end{array}$ & Notes \\
\hline $\begin{array}{l}\text { Entrust } \\
\text { (spinosad) }\end{array}$ & $1.25-2.5 \mathrm{oz}$ & 4 & 3 & $\begin{array}{l}\text { armyworms, cabbage } \\
\text { looper, leafminers, loop- } \\
\text { ers, melonworm, pickle- } \\
\text { worm, rindworms, thrips }\end{array}$ & 5 & $\begin{array}{l}\text { Do not apply more than } 6 \text { times } \\
\text { or } 9 \text { oz per acre per crop. OMRI- } \\
\text { listed². }\end{array}$ \\
\hline $\begin{array}{l}\text { Esteem Ant Bait } \\
\text { (pyriproxyfen) }\end{array}$ & $1.5-2.0 \mathrm{lb}$ & 12 & 1 & red imported fire ant & $7 \mathrm{D}$ & $\begin{array}{l}\text { Apply when ants are actively } \\
\text { foraging. }\end{array}$ \\
\hline $\begin{array}{l}\text { Extinguish } \\
\text { ((S)-methoprene) }\end{array}$ & $1.0-1.5 \mathrm{lb}$ & 4 & 0 & fire ants & $7 \mathrm{~A}$ & $\begin{array}{l}\text { Slow-acting IGR (insect growth } \\
\text { regulator). Best applied early } \\
\text { spring and fall where crop will be } \\
\text { grown. Colonies will be reduced } \\
\text { after three weeks and eliminated } \\
\text { after } 8 \text { to } 10 \text { weeks. May be } \\
\text { applied by ground equipment or } \\
\text { aerially. }\end{array}$ \\
\hline $\begin{array}{l}\text { Fulfill } \\
\text { (pymetrozine) }\end{array}$ & $2.75 \mathrm{oz}$ & 12 & 0 & $\begin{array}{l}\text { green peach aphid, melon } \\
\text { aphid, suppression of } \\
\text { whiteflies }\end{array}$ & $9 B$ & $\begin{array}{l}\text { Minimum of } 7 \text { days between } \\
\text { applications. Maximum } 5.5 \text { oz/ } \\
\text { acre/season. }\end{array}$ \\
\hline $\begin{array}{l}\text { Intrepid 2F } \\
\text { (methoxyfenopzide) }\end{array}$ & $4-10$ oz & 4 & 3 & $\begin{array}{l}\text { beet armyworm, cab- } \\
\text { bage looper, melonworm, } \\
\text { pickleworm, rindworm, } \\
\text { southern armyworm, true } \\
\text { armyworm, yellowstriped } \\
\text { armyworm }\end{array}$ & 18 & $\begin{array}{l}\text { Do not make more than } 4 \text { appli- } \\
\text { cations per season. }\end{array}$ \\
\hline $\begin{array}{l}\text { Javelin WG } \\
\text { (Bacillus thuringiensis } \\
\text { subspecies kurstaki) }\end{array}$ & $0.12-1.50 \mathrm{lb}$ & 4 & 0 & $\begin{array}{l}\text { most caterpillars, but } \\
\text { not Spodoptera species } \\
\text { (armyworms) }\end{array}$ & $11 \mathrm{~B} 2$ & $\begin{array}{l}\text { Treat when larvae are young. } \\
\text { Thorough coverage is essential. } \\
\text { OMRI-listed². }\end{array}$ \\
\hline $\begin{array}{l}\text { Kelthane 50WSP } \\
\text { (dicofol) }\end{array}$ & $1.25 \mathrm{lb}$ & 48 & 2 & mites & 20 & $\begin{array}{l}\text { Do not apply more than twice per } \\
\text { season. }\end{array}$ \\
\hline $\begin{array}{l}\text { Knack IGR } \\
\text { (pyriproxyfen) }\end{array}$ & $8-10 \mathrm{fl} \mathrm{oz}$ & 12 & 7 & whiteflies (immatures) & $7 \mathrm{D}$ & $\begin{array}{l}\text { Do not apply more than twice per } \\
\text { season. }\end{array}$ \\
\hline $\begin{array}{l}\text { Kryocide } \\
\text { (cyrolite) }\end{array}$ & $8-16 \mathrm{lb}$ & 12 & 14 & $\begin{array}{l}\text { cabbage looper, } \\
\text { Diabrotica beetles } \\
\text { (cucumber beetles), flea } \\
\text { beetles, melonworm, } \\
\text { pickleworm }\end{array}$ & $9 A$ & $\begin{array}{l}\text { Do not exceed } 64 \mathrm{lb} / \text { acre per } \\
\text { season. }\end{array}$ \\
\hline $\begin{array}{l}\text { *Lannate LV } \\
\text { (methomyl) }\end{array}$ & LV: $1.5-3.0 \mathrm{pt}$ & 48 & $\begin{array}{l}1=11 / 2 \\
\text { pts } \\
3=11 / 2+ \\
\text { pts }\end{array}$ & $\begin{array}{l}\text { aphids, beet armyworm, } \\
\text { cucumber beetles, fall } \\
\text { armyworm, flea beetles, } \\
\text { granulate cutworms, } \\
\text { loopers, melonworm, } \\
\text { pickleworm, tobacco } \\
\text { budworm, variegated } \\
\text { cutworm, yellowstriped } \\
\text { armyworm }\end{array}$ & $1 \mathrm{~A}$ & \\
\hline $\begin{array}{l}\text { *Lannate SP } \\
\text { (methomyl) }\end{array}$ & SP: $0.5-1.0 \mathrm{lb}$ & 48 & $\begin{array}{l}1=1 / 2 \mathrm{lb} \\
3=1 / 2+ \\
\mathrm{lb}\end{array}$ & See above & & \\
\hline $\begin{array}{l}\text { Lepinox WDG } \\
\text { (Bacillus thuringiensis } \\
\text { subspecies kurstaki) }\end{array}$ & $1.0-2.0 \mathrm{lb}$ & 12 & 0 & $\begin{array}{l}\text { for most caterpillars, } \\
\text { including beet armyworm } \\
\text { (see label) }\end{array}$ & $11 \mathrm{~B} 2$ & $\begin{array}{l}\text { Treat when larvae are small. } \\
\text { Thorough coverage is essential. }\end{array}$ \\
\hline $\begin{array}{l}\text { M-Pede } \mathbf{4 9 \%} \text { EC } \\
\text { (Soap, Insecticidal) }\end{array}$ & $1-2 \% \mathrm{~V} / \mathrm{V}$ & 12 & 0 & $\begin{array}{l}\text { aphids, leafhoppers, } \\
\text { mites, plant bugs, thrips, } \\
\text { whiteflies }\end{array}$ & - & OMRI-listed². \\
\hline
\end{tabular}


Table 15. Continued.

\begin{tabular}{|c|c|c|c|c|c|c|}
\hline $\begin{array}{l}\text { Trade Name } \\
\text { (Common Name) }\end{array}$ & $\begin{array}{l}\text { Rate } \\
\text { (product/acre) }\end{array}$ & $\begin{array}{l}\text { REI } \\
\text { (hours) }\end{array}$ & $\begin{array}{l}\text { Days to } \\
\text { Harvest }\end{array}$ & Insects & $\begin{array}{l}\text { MOA } \\
\text { Code }^{1}\end{array}$ & Notes \\
\hline $\begin{array}{l}\text { *MSR Spray } \\
\text { Concentrate (oxy- } \\
\text { demeton-methyl) }\end{array}$ & $1.5-2.0 \mathrm{pt}$ & 48 & 7 & aphids, mites & $1 \mathrm{~B}$ & $\begin{array}{l}\text { Do not apply more than } 2 \text { times } \\
\text { per season. }\end{array}$ \\
\hline $\begin{array}{l}\text { Neemix } 4.5 \\
\text { (azadirachtin) }\end{array}$ & $4-16 \mathrm{fl} \mathrm{oz}$ & 12 & 0 & $\begin{array}{l}\text { fall armyworm, leafmin- } \\
\text { ers, melonworm, pick- } \\
\text { leworm, rindworms, } \\
\text { squash bug, squash vine } \\
\text { borer, tobacco budworm, } \\
\text { whiteflies }\end{array}$ & 26 & $\begin{array}{l}\text { IGR and feeding repellant. } \\
\text { Greenhouse and field use. OMRI- } \\
\text { listed }^{2} \text {. }\end{array}$ \\
\hline $\begin{array}{l}\text { Oberon 2SC } \\
\text { (spiromesifen) }\end{array}$ & $7.0-8.5 \mathrm{fl} \mathrm{oz}$ & 12 & 7 & $\begin{array}{l}\text { twospotted spider mite, } \\
\text { whiteflies }\end{array}$ & 23 & $\begin{array}{l}\text { Maximum amount per crop: } 25.5 \\
\text { fl oz/acre. No more than } 3 \text { appli- } \\
\text { cations. }\end{array}$ \\
\hline $\begin{array}{l}\text { Oil, Insecticidal } \\
\text { SunSpray } 98.8 \% \\
\text { Ulta-Fine } \\
\text { JMS Stylet Oil } \\
\text { Others }\end{array}$ & $\begin{array}{l}3-6 \mathrm{qts} / 100 \mathrm{gal} \\
\text { (JMS) }\end{array}$ & 4 & 0 & $\begin{array}{l}\text { aphids, leafhoppers, } \\
\text { leafminers, mites, thrips, } \\
\text { whiteflies, aphid-transmit- } \\
\text { ted viruses (JMS) }\end{array}$ & -- & $\begin{array}{l}\text { Organic Stylet-0il is } \\
\text { OMRI-listed }^{2} \text {. }\end{array}$ \\
\hline $\begin{array}{l}\text { Platinum } \\
\text { (thiamethoxam) }\end{array}$ & $5-8 \mathrm{fl} \mathrm{oz}$ & 12 & 30 & $\begin{array}{l}\text { aphids, flea beetles, } \\
\text { whiteflies }\end{array}$ & $4 \mathrm{~A}$ & $\begin{array}{l}\text { For most crops that are not on } \\
\text { the label, a 120-day plant-back } \\
\text { interval must be observed. }\end{array}$ \\
\hline $\begin{array}{l}\text { *Pounce } 3.2 \text { EC (per- } \\
\text { methrin) }\end{array}$ & $4-80 z$ & 12 & 0 & $\begin{array}{l}\text { aphids, cabbage looper, } \\
\text { cucumber beetles, cut- } \\
\text { worms, leafhoppers, } \\
\text { leafminers, Lygus bug, } \\
\text { melonworm, pickleworm, } \\
\text { plant bugs, rindworms, } \\
\text { squash vine borer, stink } \\
\text { bugs }\end{array}$ & 3 & \\
\hline $\begin{array}{l}\text { Prokil Cryolite } 96 \\
\text { (cyrolite) }\end{array}$ & 8-16 lb & 12 & 14 & $\begin{array}{l}\text { cabbage looper, } \\
\text { Diabrotica beetles (cum- } \\
\text { cumber beetles), flea } \\
\text { beetles, melonworm, } \\
\text { pickleworm }\end{array}$ & $9 \mathrm{~A}$ & \\
\hline $\begin{array}{l}\text { Pyrellin EC } \\
\text { (pyrethrin + rotenone) }\end{array}$ & $1-2 \mathrm{pt}$ & 12 & 12 hours & $\begin{array}{l}\text { aphids, leafhoppers, } \\
\text { leafminers, loopers, lygus } \\
\text { bug, mites, plant bugs, } \\
\text { thrips, whiteflies }\end{array}$ & 3,21 & $\begin{array}{l}\text { Can be used on greenhouse veg- } \\
\text { etables. }\end{array}$ \\
\hline $\begin{array}{l}\text { Pyronyl Crop Spray } \\
\text { (pyrethrin + piperonyl } \\
\text { butoxide) }\end{array}$ & $1-12 \mathrm{fl} \mathrm{oz}$ & 12 & 12 hours & $\begin{array}{l}\text { ants, aphids, armyworms, } \\
\text { cabbage looper, corn ear- } \\
\text { worm, cucumber beetles, } \\
\text { flea beetles, leafhoppers, } \\
\text { thrips, whiteflies }\end{array}$ & 3 & $\begin{array}{l}\text { Can be used on greenhouse veg- } \\
\text { etables. }\end{array}$ \\
\hline $\begin{array}{l}\text { Sevin 80S, 4F, XLR } \\
\text { (carbaryl) }\end{array}$ & $\begin{array}{l}\text { 80S: } 0.63-1.25 \\
\text { lb } \\
\text { 4F, XLR: } 0.5- \\
1.0 \text { qt }\end{array}$ & 12 & 3 & $\begin{array}{l}\text { cucumber beetles, flea } \\
\text { beetles, leafhoppers, } \\
\text { melonworm, pickleworm, } \\
\text { squash bug }\end{array}$ & $1 \mathrm{~A}$ & $\begin{array}{l}\text { Do not apply more than } 7.5 \mathrm{lb} \text { or } \\
6 \text { qt per acre per year. }\end{array}$ \\
\hline $\begin{array}{l}\text { SpinTor } 2 \text { SC } \\
\text { (spinosad) }\end{array}$ & 4-8 fl oz & 4 & 3 & $\begin{array}{l}\text { armyworms, cabbage } \\
\text { looper, leafminers, melon- } \\
\text { worm, pickleworm, thrips }\end{array}$ & 5 & $\begin{array}{l}\text { Do not apply more than } 3 \text { times } \\
\text { in a } 21 \text {-day period. Rotate to a } \\
\text { different class of product for } 21 \\
\text { days. }\end{array}$ \\
\hline Sulfur & See label & 24 & 1 & mites & -- & \\
\hline
\end{tabular}




\section{Chapter 27: Cucurbit Production in Florida}

Table 15. Continued.

\begin{tabular}{|c|c|c|c|c|c|c|}
\hline $\begin{array}{l}\text { Trade Name } \\
\text { (Common Name) }\end{array}$ & $\begin{array}{l}\text { Rate } \\
\text { (product/acre) }\end{array}$ & $\begin{array}{l}\text { REI } \\
\text { (hours) }\end{array}$ & $\begin{array}{l}\text { Days to } \\
\text { Harvest }\end{array}$ & Insects & $\begin{array}{l}\text { MOA } \\
\text { Code }^{1}\end{array}$ & Notes \\
\hline $\begin{array}{l}\text { *Telone C-35 (dichloro- } \\
\text { propene + chloropicrin) } \\
\text { *Telone II } \\
\text { (dichloropropene) }\end{array}$ & See label & 5 days & preplant & symphylans, wireworms & -- & $\begin{array}{l}\text { See supplemental label for use } \\
\text { restrictions in south and central } \\
\text { Florida. }\end{array}$ \\
\hline $\begin{array}{l}\text { Trigard } \\
\text { (cyromazine) }\end{array}$ & $2.660 z$ & 12 & 0 & leafminers & 17 & $\begin{array}{l}\text { Do not make more than six appli- } \\
\text { cations. }\end{array}$ \\
\hline $\begin{array}{l}\text { Trilogy } \\
\text { (extract of neem oil) }\end{array}$ & $0.5-2.0 \% \mathrm{~V} / \mathrm{V}$ & 4 & 0 & $\begin{array}{l}\text { aphids, mites, suppres- } \\
\text { sion of thrips and white- } \\
\text { flies }\end{array}$ & 26 & $\begin{array}{l}\text { Apply morning or evening to } \\
\text { reduce potential for leaf burn. } \\
\text { Toxic to bees exposed to direct } \\
\text { treatment. OMRI-listed?2. }\end{array}$ \\
\hline $\begin{array}{l}\text { Venom } \\
\text { (dinotefuran) }\end{array}$ & $\begin{array}{l}\text { foliar: } 1-4 \text { oz } \\
\text { soil: } 5-6 \text { oz }\end{array}$ & 12 & $\begin{array}{l}\text { foliar: } 1 \\
\text { soil: } 21\end{array}$ & $\begin{array}{l}\text { green peach aphid, } \\
\text { leafhoppers, leafminers, } \\
\text { melon aphids, thrips, } \\
\text { whiteflies }\end{array}$ & $4 \mathrm{~A}$ & $\begin{array}{l}\text { Do not apply more than } 6 \text { oz per } \\
\text { acre per season (foliar) or } 12 \mathrm{oz} \\
\text { (soil) per acre per season. Use } \\
\text { only one application method (soil } \\
\text { or foliar). }\end{array}$ \\
\hline $\begin{array}{l}\text { *Vydate L } \\
\text { (oxamyl) }\end{array}$ & $2-4 \mathrm{pt}$ & 48 & 1 & aphids, leafminers, thrips & $1 \mathrm{~A}$ & $\begin{array}{l}\text { Do not apply more than } 24 \text { pt per } \\
\text { acre per season. }\end{array}$ \\
\hline $\begin{array}{l}\text { Xentari DF } \\
\text { (Bacillus thuringiensis } \\
\text { subspecies aizawai) }\end{array}$ & $0.5-2.0 \mathrm{lb}$ & 4 & 0 & caterpillars & 11B1 & $\begin{array}{l}\text { Treat when larvae are young. } \\
\text { Thorough coverage is essential. } \\
\text { May be used in the greenhouse. } \\
\text { Can be used in organic produc- } \\
\text { tion. }\end{array}$ \\
\hline
\end{tabular}

The pesticide information presented in this table was current with federal and state regulations at the time of revision. The user is responsible for determining the intended use is consistent with the label of the product being used. Use pesticides safely. Read and follow label instructions.

1 Mode of Action codes for vegetable pest insecticides from the Insecticide Resistance Action Committee (IRAC) Mode of Action Classification v.3.3 October 2003. 1A. Acetylcholine esterase inhibitors, Carbamates 1B. Acetylcholine esterase inhibitors, Organophosphates

2A. GABA-gated chloride channel antagonists

3. Sodium channel modulators

4A. Nicotinic Acetylcholine receptor agonists/antagonists, Neonicotinoids

5. Nicotinic Acetylcholine receptor agonists (not group 4)

6. Chloride channel activators

7A. Juvenile hormone mimics, Juvenile hormone analogues

7D. Juvenile hormone mimics, Pyriproxifen

9A. Compounds of unknown or non-specific mode of action (selective feeding blockers), Cryolite

9B. Compounds of unknown or non-specific mode of action (selective feeding blockers), Pymetrozine

11B1. Microbial disruptors of insect midgut membranes, B.t. var aizawai

11B2. Microbial disruptors of insect midgut membranes, B.t. var kurstaki

12B. Inhibitors of oxidative phosphorylation, disruptors of ATP formation, Organotin miticide

15. Inhibitors of chitin biosynthesis, type 0, Lepidopteran

16. Inhibitors of chitin biosynthesis, type 1, Homopteran

17. Inhibitors of chitin biosynthesis, type 2, Dipteran

18. Ecdysone agonist/disruptor

20. Site II electron transport inhibitors

21. Site I electron transport inhibitors

22. Voltage-dependent sodium channel blocker

23. Inhibitors of lipid biosynthesis

25. Neuroactive (unknown mode of action)

26. Unknown mode of action, Azadirachtin

2 OMRI listed: Listed by the Organic Materials Review Institute for use in organic production.

* Restricted Use Pesticide 
Table 16. Breakeven production costs of cucumber at various yield levels in southwest Florida, 2004-2005.

\begin{tabular}{|lrrrrr||}
\hline & & \multicolumn{3}{c|}{ Yield (bushels/acre) } \\
\cline { 2 - 6 } & Cost per acre & $\mathbf{4 0 0}$ & $\mathbf{5 0 0}$ & $\mathbf{6 0 0}$ & $\mathbf{7 0 0}$ \\
\hline \hline Variable Costs & $\$ 1,521.22$ & $\$ 3.80$ & $\$ 3.04$ & $\$ 2.54$ & $\mathbf{8 0 0}$ \\
Fixed Costs & $\$ 731.24$ & $\$ 1.83$ & $\$ 1.46$ & $\$ 1.22$ & $\$ 2.17$ \\
Harvest Cost/unit & & $\$ 4.66$ & $\$ 4.66$ & $\$ 4.66$ & $\$ 1.90$ \\
Total Cost/unit & & $\$ 10.29$ & $\$ 9.16$ & $\$ 8.41$ & $\$ 0.91$ \\
\hline
\end{tabular}

Table 17. Breakeven production costs of summer squash at various yield levels in the Miami-Dade County area, 2004-2005.

\begin{tabular}{|c|c|c|c|c|c|c|}
\hline & \multirow[b]{2}{*}{ Cost per acre } & \multicolumn{5}{|c|}{ Yield (bushels/acre) } \\
\hline & & 300 & 338 & 375 & 413 & 450 \\
\hline Variable Costs & $\$ 1,421.03$ & $\$ 4.74$ & $\$ 4.20$ & $\$ 3.79$ & $\$ 3.44$ & $\$ 3.16$ \\
\hline Fixed Costs & $\$ 1,148.26$ & $\$ 3.83$ & $\$ 3.40$ & $\$ 3.06$ & $\$ 2.78$ & $\$ 2.55$ \\
\hline Harvest Cost/unit & & $\$ 5.30$ & $\$ 5.30$ & $\$ 5.30$ & $\$ 5.30$ & $\$ 5.30$ \\
\hline Total Cost/unit & & $\$ 13.86$ & $\$ 12.90$ & $\$ 12.15$ & $\$ 11.52$ & $\$ 11.01$ \\
\hline
\end{tabular}

Table 18. Breakeven production costs of watermelon at various yield levels in the Manatee/Hillsborough areas, 2004-2005.

\begin{tabular}{|lcccccc|}
\hline & & \multicolumn{3}{c|}{ Yield (cwt/acre) } \\
\cline { 3 - 6 } & Cost per acre & $\mathbf{2 8 0}$ & $\mathbf{3 0 0}$ & $\mathbf{3 2 0}$ & $\mathbf{3 4 0}$ & $\mathbf{3 6 0}$ \\
\hline \hline Variable Costs & $\$ 1,400.50$ & $\$ 5.00$ & $\$ 4.67$ & $\$ 4.38$ & $\$ 4.12$ & $\$ 3.89$ \\
Fixed Costs & $\$ 697.30$ & $\$ 2.49$ & $\$ 2.32$ & $\$ 2.18$ & $\$ 2.05$ & $\$ 1.94$ \\
Harvest Cost/unit & & $\$ 2.60$ & $\$ 2.60$ & $\$ 2.60$ & $\$ 2.60$ & $\$ 2.60$ \\
Total Cost/unit & & $\$ 10.09$ & $\$ 9.59$ & $\$ 9.16$ & $\$ 8.77$ \\
\hline
\end{tabular}

Table 19. Breakeven production costs of watermelon at various yield levels in the southwest Florida area, 2004-2005.

\begin{tabular}{|c|c|c|c|c|c|c|}
\hline & \multirow[b]{2}{*}{ Cost per acre } & \multicolumn{5}{|c|}{ Yield (cwt/acre) } \\
\hline & & 300 & 320 & 340 & 360 & 380 \\
\hline Variable Costs & $\$ 1,966.13$ & $\$ 6.55$ & $\$ 6.14$ & $\$ 5.78$ & $\$ 5.46$ & $\$ 5.17$ \\
\hline Fixed Costs & $\$ 1,019.67$ & $\$ 3.40$ & $\$ 3.19$ & $\$ 3.00$ & $\$ 2.83$ & $\$ 2.68$ \\
\hline Harvest Cost/unit & & $\$ 2.95$ & $\$ 2.95$ & $\$ 2.95$ & $\$ 2.95$ & $\$ 2.95$ \\
\hline Total Cost/unit & & $\$ 12.90$ & $\$ 12.28$ & $\$ 11.73$ & $\$ 11.24$ & $\$ 10.81$ \\
\hline
\end{tabular}

